CAROLINE MENEZES SANTANA

ESTUDO EPIDEMIOLÓGICO DAS CONDIÇÕES BUCAIS DE PACIENTES COM LÚPUS ERITEMATOSO SISTÊMICO ATENDIDOS NO HOSPITAL UNIVERSITÁRIO DE BRASÍLIA - DF

\title{
BRASÍLIA
}

2016

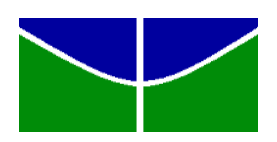

UNIVERSIDADE DE BRASÍLIA 
FACULDADE DE CIÊNCIAS MÉDICAS

PROGRAMA DE PÓS-GRADUAÇÃO EM CIÊNCIAS MÉDICAS

\title{
CAROLINE MENEZES SANTANA
}

\section{ESTUDO EPIDEMIOLÓGICO DAS CONDIÇÕES BUCAIS DE PACIENTES COM LÚPUS ERITEMATOSO SISTÊMICO ATENDIDOS NO HOSPITAL UNIVERSITÁRIO DE BRASÍLIA - DF}

\begin{abstract}
Dissertação apresentada como requisito parcial para a obtenção do Título de Mestre em Ciências Médicas pelo Programa de Pós-Graduação em Ciências Médicas da Universidade de Brasília.

Área de Concentração: Saúde bucal e sistêmica.
\end{abstract}

Orientador: Prof. Dr. Rivadávio F. B. de Amorim

Coorientadora: Profa. Dra. Denise P. Falcão da Rocha

BRASÍLIA

2016 
Ficha catalográfica elaborada automaticamente, com os dados fornecidos pelo(a) autor(a)

\begin{tabular}{|c|c|}
\hline MM543e & $\begin{array}{l}\text { MENEZES SANTANA, CAROLINE } \\
\text { ESTUDO EPIDEMIOLÓGICO DAS CONDIÇŌES BUCAIS DE } \\
\text { PACIENTES COM LÚPUS ERITEMATOSO SISTEMMICO ATENDIDOS } \\
\text { NO HOSPITAL UNIVERSITARIO DE BRASILIA - HUB / } \\
\text { CAROLINE MENEZES SANTANA; Orientador RIVADAVIO } \\
\text { FERNANDES BATISTA DE AMORIM; CO-Orientador DENISE } \\
\text { PINHEIRO FALCÃO DA ROCHA. -- Brasilia, } 2016 . \\
\quad 88 \text { p. }\end{array}$ \\
\hline & $\begin{array}{l}\text { Dissertação (Mestrado - Mestrado em Ciências } \\
\text { Médicas) -- Universidade de Brasilia, } 2016 \text {. }\end{array}$ \\
\hline & $\begin{array}{l}\text { 1. LÚPUS ERITEMATOSO SISTÊMICO. } 2 \text {. MANIFESTAÇÖES } \\
\text { BUCAIS. } 3 \text {. FLUXO SALIVAR. } 4 \text {. XEROSTOMIA. } 5 \text {. DOENÇA } \\
\text { PERIODONTAL. I. FERNANDES BATISTA DE AMORIM, } \\
\text { RIVADAVIO, orient. II. PINHEIRO FALCÃO DA ROCHA, } \\
\text { DENISE, CO-orient. III. TIttulo. }\end{array}$ \\
\hline
\end{tabular}




\section{CAROLINE MENEZES SANTANA}

ESTUDO EPIDEMIOLÓGICO DAS CONDIÇÕES BUCAIS DE PACIENTES COM LÚPUS ERITEMATOSO SISTÊMICO ATENDIDOS NO HOSPITAL

UNIVERSITÁRIO DE BRASÍLIA - DF

Dissertação apresentada como requisito parcial para a obtenção do Título de Mestre em Ciências Médicas pelo Programa de Pós-Graduação em Ciências

Médicas da Universidade de Brasília.

Aprovado em:

\section{BANCA EXAMINADORA}

Prof. Dr (presidente) Rivadávio Fernandes Batista de Amorim Instituição - Universidade de Brasília - UnB

Julgamento: Assinatura:

Prof. Dr. Ciro Martins Gomes

Instituição - Universidade de Brasília - UnB

Julgamento: Assinatura:

Profa. Dra. Gisele Lago Martinez

Instituição - Centro Universitário Unieuro

Julgamento: Assinatura:

Profa. Dra. Lenora Gandolfi

Instituição - Universidade de Brasília - UnB

Julgamento: Assinatura: 
Aos meus amados pais, Jorge e Cléa, pelo amor incondicional e pela confiança que sempre em mim depositaram. Ao meu esposo, Rubens, por todo amor, apoio e paciência. À minha filha Luisa, por me fazer sentir o maior amor do mundo. 


\section{AGRADECIMENTOS}

À Deus, por tudo que sou e conquistei.

Aos pacientes com lúpus eritematoso sistêmico pela colaboração na realização deste trabalho.

Ao Prof. Dr. Rivadávio Amorim, meu orientador, pela confiança, pela oportunidade, por todas as portas que se abriram em função desse trabalho e por despertar em mim o interesse pela pesquisa.

À professora Denise Falcão, pela sua dedicação infindável na realização deste levantamento, pela enorme contribuição à minha vida profissional e pessoal $\mathrm{e}$ meu reconhecimento pela sua ética, sabedoria e humanismo. Por sua excepcional capacidade científica, minha gratidão pela honra do convívio acadêmico.

À professora Maria do Carmo, com quem muito aprendi, agradeço a atenção e a oportunidade a mim concedida ao apresentar-me o programa de Pós-Graduação em Ciências Médicas da Universidade de Brasília.

À equipe NEIPS - Núcleo de Ensino Integrado e Pesquisa em Saúde, em especial Nathalya Lopes, Mariana Branco, Aline Lauria, Flávia Nunes, Rafaelly Stavale, Francisca Macêdo e Thalita Silva pela dedicação, incentivo e amizade. Vocês foram fundamentais na realização deste trabalho. Para vocês, o meu muito obrigada seria pouco.

Às amigas Walkiria Lima e Priscila Naiff pela ajuda e presteza na realização deste trabalho.

À Dr $^{\mathrm{a}}$ Licia Maria Henrique Mota por ter propiciado a realização deste estudo no Serviço de Reumatologia / Ambulatório de Colagenose do Hospital Universitário de Brasília (HUB).

Aos demais reumatologistas da equipe médica do ambulatório, que colaboraram para o fechamento de diagnóstico do LES.

Aos assistentes, residentes e funcionários, em especial à Sra. Francisca e Edvânia do Serviço de Reumatologia do Hospital Universitário de Brasília.

Ao Gledson Alessandro Ribeiro da Silva, pela ajuda na parte burocrática do programa de Pós-Graduação em Ciências Médicas.

A toda a minha família e amigos pelo incentivo e paciência nestes anos de estudo. 
Aos meus pais Jorge e Cléa, que sabiamente acreditam que a educação é o maior legado que se pode deixar para os filhos.

Ao meu marido Rubens, que sempre acreditou no meu crescimento profissional e que ajudou diretamente na realização deste trabalho.

À CAPES pelo apoio financeiro a essa pesquisa. 
"Conheça todas as teorias, domine todas as técnicas, mas ao tocar uma alma humana, seja apenas outra alma humana." 


\section{RESUMO}

Introdução: O lúpus eritematoso sistêmico (LES) é uma doença autoimune multissistêmica e de etiologia desconhecida. É de natureza inflamatória, pleomórfica, com múltiplas manifestações de interesse médico. Apresenta-se com períodos de atividade e remissão, mas é potencialmente progressiva e incapacitante e pode acometer adultos e crianças. Objetivo: Realizar levantamento epidemiológico das condições bucais dos pacientes com LES atendidos no Hospital Universitário de Brasília para conhecer suas necessidades específicas e estabelecer um plano de ação odontológico. Metodologia: Foram avaliados pacientes de ambos os gêneros e de qualquer idade. As informações médicas foram coletadas pelos reumatologistas, durante consultas de monitoramento do LES. O exame clínico bucal foi realizado por quatro examinadores experientes. Foi registrada a avaliação do fluxo salivar em repouso, queixa de xerostomia, presença de lesão em tecidos moles, sondagem periodontal, índice de dentes cariados, perdidos e restaurados (CPO-d). Resultados: Foram avaliados 69 pacientes, sendo 1 do sexo masculino. A mediana do fluxo salivar de repouso (percentil 25 e 75$)$ foi de $0,41 \mathrm{~mL} / \mathrm{min}(0,18$ e $0,60)$, sendo que a faixa etária de 45 a 64 anos $(n=20)$ apresentou fluxo de 0,18 $\mathrm{mL} / \mathrm{min}(0,10$ e 0,53$)$ e $33 \%$ do total de pacientes reportaram ocorrência de xerostomia contínua. Verificou-se que $26 \%$ dos pacientes apresentavam lesões bucais. Dentre as lesões presentes, 21 (57\%) eram mácula eritematosa e do total de lesões, 34\% estavam em palato duro. A mediana do índice de placa visível foi de 61,3; do índice de sangramento 25 e a profundidade de sondagem foi de 1,6. A recessão gengival apresentou mediana de 0,3 enquanto que a perda do nível de inserção clínica foi de 1,3. O índice CPOD foi de 16,35. Conclusão: Quanto à saliva, verificou-se que: a taxa média de fluxo salivar sem estímulo apresentou-se dentro dos padrões de normalidade; a xerostomia estava presente em $32 \%$, semelhante à população geral - 30\% (Silvestre, 2011; Anurang, 2006). Quanto as lesões bucais: $36 \%$ dos pacientes apresentaram lesões bucais. A prevalência das lesões é semelhante a outros estudos, porém o tipo de lesão mais prevalente é diferente. Em relação a doença periodontal: A prevalência de DP foi de $36 \%$, menor que os reportados na literatura. O alto índice de placa comparado ao ISS, PS, REC e NIC pode estar associado ao uso de corticoide feito por esses pacientes. Comparandose nossos resultados relativos à condição periodontal e índice CPOD com os 
resultados da Pesquisa Nacional de Saúde Bucal (2011) do Ministério da Saúde, constatou-se que: a população estudada apresentou maior índice médio de sangramento gengival, porém a média de profundidade de sondagem foi menor; o índice CPOD nas faixas etárias comparadas foi menor. Os achados bucais encontrados apontam a não necessidade de abordagem específica para o paciente com LES.

Descritores: lúpus eritematoso sistêmico; manifestações bucais; fluxo salivar; xerostomia; doença periodontal. 


\section{ABSTRACT}

Background: The Systemic Lupus Erythematosus (SLE) is na autoimmune disease, of unknow etiology, multisystemic, of na inflamatory autoimmune nature, pleomorphic, with multiple possible manifestations, with multiple manifestations of medical interest. Objective: to realize an epidemiologic survey of the oral conditions of patients with SLE that are treated at the University Hospital of Brasília (HUB) to know the specific needs and establish a dental plan of action for this group of patients. Methodology: Was evaluated patients with SLE treated at the Rheumatology Department of the University Hospital of Brasilia (HUB), of both genders and of all ages. Rheumatologists collected medical information during the LES monitoring queries. Four experienced examiners performed the oral exam. Salivary flow and the presence of xerostomia. It was recorded the presence of lesions in soft tissues, periodontal probing, index of decayed, missing and filled teeth (DMF). Results: Was evaluated 69 patients, 1 male. Median salivary flow at rest (25th and 75th percentiles) was 0.41 milliliters/minute $(0.18$ and 0.60$)$, and the age group 45-64 years $(n=20)$ showed flow 018 milliliters/minute $(0.10$ to 0.53$)$ and $33 \%$ of patients reported occurrence of continuous xerostomia. It was found that $26 \%$ of the patients had oral lesions. Among the present lesions, 21 (57\%) were erythematous macula and of the total injuries, $34 \%$ were in the hard palate. The median of the visible plaque index was 61.3; bleeding index 25 and the probing depth was 1.6. The gingival recession presented a median of 0.3 while the level of the clinical attachment loss was 1.3. The DMF index was 16.35. Conclusion: As the saliva, it was found that: the average rate of unstimulated salivary flow was within the normal range; xerostomia was present in $32 \%$, similar to the general population $30 \%$ (Silvestre, 2011; Anurang, 2006). As the oral lesions: 36\% of patients had oral lesions. The prevalence of lesions is similar to other studies, but the most prevalent type of injury is different. In relation to periodontal disease: The prevalence of PD was $36 \%$ lower than those reported in the literature. The high plaque index compared to the ISS, PS, REC and NIC may be associated with the use of steroids made by these patients. Comparing our results for the periodontal condition and DMFT with the results of the National Oral Health Survey (2011) the Ministry of Health, it was found that: the study population had higher average rate of gingival bleeding, but the 
mean depth poll was lower; the DMFT compared the age groups was lower. The oral findings indicate not need specific approach for patients with SLE.

Keywords: systemic lupus erythematosus; oral manifestations; salivary flow; xerostomia; periodontal disease. 


\section{LISTA DE FIGURAS}

FIGURA 01 - Diagnóstico de LES pelos 11 critérios da ACR.

FIGURA 02 - Rash malar com lesões escamosas em paciente do sexo feminino.

FIGURA 03 - Rash malar com áreas cicatriciais hiperpigmentadas em paciente do sexo feminino.

FIGURA 04 - Lesão discoide com áreas de descamação ceratótica e crostículas em paciente do sexo feminino com 9 anos de idade.

FIGURA 05 - Lesão discoide no peito, braço e mão direita em paciente adulta.

FIGURA 06 - Lesão oral eritematosa na mucosa jugal esquerda em paciente edêntulo com prótese sobre implantes.

FIGURA 07 - Lesão oral eritematosa na mucosa jugal direita e lesão eritematosa na região do palato de paciente do sexo feminino.

FIGURA 08 - Lesão oral eritematosa na região do palato de paciente edêntula.

FIGURA 09 - Lesão oral eritematosa na região do palato de paciente do sexo masculino com todos os dentes permanentes.

FIGURA 10 - Mancha hipercrômica em lábio superior entremeadas com área de acromia que borram a linha do vermelhão do lábio.

FIGURA 11 - Imagem ilustrativa do periodonto.

FIGURA 12 - Doença periodontal em paciente com LES em que se verifica deposição de cálculo dentário e perda de nível de inserção.

FIGURA 13 - Presença de xerostomia.

FIGURA 14 - Índice médio de placa visível por faixa etária.

FIGURA 15 - Índice médio de sangramento a sondagem por faixa etária.

FIGURA 16 - Profundidade média de sondagem de bolsa periodontal.

FIGURA 17 - Recessão gengival média por faixa etária.

FIGURA 18 - Nível médio de perda de inserção clínica por faixa etária.

FIGURA 19 - Índice CPOD por faixa etária.

FIGURA 20 - Pacientes edêntulos em diversas faixas etárias.

FIGURA 21 - Núcleo familiar de convivência diária.

FIGURA 22 - Tempo de formulação do diagnóstico do LES em meses por faixa etária.

FIGURA 23 - SLICC

FIGURA 24 - SLEDAI 
FIGURA 25 - Classificação do LES e NF quanto à atividade.

FIGURA 26 - Medicamentos administrados em pacientes com LES. 


\section{LISTA TABELAS}

TABELA 1 - Interrupção do sono noturno para ingestão de água.

TABELA 2 - Lesões orais.

TABELA 3 - Tabagismo.

TABELA 4 - Etilismo.

TABELA 5 - Cor declarada. 


\section{LISTA DE ABREVIATURAS E SIGLAS}

ACR American College of Rheumatology

ARA American Rheumatism Association

CPI Community Periodontal Index-CPI

CPOD Índice de Dentes Cariados Perdidos e Restaurados

DP Doença Periodontal

DTM Disfunção Temporomandibular

DMF Decay Missing and Filled Index

HUB Hospital Universitário de Brasília

LES Lúpus Eritematoso Sistêmico

NL Nefrite Lúpica

OMRS Oral Mucosa Rating Scale

OMS Organização Mundial de Saúde

SLE Systemic Lupus Erythematosus

SLEDAI Systemic Lupus Erythematosus Disease Activity Index

SLICC Systemic Lupus International Collaborating Clinics 
SUMÁRIO

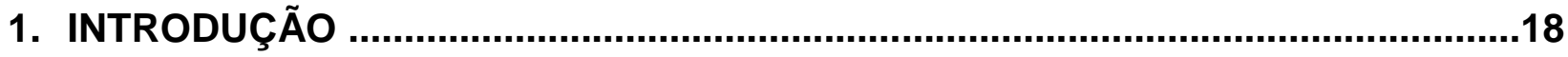

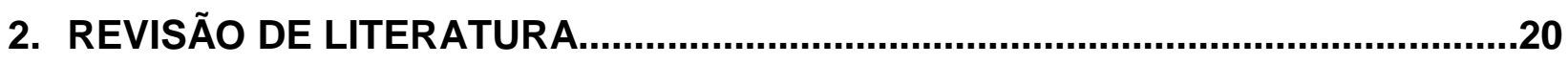

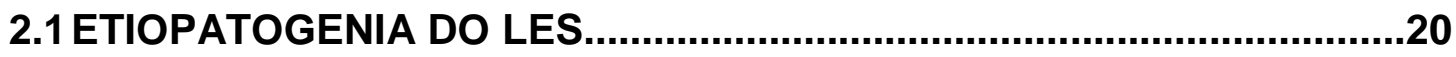

2.2CRITÉRIOS DE DIAGNÓSTICO..........................................................21

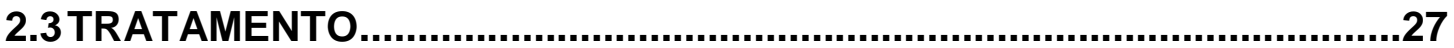

2.4EPIDEMIOLOGIA DAS CONDIÇÕES BUCAIS DOS PACIENTES COM LES .28

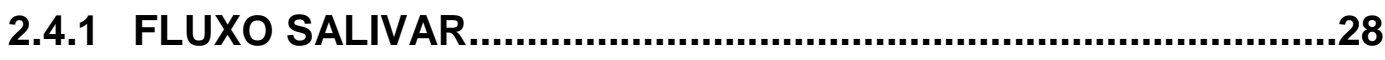

2.4.2 LESÕES BUCAIS.................................................................30

2.4.3 CONDIÇÃO PERIODONTAL....................................................32

2.4.4 ÍNDICE CPOD......................................................................36

3. JUSTIFICATIVA

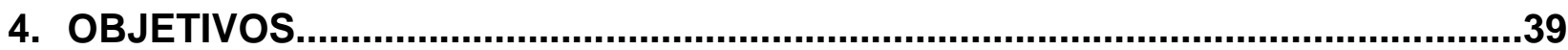

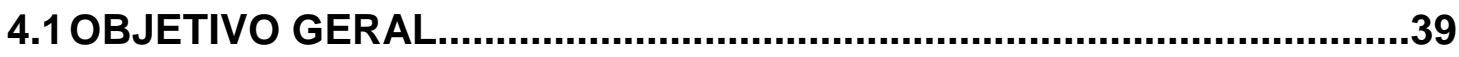

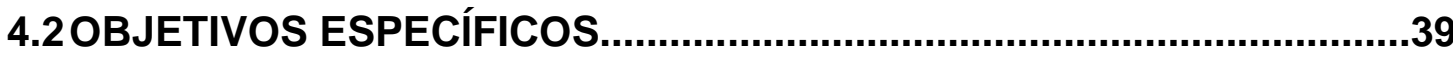

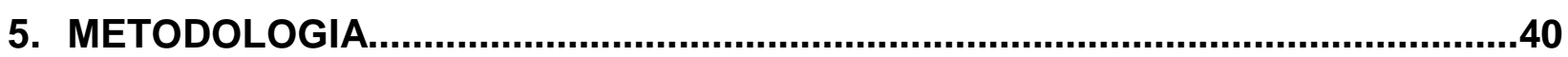

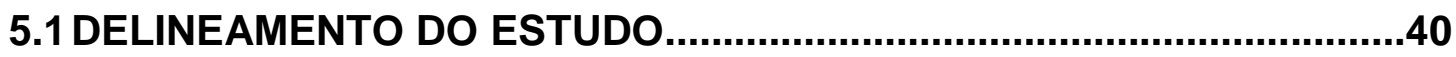

5.2POPULAÇÃO E AMOSTRA DO ESTUDO............................................40

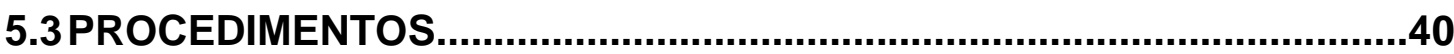

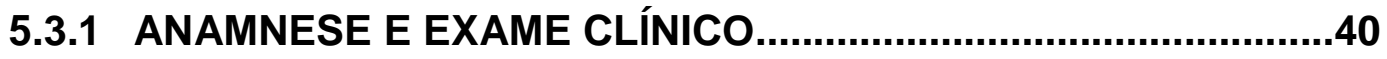

5.3.2 AVALIAÇÃO DO FLUXO SALIVAR EM REPOUSO.....................40

5.3.3 AVALIAÇÃO DE PRESENÇA DE LESÕES BUCAIS...................41

5.3.4 AVALIAÇÃO PERIODONTAL ................................................

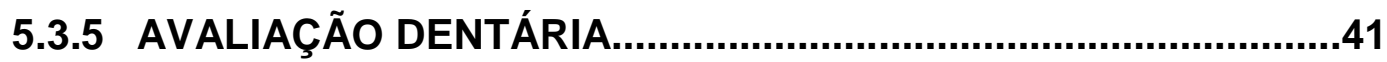

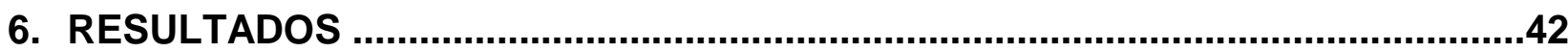

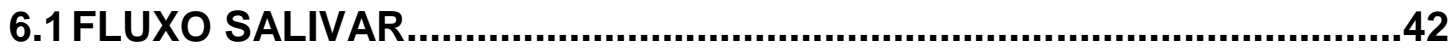

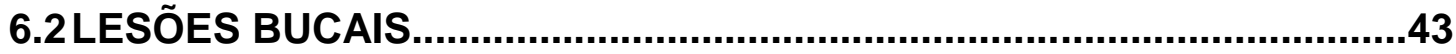

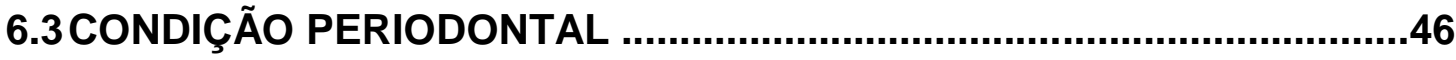

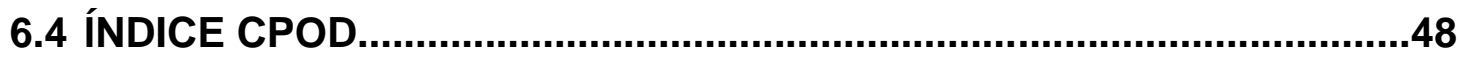

6.5CONDIÇÕES SÓCIO DEMOGRÁFICAS ............................................50

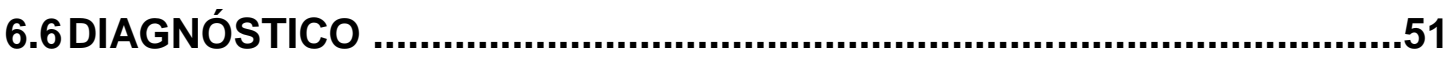

6.7 MEDICAMENTOS ADMINISTRADOS..................................................53 


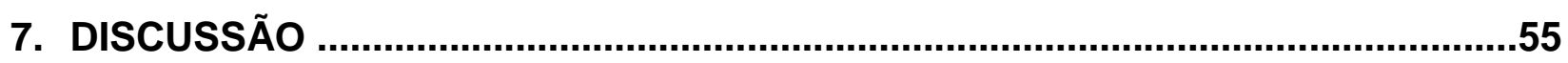

8. CONCLUSÃO

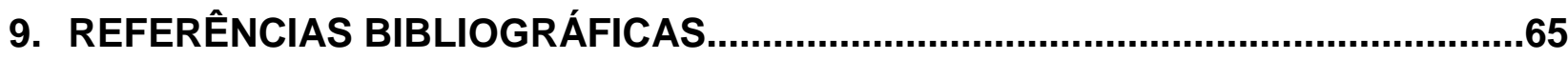

10. APÊNDICES

11. ANEXOS

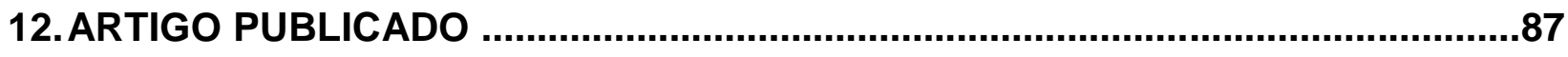




\section{INTRODUÇÃO}

O ser humano apresenta um sistema imunológico ativo, fazendo com que o corpo elabore uma resposta eficaz contra qualquer antígeno, eliminando elementos estranhos. A principal função do sistema imunológico é atuar na defesa do organismo contra agentes infecciosos, porém, mesmo substâncias não infecciosas são atacadas. Para isto ocorrer, basta o organismo considerar um elemento como substância estranha(1). Assim, o sistema imune pode falhar e considerar o próprio organismo como antígeno e causar as chamadas doenças autoimunes(2).

O lúpus eritematoso sistêmico (LES) é uma doença autoimune multissistêmica, de etiologia desconhecida. É de natureza inflamatória, pleomórfica, com múltiplas manifestações de interesse médico. Apresenta-se com períodos de atividade e remissão, mas é potencialmente progressiva e incapacitante e pode acometer adultos e crianças $(3,4)$. Caracteriza-se pela formação de autoanticorpos e deposição de imunocomplexos, o que ocasiona inflamação em tecidos e órgãos(5).

Ao longo do curso da doença, fatores genéticos não parecem desempenhar o papel mais importante(6). Entretanto, verifica-se que o LES é mais frequente em populações hispânicas, afrodescendentes e asiáticos, sendo os indivíduos de etnia branca menos susceptíveis(7).

Sua prevalência na população global é de 40-50 casos por 100000 pessoas. Observa-se clara preponderância do sexo feminino, sendo que de cada dez ocorrências, somente uma acomete o gênero masculino(8). A maioria dos estudos sobre a incidência de LES foram feitos nos EUA ou na Europa. Porém, verificou-se uma taxa de incidência anual de 8,7 por 100.000 habitantes em uma cidade do nordeste brasileiro, com a maior frequência no sexo feminino, observando-se a razão de 8 casos em mulheres para cada homem(9).

Os primeiros sintomas surgem preferencialmente entre a segunda e a quarta década de vida, porém pode se manifestar em qualquer idade, inclusive em crianças(10). Apenas vinte e cinco por cento dos casos ocorrem dentro das duas primeiras décadas de vida e há predomínio do sexo feminino em todas as faixas etárias. Nos adolescentes, a relação masculino: feminino varia de 1:8 a 1:13(11).

No Brasil, o projeto de Lei $7797 / 10$, do Senado, incluiu o lúpus entre as doenças cujas pessoas são dispensadas de cumprir prazo de carência para usufruir 
dos benefícios de auxílio-doença e aposentadoria por invalidez(12). Tal iniciativa demostra o grau de comprometimento sistêmico que o LES pode causar no doente $e$ a consequente perda de qualidade de vida.

Embora o tempo entre o início dos sintomas e o diagnóstico tenha diminuído ao longo dos $\operatorname{anos}(13,14)$, o atraso ou a falta de tratamento pode aumentar a probabilidade de danos em órgãos devido à atividade da doença inflamatória persistente.

Nos EEUU, o custo de saúde médio para pacientes com LES foi estimado entre US \$ 12.000 e US \$24.000(15, 16). O diagnóstico precoce LES em comparação com diagnóstico de LES tardio está associado com menores taxas de crises de LES, menor utilização de recursos de saúde e consequentemente menores custos(17).

Se por um lado o Estado tem que arcar com uma aposentadoria por invalidez, com proventos integrais, por outro, deixa de arrecadar parte das contribuições previdenciárias. Isto porque a doença isenta o contribuinte de parte do seu recolhimento. Além disso, é concedida isenção do imposto de renda sobre essa aposentadoria. Portanto, trata-se de um custo significativo para o Estado brasileiro(129).

Além das comorbidades sistêmicas, estudos afirmam que lesões bucais indolores são achados frequentes em pacientes com $\operatorname{LES}(18,19)$, tendo estas últimas prevalência que varia entre $6,5 \%$ e $80 \%(19,20)$.

Verifica-se que os pacientes lúpicos necessitam de cuidados bucais especiais, principalmente devido ao fato de estarem mais susceptíveis às infecções(21). Esses indivíduos podem ser afetados por uma variedade de problemas orofaciais como boca ardente, hipossalivação, xerostomia, disfunções temporomandibulares (DTMs), gengivite descamativa, doença periodontal (DP) e disgeusia(18, 22).

Considerando-se a DP uma doença de caráter inflamatório que sofre influência de fatores infecciosos, assim como o LES, afirma-se que o LES influenciaria a progressão da DP(19). 


\section{REVISÃO DE LITERATURA}

\subsection{ETIOPATOGENIA DO LES}

O LES é uma doença autoimune complexa e heterogênea e apesar dos inúmeros esforços realizados, até o momento, sua etiologia e patogenia permanecem desconhecidas, permitindo uma série de especulações sobre seus possíveis fatores desencadeantes e perpetuadores(23).

Há duas questões fundamentais nos estudos da etiopatogenia do LES. Uma, é que alterações genéticas predispõem o indivíduo a desenvolver lúpus e a outra é como fatores externos podem influir nas alterações da tolerância imunológica(24).

O lúpus é considerado o modelo de estudo para doenças autoimunes de herança poligênica, que envolvem genes individualmente polimórficos que interagem com o ambiente e causam a expressão fenotípica da doença(25, 26). Estima-se que aproximadamente 100 genes contribuam para o desenvolvimento do LES, mas que apenas 10 a 20 destes genes estejam operantes em um paciente(27).

Embora, um grande número de genes candidatos e de possíveis mecanismos etiopatogênicos tenham sido descritos no LES, ainda não existe um modelo que explique como estes genes e fatores ambientais interagem para construir o fenótipo lúpico. Porém, dados epidemiológicos do risco de desenvolvimento do LES em irmãos, sua agregação familiar e sua concordância em gêmeos monozigóticos suportam o componente genético desta doença(28). A predisposição genética é um fator importante no desenvolvimento do LES, uma vez que observou-se que a concordância da doença em gêmeos idênticos é de $24 \%$, em comparação com cerca de $2 \%$ em gêmeos dizigóticos(28).

Fatores endócrinos (estrógenos), ambientais (luz ultravioleta), imunológicos, genéticos e infecciosos (vírus) contribuem, de forma conjunta, para o desenvolvimento da doença(10). Especula-se que em decorrência da similaridade entre alguns antígenos celulares e virais, infeções brandas ou agudas podem desencadear ou agravar o lúpus, como o caso da infecção pelo vírus Epstein$\operatorname{Barr}(10)$. 
Afirmam-se que a luz ultravioleta $(40$ a $60 \%$ dos pacientes são fotossensíveis), dietas ricas em gorduras saturadas, poluentes, cigarro e talvez o estresse físico ou psicológico extremo também podem desencadear ou agravar o $\operatorname{LES}(29,30)$.

Além do fator microbiológico, um estudo demonstra que o próprio medicamento para tratamento do LES pode levar ao estado do LES induzido, reforçando a importância na precisão do diagnóstico antes de iniciar o tratamento(2).

O fato de a doença ser mais predominante no sexo feminino levou estudos a apontar que a menarca e a menopausa precoces, além do uso de estrogênio exógeno, estão relacionadas com a suscetibilidade ao desenvolvimento do LES(31). O estrogênio desempenha função importante na maturação das células $B$ e na quebra da tolerância imunológica no LES, o que pode, em parte, explicar a maior prevalência do LES em mulheres(32, 33).

\subsection{CRITÉRIOS DE DIAGNÓSTICO}

O diagnóstico de LES está baseado em quatro ou mais dos onze critérios definidos pelo American College of Rheumatology (ACR)(34) (Figura 01). As manifestações clínicas mais prevalentes são: artrite (81\%), fotossensibilidade (70\%) e rash malar $(63 \%)(9)$.

O diagnóstico do LES é muito complexo, uma vez que, sinais e sintomas clínicos são extremamente variados e podem imitar outros tipos de doenças, como artrite reumatóide ou outros distúrbios autoimunes sistêmicos(35).

\section{American College of Reumatology - onze critérios para diagnóstico do LES}

1. Eritema malar: lesão eritematosa fixa em região malar, plana ou em relevo, tendendo a poupar sulco nasolabial. (Figura 2 e 3)

2. Lúpus discóide: lesões eritematosas infiltradas, com escamas queratóticas aderidas e tampões foliculares, que evolui com cicatriz atrófica e discromia, podendo aparecer em lesões antigas. (Figura 4 e 5)

3. Fotossensibilidade: eritema cutâneo, as vezes máculo-papular, como resultado de uma exposição solar.

4. Úlceras orais: ulceração oral ou nasofaringeana, indolor, observada pelo médico ou cirurgião-dentista durante seu exame físico. (Figuras 6, 7, 8 e 9) 


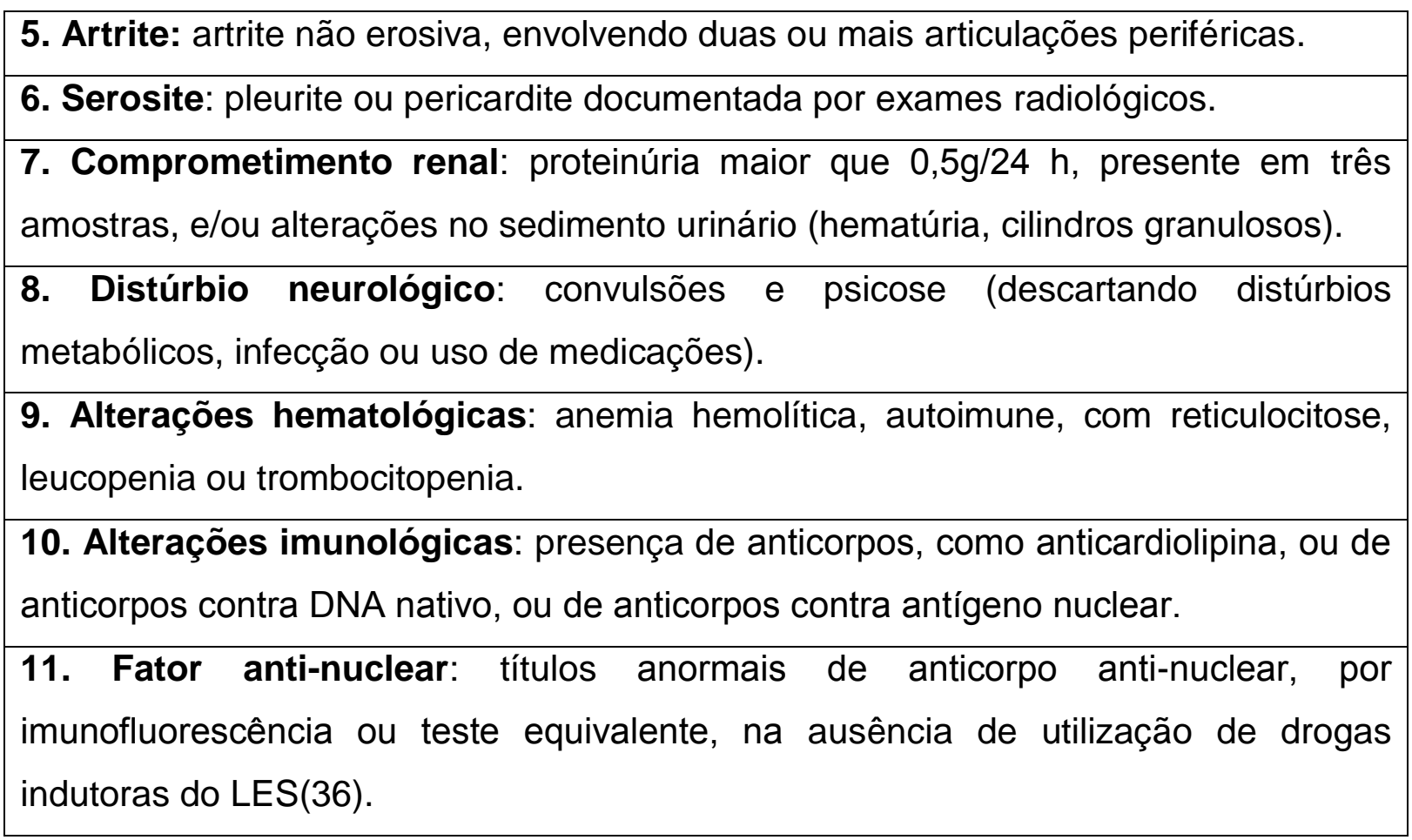

FIGURA 01. Onze critérios para diagnóstico do LES.

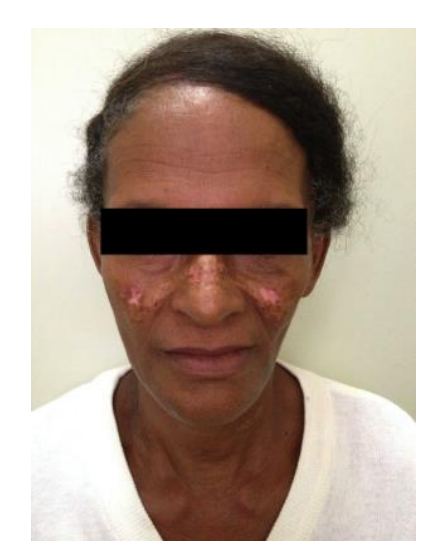

FIGURA 02. Rash malar com lesões escamosas em paciente do sexo feminino.

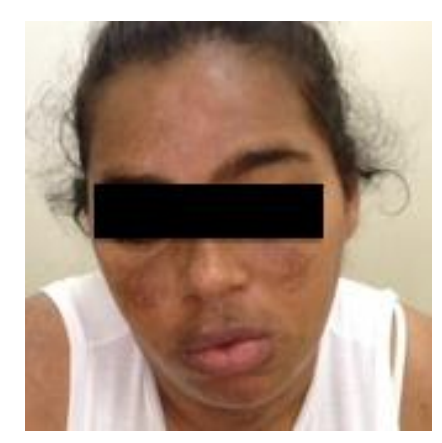

FIGURA 03. Rash malar, com áreas cicatriciais hiperpigmentadas, em paciente do sexo feminino. 


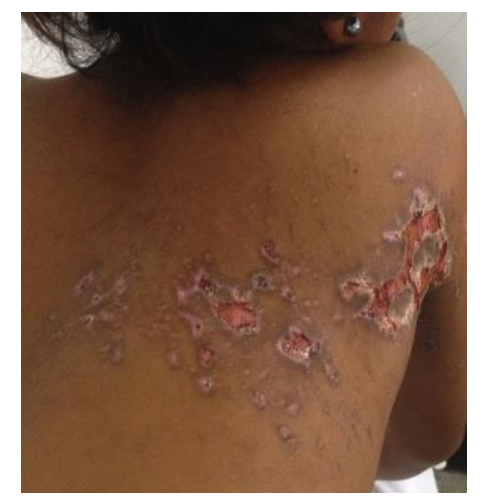

FIGURA 04. Lesão discoide com áreas de descamação ceratótica e crostículas em paciente do sexo feminino de 9 anos.
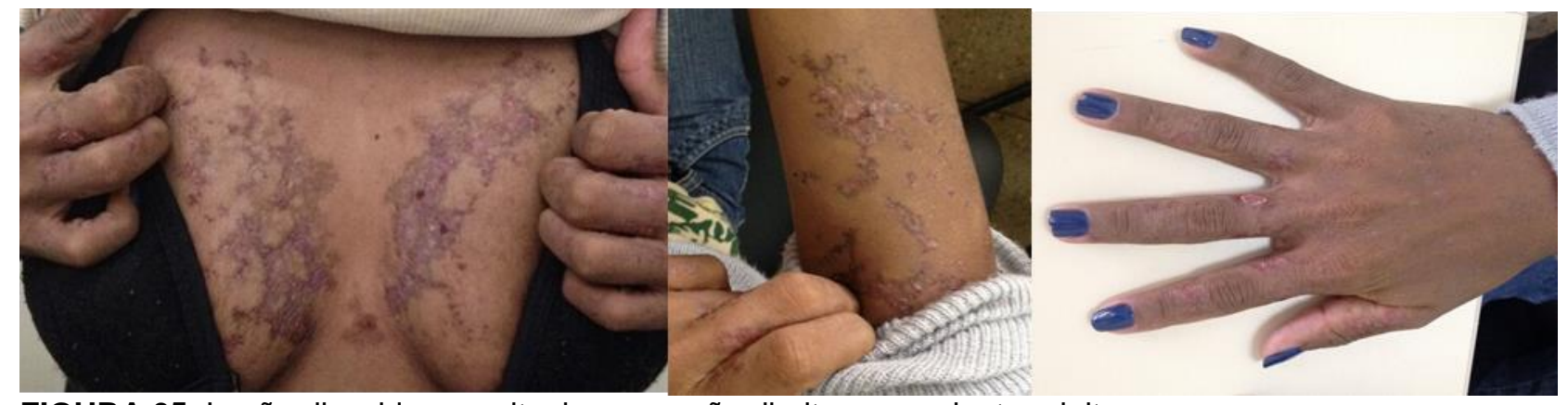

FIGURA 05. Lesão discoide no peito, braço e mão direita em paciente adulta.

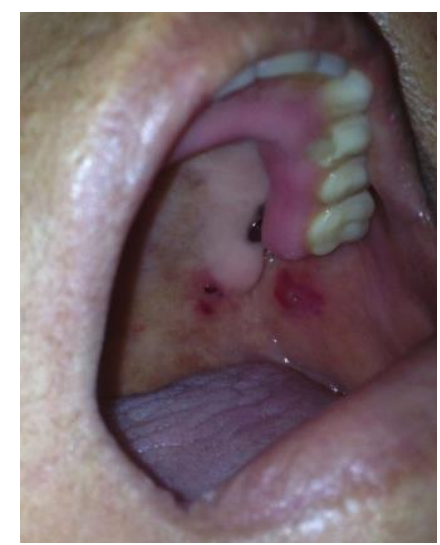

FIGURA 06. Lesão oral eritematosa na mucosa jugal esquerda em paciente edêntulo com prótese sobre implantes. 


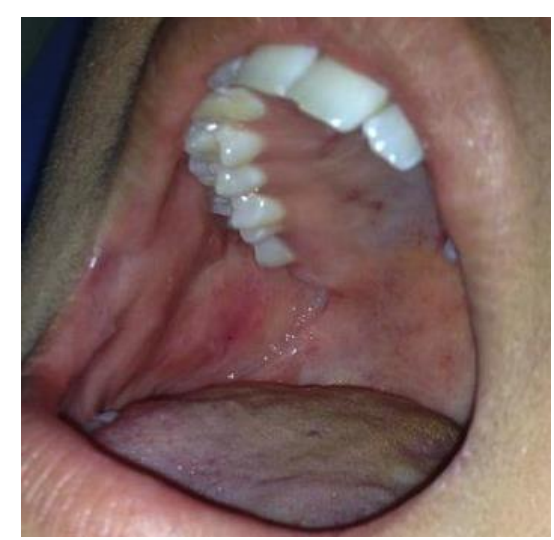

FIGURA 07. Lesão oral eritematosa na mucosa jugal direita e lesão eritematosa na região do palato de paciente do sexo feminino.

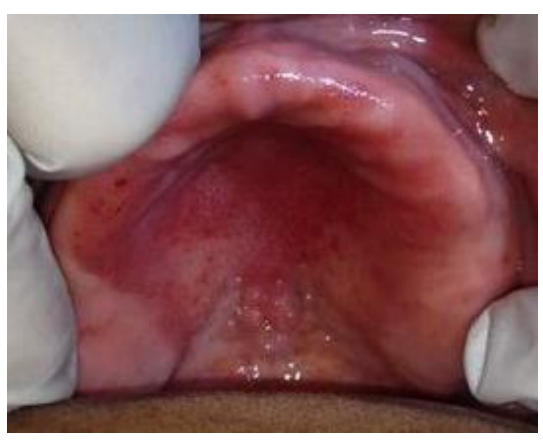

FIGURA 08. Lesão oral eritematosa na região do palato de paciente edêntula.

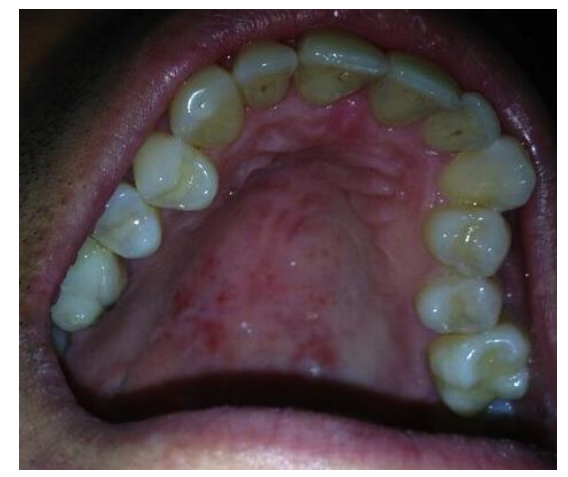

FIGURA 09. Lesão oral eritematosa na região do palato de paciente do sexo masculino com todos os dentes permanentes.

O quadro clínico do LES é bastante polimorfo, podendo acometer qualquer órgão ou sistema e apresentar variadas evoluções e prognósticos. Por exemplo, alguns pacientes apresentam eritema malar, febre, artrite, remissão espontânea. Outros pacientes, no entanto, apresentam doença grave e progressiva, com envolvimento renal e de sistema nervoso central. Qualquer sinal ou sintoma pode ser a primeira e única manifestação da doença e esta pode persistir ou recorrer por 
meses ou anos até o diagnóstico de LES ser confirmado pela presença de outros acometimentos(10, 11, 37).

Outras manifestações clínicas também são observadas. A ocorrência de lesões bolhosas, generalizadas pode representar uma urgência no manejo do LES. As erupções vesicobolhosas são disseminadas, predominando em face, pescoço e extremidades superiores. Elas podem aparecer em associação com a reativação da doença. O diagnóstico diferencial deve ser feito com pênfigo bolhoso, porfiria cutânea tardia, dermatite herpetiforme, epidermólise bolhosa e infecção. O diagnóstico é clínico e histopatológico(38).

O paciente com LES pode evoluir com encefalite, manifestada por convulsões, psicose e/ou estado confusional agudo. O diagnóstico é eminentemente clínico, sendo importante excluir outras etiologias, como sepse, medicações e alterações metabólicas $(39,40)$.

As manifestações gastrointestinais são pouco comuns no LES. Podem ocorrer náusea, vômito, diarreia e dor abdominal(41), além de vasculite mesentérica, e, por vezes, enterorragia(38).

Outra possível manifestação é a pneumonite, que pode se apresentar de forma aguda (pneumonite), alveolar; ou de forma crônica, intersticial. A pneumonite assemelha-se a uma pneumonia, com dispneia, tosse, febre, hemoptise e pleurisia(38).

O paciente lúpico pode ainda procurar uma unidade de emergência com quadro de pericardite ou mesmo com tamponamento cardíaco. O quadro clínico inclui dor torácica, atrito pericárdico, abafamento de bulhas, pulso paradoxal e estase jugular. Os três últimos sinais constituem evidência de tamponamento cardíaco em evolução(38).

Após confirmação do diagnóstico de LES, é necessário avaliar o potencial acometimento sistêmico da doença, e, para isso, o exame inicial é a pesquisa de anticorpos antinucleares. A investigação complementar dessas doenças é mais abrangente, uma vez que são condições que afetam múltiplos tecidos, exigindo a avaliação de diversos parâmetros bioquímicos, hematológicos e por imagem(38). 
O SLICC (Systemic Lupus International Collaborating Clinics) (ANEXO 1) foi projetado para ajudar a classificar o LES. Este índice avalia critérios muito complexos e pode ser usado quanto aos critérios do American College of Reumatology. Aplicação do questionário é importante não apenas para a classificação mas também para o diagnóstico precoce da mesma(42).

O SLEDAI (Systemic Lupus Erythematosus Disease Activity Index) (ANEXO 2) é um índice importante para avaliar a atividade do LES(43). Esse instrumento inclui, em sua avaliação, parâmetros clínicos e laboratoriais, levando-se em conta o órgão acometido. Avalia a atividade da doença com relação aos últimos 10 dias. Escores superiores a 8 indicam doença ativa. Variação de três pontos entre uma visita e outra é aceita como ativação da doença, e variações maiores ou iguais a 12 pontos significam atividade grave(44). Proposto inicialmente para adultos tem aplicabilidade reconhecida também em crianças(45).

A atividade inflamatória do LES pode ser definida pela presença de manifestações potencialmente reversíveis(46). Assim, a atividade da doença é o reflexo das características e da graduação do acometimento do órgão afetado. $A$ capacidade de avaliar o grau de atividade da doença no paciente com LES é de extrema importância, já que muitas decisões terapêuticas dependem da assertividade da decisão clínica do médico referente à atividade da doença(47).

No ano de 2000, o SLEDAI foi revisado, dando origem ao SLEDAI2K(43). A modificação proposta incluía a atividade persistente de alguns parâmetros, e não a pontuação desses parâmetros apenas nos casos de início ou recorrência. A persistência do eritema, das úlceras mucosas, da alopécia e da proteinúria superior a $0,5 \mathrm{~g}$ em 24 horas podem ser usados em trabalhos para a avaliação da atividade da doença $(43,48)$.

O tempo médio entre o início dos sintomas da doença e o diagnóstico tem sido relatado ser de 9 meses para aqueles diagnosticados após 2000(13). No entanto, enfatiza-se que um maior esforço deve ser feito para identificar novos biomarcadores que permitam diagnosticar SLE mais cedo(17). 


\subsection{TRATAMENTO}

O quadro clínico, exames laboratoriais e radiológicos devem ser minuciosamente avaliados devido à complexidade da doença antes de o reumatologistas estabelecer o tratamento(38). Recomenda-se que, sempre que possível, seja solicitada a avaliação de um especialista do órgão acometido antes de iniciar o tratamento da doença(38).

A terapêutica do LES baseia-se na administração de corticoide e imunossupressores para atenuar a resposta do sistema imune, controlar os sintomas e prevenir complicações futuras(49). Para alcançar o sucesso no tratamento medicamentoso, o paciente deve receber cuidados individualizados sob supervisão de um médico responsável, pois o comprometimento de muitos sistemas leva a uma maior gravidade da doença e é comum fazer uso concomitante de diversos medicamentos prescritos por diversos especialistas distintos(49). Por exemplo, paciente com nefrite e lesões cutâneas pode necessitar de corticoide e imunossupressor, utilizado para o tratamento da nefrite e em associação à talidomida, no tratamento das lesões cutâneas(50).

O objetivo do tratamento é restabelecer a homeostase imunológica controlando o sistema e preservando órgãos. $O$ tratamento medicamentoso que inclui ainda 0 uso de antiinflamatórios não hormonais, de antimaláricos, de corticosteróides, de drogas imunossupressoras e recentemente de agentes biológicos(11), é um desafio relevante, pois nenhuma intervenção terapêutica leva à cura.

Os antimaláricos, preferencialmente do sulfato de hidroxicloroquina, são indicados com a finalidade de reduzir a atividade da doença e tentar poupar o uso de corticóide. Porém, deve-se monitorar os efeitos colaterais do tratamento prolongado da doença, independentemente do órgão ou do sistema afetado(11).

Sabe-se que o corticoide atua sobre os tecidos periodontais e pode reduzir 0 processo inflamatório da DP(51). Um trabalho verificou que pacientes com LES sob corticoterapia apresentavam DP leve e respondiam melhor ao tratamento odontológico(52). 
Depressão e hipertensão, são comorbidades comuns em pacientes com LES, e as medicações utilizadas podem influenciar a saúde oral, devido ao seu efeito xerostômicos causados pelos antidepressivos e anti-hipertensivos $(53,54)$.

Outro fator, muito importante no tratamento, é a mudança dos hábitos de vida. Deve-se informar ao paciente e aos familiares o que é a doença, sua evolução, transmitir ao paciente a motivação necessária para a adesão ao tratamento, o repouso nos períodos de atividade sistêmica da doença, o uso de guarda-sol, bonés e protetor contra a luz solar, além de evitar o tabagismo(35).

A abordagem odontológica em pacientes com LES é importante, uma vez que crianças e adolescentes sob tratamento com drogas imunossupressoras apresentam um maior risco de desenvolver complicações sistêmicas a partir de infecções orais(55). Verificou-se que a redução na progressão da infecção periodontal, por meio do tratamento periodontal, diminui os níveis de marcadores inflamatórios, como IL-6, TNF-11 e proteína C reativa, que são comuns ao LES e à periodontite, e isso contribui para a redução da inflamação sistêmica nesses pacientes(56).

\subsection{EPIDEMIOLOGIA DAS CONDIÇÕES BUCAIS DO PACIENTES COM LES}

O acometimento da cavidade bucal é comum nos pacientes com LES(34). Essas manifestações orais podem ser influenciadas pela terapêutica, podendo 0 cirurgião-dentista (estomatologista) ser o primeiro profissional da saúde a diagnosticar tais achados(32).

No que tange os aspectos dentários e periodontais em pacientes com LES, os trabalhos são escassos e controversos, além de não apresentarem uniformidade metodológica, o que torna difícil o estabelecimento entre as condições (51, 57-60).

\subsubsection{FLUXO SALIVAR}

A complexidade da composição molecular de saliva demonstra a sua importância relacionada com a manutenção da integridade oral e sistêmica, sendo a primeira linha de defesa oral(61).

As funções de saliva incluem(61):

- reparação de tecidos (presença do fator de crescimento epidérmico que promove a cicatrização da via oral, orofaringe, e mucosa gastroesofágica);

- lubrificação da boca, orofaringe e esôfago); 
- tamponamento (fosfato, bicarbonato, e proteínas)

- digestão (formação do bolo alimentar e digestão do amido, proteínas e lipídios);

- gustação (solubilidade de moléculas e de maturação dos bostões gustatórios);

- ação antimicrobiana (presença de anticorpos lgA / IgM e lgG, lisozima e lactoferrina, sistema de peroxidase / cistatina / mucina, e histatina);

- manutenção da integridade do dente (maturação do esmalte e remineralização)(62, 63);

- sistema de defesa(61).

Os termos hipofunção salivar ou hipossalivação e xerostomia são muitas vezes utilizados de forma incorreta. Hipossalivação refere-se a um fluxo salivar diminuído, enquanto que a xerostomia se refere à uma experiência subjetiva da boca seca. Isto é ainda mais complicado pelo fato de alguns pacientes com hipossalivação não apresentarem xerostomia e, por outro lado, aqueles com xerostomia podem ter taxas de fluxo salivar normal(64)I. No entanto, xerostomia é um sintoma comum e primário associado ou não com hipofunção da glândula salivar. Normalmente, a xerostomia ocorre quando a secreção salivar diminuiu para metade dos valores normais de um indivíduo(64).

Afirma-se que a xerostomia está presente entre 75 a 100\% dos pacientes com LES(65). Um estudo mostra um grupo de pacientes com LES e sem outras doenças sistêmicas e nenhum dos pacientes queixava-se de xerostomia. No entanto, esses pacientes apresentavam fluxo salivar significativamente mais baixos do que os controles. Em outro estudo, pacientes com LES e xerostomia(66) tinham fluxo salivar significativamente mais baixos comparados com controles saudáveis(67).

A redução do fluxo salivar pode ser causada por vários fatores incluindo doenças sistêmicas, radioterapia em região cérvico-encefálica, iodoterapia, outras doenças autoimunes como Síndrome de Sjogren e uso de medicamentos(68, 69).

Durante o curso do LES os pacientes passam a usar vários medicamentos que podem interferir na secreção de saliva (70). Sabe-se que o uso de alguns medicamentos pode reduzir o fluxo salivar, como diuréticos, anti-hipertensivos, anti- 
histamínicos, sedativos, analgésicos opioides, antidepressivos tricíclicos e antipsicóticos(71).

Como consequência da redução do fluxo, o paciente poderá apresentar halitose e distúrbios do sono (sono interrompido para ingerir água diversas vezes ao longo da noite e, consequentemente, urinar). Tais ocorrências comprometem a qualidade de vida do indivíduo(72, 73).

Verifica-se que, dos pacientes com LES que sofrem de hipossalivação, a atividade da doença bem como a idade em anos são os fatores estatisticamente significantes para a redução do fluxo salivar(74). Ademais, que a prevalência é de $79,2 \%$ quando comparado com a população geral, que é de $20 \%(61)$.

Assim, acredita-se que pacientes com LES podem apresentar maior incidência de lesões de cárie, uma vez que o baixo fluxo salivar também está associada a uma redução da capacidade de tamponamento $(75,76)$.

\subsubsection{LESÕES BUCAIS}

Lesões bucais indolores são achados frequentes em pacientes com LES com prevalência que varia entre $6,5 \%$ a $80 \%(18,19)$. O eritema é a lesão clínica mais comum (35\%), seguido por lesões discoides (16\%) e ulcerações (6\%)(18-20). Todavia, não está claro se a presença de lesões bucais é preditiva para a atividade da doença(18-20). Observa-se que as regiões bucais comumente afetadas são língua, mucosa jugal, lábios e palato(19, 20, 22).

As lesões bucais que se manifestam como úlceras crônicas ou eritematosas, podem ter dimensões variadas, com períodos de exacerbação e remissão e aspectos histopatológicos diversos(19, 20).

Estudos afirmam que ulcerações na mucosa oral dos pacientes com LES(34, 64, 77-79) estão associadas ao aumento da atividade da doença sem mudanças significativas na sorologia(77). Lesões como leucoplasia também tem sido reportadas em pacientes com LES(80), além de lesões com bordas vermelhas(81). 
Embora ulcerações na mucosa oral sejam as mais frequentes em pacientes lúpicos(82, 83), outras lesões também podem surgir. Lesões semelhantes ao líquen plano, já foram descritas $(78,80,84)$ e foram encontradas em pacientes com menos de 2 anos de diagnóstico(84).

Placas reticulares vermelhas e brancas também têm sido observadas em pacientes com $\operatorname{LES}(85,86)$. A maioria dessas lesões mostraram mudanças histopatológicas específicas ao LES, porém padrões histológicos e imunológicos podem ser inespecíficos $(87,88)$.

Em adição, as lesões bucais no LES podem se apresentar como erosões de mucosa, placas de superfície descamativa ou fissuras com tendência hemorrágica, ulcerações ou erosões no interior de placas ou estrias brancas irradiadas (lesões discóides), e máculas eritematosas extensas que podem ou não estar acompanhadas de áreas ulcerativas ou erosadas(32).

Em um mesmo paciente, é possível encontrar expressão de todas estas combinações(20). O tamanho das lesões é variável, sendo que as úlceras podem variar desde uma pequena erosão superficial até uma área larga e extensa, sendo importante o profissional reconhecer estas diferentes apresentações clínicas, vislumbrando a possibilidade do estabelecimento de um diagnóstico precoce(6, 89).

As lesões em lábio são muitas vezes associadas com lesões semelhantes em outras regiões anatômicas. Porém, a manifestação exclusiva em lábio pode ocorrer. Pápulas pequenas em tons de rosa, placas em forma de moeda e lesões difusas podem estar presentes e mesmo as lesões incipientes tendem acometer 0 vermelhão. As lesões podem tornar-se despigmentada (Figura 10), ceratótica, corroída, atrófica e verrucosa(90).

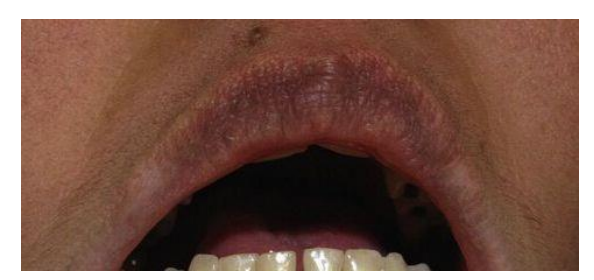

FIGURA 10. Mancha hipercrômica em lábio superior entremeadas com área de acromia que borram a linha do vermelhão do lábio. 
Hiperqueratose e acantose são achados comuns, possivelmente produzidos como uma resposta do epitélio à agressão crônica. Degeneração do estrato basal e espessamento da membrana basal também foram observados na maioria dos $\operatorname{casos}(20)$.

Há relação direta e significativa entre a quantidade de uso de corticosteroide e a presença de lesões da mucosa oral(91). Esta evidencia que os pacientes com doses mais elevadas de corticosteroides estão na fase ativa da doença, com mais lesões neste período. Porém, também deve ser considerado que as lesões bucais podem ser um efeito colateral de doses elevadas de corticosteróides(91).

Portanto, as lesões de mucosa bucal em pacientes com LES podem se apresentar com aspectos clínicos e histopatológicos variados, havendo discordâncias no que se refere à prevalência destas manifestações. Tratamentos imunossupressores provavelmente devem manter pacientes livres de alterações na $\operatorname{mucosa}(20)$.

\subsubsection{CONDIÇÃO PERIODONTAL}

O dente é suportado pelo osso alveolar através de um sistema ligamentar conhecido por periodonto. Este compreende os seguintes tecidos: gengiva, ligamento periodontal, cemento radicular e osso alveolar (Figura 11). O dente está inserido ao osso através de uma articulação semirrígida denominada gonfose, ricamente vascularizada e inervada(92).

A estrutura dento-gengival é representada pelo sulco gengival e pela faixa de epitélio juncional, que exercem um selamento biológico nas margens dos dentes com determinado grau de permeabilidade(93).

A principal função do periodonto é inserir o dente no tecido ósseo dos maxilares e manter a integridade da superfície da mucosa mastigatória. O periodonto está sujeito a modificações morfológicas e funcionais decorrentes da carga mastigatória, direcionamento das forças, idade e alterações do ambiente oral(94). 


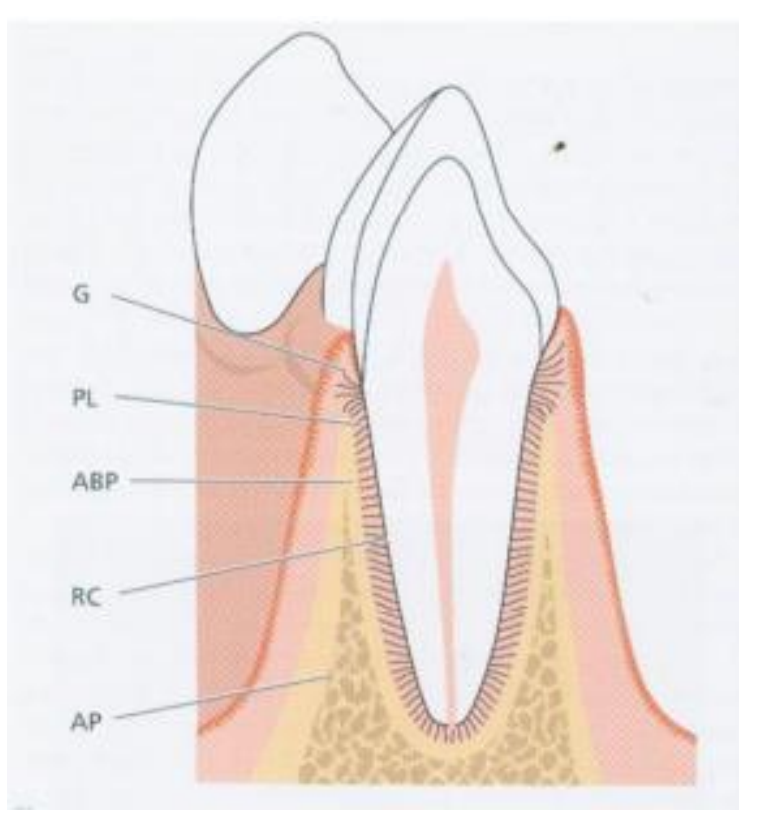

Fonte: Lindhe et. al. 2010.

FIGURA 11. Imagem ilustrativa do periodonto.

Componentes anatômicos do periodonto: Gengiva $(\mathrm{G})$, Ligamento periodontal (PL), Cemento Radicular (RC). O Osso Alveolar é constituido por dois componentes: Osso Alveolar Propriamente Dito (ABP) e Processo Alveolar (AP).

Embora as bactérias periodontopatogênicas sejam consideradas etiologicamente mais importantes na DP, uma combinação de diversos fatores influencia a extensão e a gravidade dessa doença(94). As alterações nos níveis de hormônios durante a puberdade, gestação e menopausa podem modificar a resposta do hospedeiro em relação à placa bacteriana, aumentando a intensidade de progressão da doença periodontal $(95,96)$.

Sucintamente, a DP classifica-se em dois grupos, gengivite e periodontite. A gengivite pode ou não ser induzida por placa. Quando induzida por placa, manifestase como uma resposta inflamatória crônica à acumulação do biofilme supragengival e pode ser agravada por fatores sistêmicos (diabetes, hormônios, etc), por medicamentos (fenitoína, difenilidantoína, nifedipina e outros), ou por má nutrição (deficiência de ácido ascórbico)(94).

A gengivite não induzida por placa pode ser de origem viral (herpes), fúngica (candida), bacteriana específica (Neisseria gonorrhea), genética (fibromatose hereditária), condições sistêmicas (desordens muco-cutâneas), alérgica, traumática ou não específica(94). 
A periodontite é uma doença inflamatória crônica que resulta de uma complexa infecção polimicrobiana que destroi o periodonto, como consequência da perturbação da homeostase entre a microbiota subgengival $e$ as defesas do hospedeiro em indivíduos sensíveis(97). Representa uma progressão da gengivite com perda do osso alveolar e extensão do dano às fibras do ligamento periodontal, com migração do epitélio juncional e manifestações disseminadas do processo inflamatório e imunopatológico dos tecidos(92).

Dados sobre a prevalência da periodontite são dependentes de como a doença é definida e a faixa etária avaliada. Porém, cerca de $5 \%$ a $20 \%$ da população global sofre de periodontite. Os indivíduos sofrem diferentes respostas imunoinflamatórias frente aos microrganismos. Apesar de essa susceptibilidade para a evolução da DP não estar bem estabelecida, sabe-se que a mesma está associada a fatores de risco, como o tabagismo e diabetes mellitus, ou indicadores/modificadores de risco como predisposição genética, idade avançada, etilismo, gestação, doenças sistêmicas (neoplasias e infeç̧ões crônicas), baixa renda familiar e uso de alguns fármacos como antiepiléticos(98), ciclosporina(99) e nifedipina $(100,101)$.

O diagnóstico da DP e sua graduação são feitos pelo exame clínico e complementado por radiografias(101). Além dos sítios na dentição com alteração inflamatória, o exame deve identificar a extensão da destruição tecidual(94).

Os parâmetros mais utilizados para o diagnóstico são: sangramento do sulco gengival(102), profundidade da bolsa periodontal(103), nível de inserção periodontal e, em estágios mais avançados, a mobilidade dentária e envolvimento de furca (região entre raízes de dentes multirradiculados)(94).

Embora a relação entre doença periodontal (DP) e o LES ainda não esteja totalmente estabelecida, pois ainda não se conhece exatamente a prevalência da DP nos pacientes com LES $(51,59)$, alguns aspectos comuns à DP e ao LES, podem explicar parcialmente a ocorrência da DP.

Há aspectos do LES que podem favorecer o desenvolvimento da doença periodontal. O LES possui patogênese com características semelhantes à 
patogênese da doença periodontal como a hiperatividade de linfócitos $B$, elevada produção de anticorpos $\lg G(59)$, a existência de influências genéticas, ambientais, hormonais e imunológicas $(6,65)$.

A resposta inflamatória consiste na primeira linha de defesa do organismo contra um agente agressor, podendo ser inata ou adaptativa. Nas duas respostas há participação de elementos celulares e humorais. Na defesa celular há participação dos neutrófilos, mastócitos linfócitos T e B e plasmócitos. Já na defesa humoral participam as citocinas (IL-1, IL-4, IL-6, IL-8 e fator de necrose tumoral- $\alpha$ ) e as imunoglobulinas(52).

A prostaglandina E é descrita como a responsável por muitas alterações periodontais inflamatórias que ocorrem na DP como vermelhidão, edema, degeneração do colágeno e reabsorção óssea(104). Além disso, o comprometimento vascular regional, a terapia esteroidal ou o desequilíbrio de citocinas presentes no LES podem resultar em alterações da resposta imune do hospedeiro ou em ativação de osteoclastos (responsáveis pela reabsorção do tecido ósseo) repercutindo na condição periodontal(105).

Há afirmação de que a terapia sistêmica com esteroides usada no tratamento do LES contribua para o agravamento da gengivite necrosante(106).

Além disso, a diminuição do fluxo salivar, decorrente do uso de medicamentos, pode fazer com que ocorra algo semelhante ao que ocorre na Síndrome de Sjogren, onde observa-se aumento de índice de placa, de perda óssea alveolar e do nível de inserção clínica(Figura 12)(107).

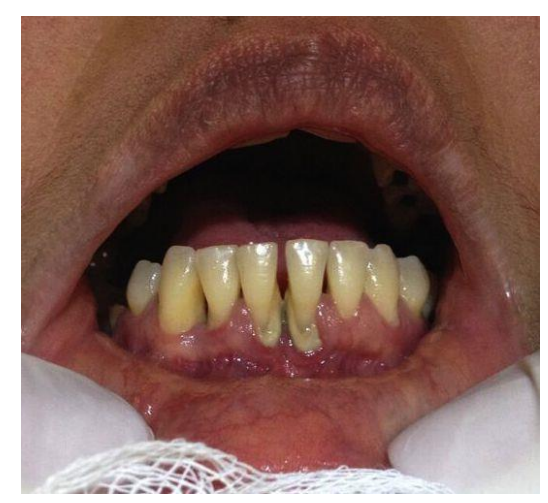

FIGURA 12. Doença periodontal em paciente com LES em que se verifica deposição de cálculo dentário e perda de nível de inserção clínica. 
Alguns estudos realizados para avaliar a doença periodontal em pacientes com LES apresentam resultados conflitantes. Um estudo realizado na Inglaterra em 27 pacientes com LES e 25 pacientes controle, afirmou que os pacientes com LES tinham profundidades de sondagem periodontal significativamente mais baixas comparados com controles saudáveis(51). Outro estudo apresentou um caso de uma paciente com LES e de gengivite generalizada severa e considerou que a doença periodontal foi ocasionada por agentes etiológicos locais em um hospedeiro suscetível devido ao LES(108).

Autores descreveram que a terapia sistêmica com esteroides usada no tratamento de LES contribuiu para o agravamento da gengivite necrosante (GUN) em paciente com LES (106). Outro estudo encontrou maiores perdas dentárias e inflamação gengival nos pacientes com LES grave e correlação da gravidade da doença periodontal com alterações no padrão de imunoglobulinas(58). Relataram suspeitar que, em combinação com imunodesregulação complexa, a terapia imunossupressora empregada no tratamento do LES seja responsável pela alta taxa de lesões periodontais em pacientes com tal condição sistêmica(58).

Há ainda os que consideraram que a coexistência da periodontite e LES é uma característica comum e que a doença periodontal deve ser considerada como uma patologia clínica do LES(57). Outros autores fizeram uma revisão de literatura e concluíram que que a associação entre LES e a periodontite não é ainda conhecida(109).

\subsection{4 ÍNDICE CPOD}

Poucos estudos foram realizados sobre as condições dentárias dos pacientes com LES(32, 110). Um estudo realizado no Brasil em 155 pacientes, sendo 94,1\% mulheres, encontrou um CPDO DE 18,5 nos pacientes com LES ativo e inativo. O índice CPO-D para o grupo LES foi 18,5 nos pacientes com LES, sendo constituído por 1,2 dentes cariados, 13,2 perdidos e 4,1 obturados (32).

Um estudo transversal realizado no México, que incluiu 60 pacientes com LES divididos em dois grupos de 30 indivíduos cada, de acordo com o índice de atividade para o diagnóstico de lúpus eritematoso (SLEDAI). A frequência de cárie foi de $85 \%$ para indivíduos com LES, sendo $73,3 \%$ para os pacientes com LES inativo e $100 \%$ para paciente com LES ativo(32). 
Outra alteração observada em um estudo foi à erupção tardia da dentição permanente e decídua em pacientes que fizeram uso crônico do corticoide, além de poder levar também à calcificação dos canais radiculares(111). 


\section{JUSTIFICATIVA}

Ao consultar (abril de 2014) os termos ((Systemic Lupus Erythematosus[Title/Abstract]) AND Oral manifestations[Title/Abstract]) AND [MeSH Terms] AND (English[lang]) OR (Portuguese[lang]) OR (Spanish[lang]) no banco de dados de pesquisa bibliográfica da PubMed foram encontrados 13 artigos. Excluindo os artigos que não tinham relação com o tema dessa pesquisa, verificou-se que foram publicados somente 08 estudos epidemiológicos sobre manifestações bucais em pacientes com LES. Dentre os estudos, apenas um foi relativo à população brasileira.

Considerando que LES é uma doença de difícil diagnóstico e que a presença de lesões bucais pode ser um sinal precoce da doença, bem como um indicador de atividade da doença, faz-se necessário elucidar outras possíveis manifestações bucais de maior ocorrência. Além disso, identificar as manifestações bucais de maior ocorrência em pacientes com LES é importante para o adequado planejamento do atendimento interdisciplinar desses pacientes.

Por ser o LES uma doença crônica e que pode ser altamente incapacitante, a identificação de achados específicos de interesse odontológico se mostra fundamental para promoção de saúde e qualidade de vida dos pacientes.

Além disso, poucos assuntos fazem uma abordagem completa das condições bucais dos pacientes com LES. 


\section{OBJETIVOS}

\subsection{OBJETIVO GERAL:}

Realizar levantamento epidemiológico das condições bucais de pacientes com LES atendidos no Hospital Universitário de Brasília para verificar se há necessidade de se estabelecer um plano de ação odontológico específico para esse grupo de pacientes.

\subsection{OBJETIVOS ESPECÍFICOS:}

Avaliar o fluxo salivar sem estímulo.

Verificar presença xerostomia.

Analisar a presença de lesões em tecidos moles da boca.

Avaliar índice de placa visível, índice de sangramento à sondagem, profundidade de sondagem, recessão gengival, nível de inserção clínica e doença periodontal. Elucidar o índice de dentes permanentes cariados, perdidos e restaurados (CPOD). 


\section{METODOLOGIA}

\subsection{DELINEAMENTO DO ESTUDO:}

Foi realizado um estudo transversal no Serviço de Reumatologia do Hospital Universitário de Brasília (HUB), onde pacientes com LES encontram-se em tratamento e acompanhamento. O estudo foi conduzido em conformidade com os princípios estabelecidos na Declaração de Helsinki da Associação Médica Americana e da Resolução 466/12 do Conselho Nacional de Saúde. Todos os indivíduos foram informados verbalmente e por escrito do objetivo do estudo e, ao concordarem com as implicações da pesquisa, foram convidados a assinarem o Termo de Consentimento Livre e Esclarecido (APÊNDICE 1). Este levantamento epidemiológico faz parte do projeto "Análise do Proteoma Salivar de pacientes com LES”, submetido e aceito pelo Comitê de Ética em Pesquisa da Universidade de Brasília (UnB) em 2013 (ANEXO 3).

\subsection{POPULAÇÃO E AMOSTRA DO ESTUDO:}

Casuística: a população total acessível era de aproximadamente 200 pacientes. Os pacientes eram informados e convidados a participar da pesquisa.

Critérios de Inclusão: indivíduos com LES diagnosticados em conformidade com os critérios estabelecidos pelo American College of Rheumatology (34); de qualquer idade com doenças nas fases ativa ou inativa; com e sem nefrite lúpica $(\mathrm{NL})$.

Critérios de Exclusão: pacientes que não concordassem em participar da pesquisa ou pacientes com diagnóstico por definir.

\subsection{PROCEDIMENTOS:}

5.3.1 ANAMNESE E EXAME CLíNICO: inicialmente os participantes foram entrevistados para a obtenção de informações médicas e demográficas assim como: idade, gênero, uso de tabaco e uso de medicamentos para controle do LES (APÊNDICE 2). O indivíduo fora considerado não fumante se nunca tivesse fumado ou se tivesse parado de fumar há mais de cinco anos. As informações médicas foram coletadas nos prontuários. Nessa etapa, os pacientes eram avaliados por um reumatologistas para determinação do SLICC (ANEXO 1) e SLEDAI (ANEXO 2).

5.3.2 AVALIAÇÃO DO FLUXO SALIVAR EM REPOUSO: o paciente foi orientado a permanecer com os olhos abertos, sentado, com os pés apoiados no chão e o corpo inclinado frontalmente, apoiando os cotovelos na parte superior das pernas. Cabeça 
inclinada para baixo, com um copo descartável bem próximo ao lábio inferior, para permitir que a saliva fluísse gravitacionalmente, sem movimentos de lábios, bochechas e língua. A coleta de saliva ocorreu durante 5 minutos. Essa amostra de saliva era pesada por uma balança de precisão para se estabelecer quantitativamente a produção de saliva e os valores eram registrados em $\mathrm{mL} /$ minuto, conforme estabelecido pela literatura científica(112). O paciente era questionado sobre queixa de xerostomia contínua, intermitente, esporádica ou ausência da mesma.

5.3.3 AVALIAÇÃo DE PRESENÇA DE LESÕES BUCAIS: as lesões bucais foram avaliadas clinicamente por quatro cirurgiões-dentistas. Estas foram examinadas clinicamente e classificadas de acordo com os seus aspectos e localização.

5.3.4 AVALIAÇÃo PERIOdONTAL: foi avaliada a condição periodontal examinando-se seis sítios por dente (vestibular, mésio-vestibular, disto-vestibular, lingual, mésio-lingual e disto-lingual) com o auxílio de uma sonda periodontal Michigan $\mathrm{O}$ com marcações de Williams. Os parâmetros observados foram: índice de placa visível de O’leary (1972)(113), índice de sangramento gengival proposto por Ainamo e Bay (1975)(114), profundidade de sondagem, recessão gengival e nível de inserção clínica.

5.3.5 AVALIAÇÃo DENTÁRIA: foi registrado o número de dentes presentes, presença de cárie coronária e radicular, restauração coronária e radicular, (índice CPOD) de acordo com os critérios da Organização mundial de saúde(115). Utilizouse espelho bucal, sonda exploradora, pinça clínica, e gaze. Foram adotadas todas as medidas de biossegurança (uso de luvas, gorros, máscaras e aventais, material esterilizado ou descartável, etc.). 


\section{RESULTADOS}

Dos pacientes atendidos regularmente no Ambulatório de Reumatologia do Hospital Universitário de Brasília, 69 aceitaram participar do estudo. A média de idade (faixa etária) dos pacientes adultos foi de 39,6 (20 a 77), sendo que 97\% eram mulheres. Apenas três pacientes possuíam idade superior a 65 anos. Do total, três eram crianças com idades de 10, 12 e 13 anos.

Dos 43 (64\%) pacientes adultos que tiveram peso, altura, frequência cardíaca, pressão sistólica e diastólica aferidos, encontrou-se os seguintes valores médios (desvio padrão): $65,5 \mathrm{Kg}( \pm 14,6), 1,58 \mathrm{~m} \mathrm{(} \pm 7 \mathrm{~cm}), 80$ batimentos por minuto $( \pm 15)$, $125,8 \mathrm{mmHg}( \pm 17,2)$ e $70,9 \mathrm{mmHg}( \pm 23,9)$, respectivamente.

\subsection{FLUXO SALIVAR}

Avaliou-se o fluxo salivar sem estímulo em 62 pacientes adultos, verificandose que a mediana do fluxo (percentil 25 e 75 ) foi de $0,41 \mathrm{~mL} / \mathrm{min}(0,18$ e 0,60 ), sendo que a faixa etária de 45 a 64 anos $(\mathrm{n}=20)$ apresentou fluxo de $0,18 \mathrm{~mL} / \mathrm{min}$ $(0,10$ e 0,53$)$. A queixa de boca seca foi avaliada em 66 pacientes adultos e 21 (32\%) reportaram ocorrência de xerostomia contínua (Figura 13). Desses, 12 (57\%) eram da faixa etária de 45 a 64 anos. Quanto às interrupções do sono noturno para ingestão de água (Tabela 1), 10 pacientes (15\%) relataram acordar duas vezes para tomar água e urinar, sendo 3 pacientes (50\%) com idades entre 35 e 44 anos.

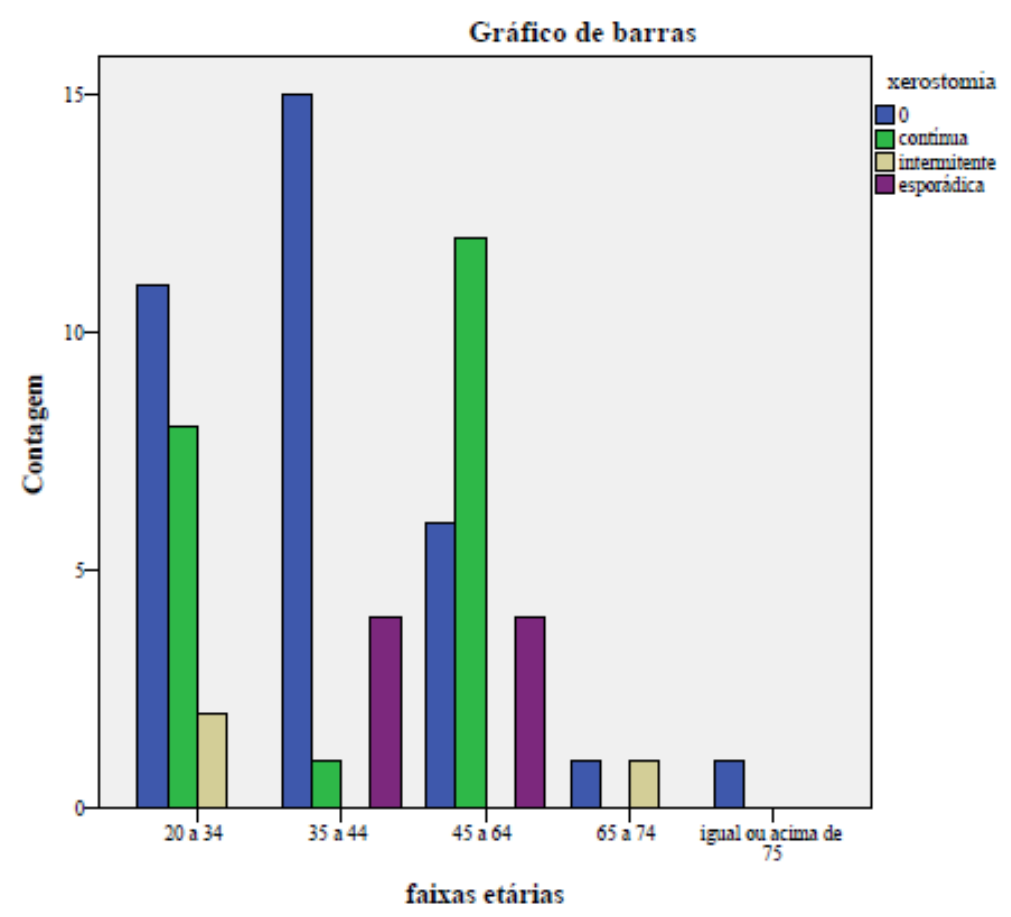

Figura 13. Presença de xerostomia. 
Tabela 01. Interrupção do sono noturno para ingestão de água:

\begin{tabular}{llrrrr}
\multicolumn{5}{c}{ interrupções do sono noturno para ingestas de água } \\
\hline \multicolumn{1}{c}{} & Frequência & Porcentagem & $\begin{array}{c}\text { Porcentagem } \\
\text { válida }\end{array}$ & $\begin{array}{c}\text { Porcentagem } \\
\text { cumulativa }\end{array}$ \\
\hline Válido & nenhuma & 38 & 57,6 & 57,6 & 57,6 \\
& uma & 8 & 12,1 & 12,1 & 69,7 \\
duas & 10 & 15,2 & 15,2 & 84,8 \\
três & 8 & 12,1 & 12,1 & 97,0 \\
5 & 1 & 1,5 & 1,5 & 98,5 \\
6 & 1 & 1,5 & 1,5 & 100,0 \\
Total & 66 & 100,0 & 100,0 & \\
\hline \hline
\end{tabular}

\subsection{LESÕES BUCAIS}

Dos 69 pacientes avaliados, 25 (36\%) apresentaram lesão bucal. Apenas 1 (5\%) era do sexo masculino, enquanto que 17 (95\%) eram do sexo feminino. Dentre as lesões presentes, 21 (59\%) possuíam mácula eritematosa, 6 (17\%) apresentavam lesão ulcerada, seguido de lesão eritematosa com ulcerações em 5 (14\%) pacientes. Apenas $2(5 \%)$ pacientes tinham candidose pseudomembranosa e $2(5 \%)$ candidose atrófica.

Das lesões relatadas, 13 (34\%) estavam em palato duro, 8 (21\%) em mucosa jugal, 5 (13\%) em fundo de vestíbulo e $3(8 \%)$ em rebordo alveolar edêntulo, (Tabela 2). 
TABELA 02. Lesões orais:

\begin{tabular}{|c|c|c|c|c|c|c|}
\hline Paciente & Sexo & Idade & Lesão Oral & Localização anatômica & SLICC & SLEDAI \\
\hline 1 & Feminino & 46 & $\begin{array}{l}\text { Mácula eritematosa } \\
\text { Candidose pseudomembranosa }\end{array}$ & $\begin{array}{l}\text { Palato duro } \\
\text { Fundo de vestíbulo superior }\end{array}$ & 2 & Não realizado \\
\hline 2 & Feminino & 71 & Mácula eritematosa & Palato duro & Não realizado & Não realizado \\
\hline 3 & Feminino & 39 & Lesão eritematosa com área de ulcerações & Lábio inferior & Não realizado & Não realizado \\
\hline 4 & Feminino & 36 & $\begin{array}{l}\text { Lesão eritematosa com áreas de ulcerações } \\
\text { Candidose pseudomembranosa }\end{array}$ & $\begin{array}{l}\text { Rebordo alveolar edêntulo } \\
\text { Rebordo superior parcialmente } \\
\text { edêntulo }\end{array}$ & Não realizado & Não realizado \\
\hline 5 & Feminino & 33 & Mácula eritematosa & Lábio inferior & Não realizado & Não realizado \\
\hline 6 & Feminino & 33 & Mácula eritematosa & Fundo de vestíbulo inferior & 4 & 0 \\
\hline 7 & Feminino & 34 & $\begin{array}{l}\text { Mácula eritematosa } \\
\text { Lesão ulcerada }\end{array}$ & $\begin{array}{l}\text { Mucosa jugal } \\
\text { Fundo de vestíbulo inferior }\end{array}$ & 0 & 0 \\
\hline 8 & Feminino & 60 & Lesão eritematosa com área central de ulceração & Palato duro & Não realizado & Não realizado \\
\hline 9 & Feminino & 50 & $\begin{array}{l}\text { Lesão ulcerada } \\
\text { Candidose atrófica }\end{array}$ & $\begin{array}{l}\text { Rebordo alveolar edêntulo } \\
\text { Palato duro }\end{array}$ & 0 & 0 \\
\hline 10 & Feminino & 54 & $\begin{array}{l}\text { Mácula eritematosa } \\
\text { Mácula eritematosa }\end{array}$ & $\begin{array}{l}\text { Palato duro } \\
\text { Fundo de vestíbulo superior }\end{array}$ & Não realizado & Não realizado \\
\hline 11 & Feminino & 44 & Mácula eritematosa & Região de forame incisivo & 0 & 2 \\
\hline 12 & Feminino & 16 & $\begin{array}{l}\text { Lesão ulcerada } \\
\text { Mácula eritematosa } \\
\text { Mácula eritematosa }\end{array}$ & $\begin{array}{l}\text { Bordo de língua } \\
\text { Palato duro } \\
\text { Muscosa jugal }\end{array}$ & Não realizado & Não realizado \\
\hline 13 & Masculino & 36 & Mácula eritematosa & Palato duro & Não realizado & Não realizado \\
\hline 14 & Feminino & 56 & $\begin{array}{l}\text { Mácula eritematosa } \\
\text { Candidose atrófica }\end{array}$ & $\begin{array}{l}\text { Palato duro e rebordo alveolar edêntulo } \\
\text { Palato duro }\end{array}$ & 0 & 0 \\
\hline 15 & Feminino & 47 & Mácula eritematosa & Mucosa jugal & 0 & 0 \\
\hline 16 & Feminino & 65 & Lesão ulcerada & Genviva inserida dos dentes 11,21 e 22 & Não realizado & Não realizado \\
\hline 17 & Feminino & 78 & Lesão ulcerada central com área eritematosa & Palato duro (suspeita de malignidade) & Não realizado & Não realizado \\
\hline
\end{tabular}




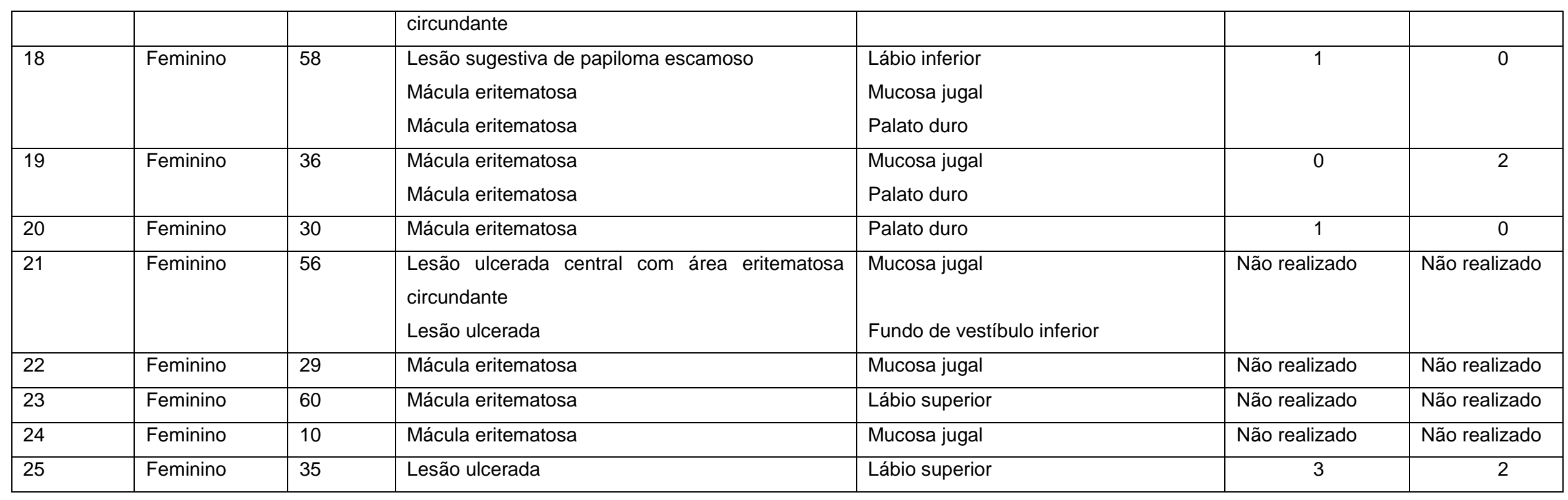




\subsection{CONDIÇÃO PERIODONTAL}

Do total dos pacientes adultos, 60 (91\%) tiveram a condição periodontal avaliada. A mediana (percentil 25 e 75) do índice de placa visível foi de 61,3 (33,3 e 87,9) (Figura 14), do índice de sangramento, 25 (6 e 57,4) (Figura 15) e a profundidade de sondagem, 1,6 (0,5 e 3,4) (Figura 16).

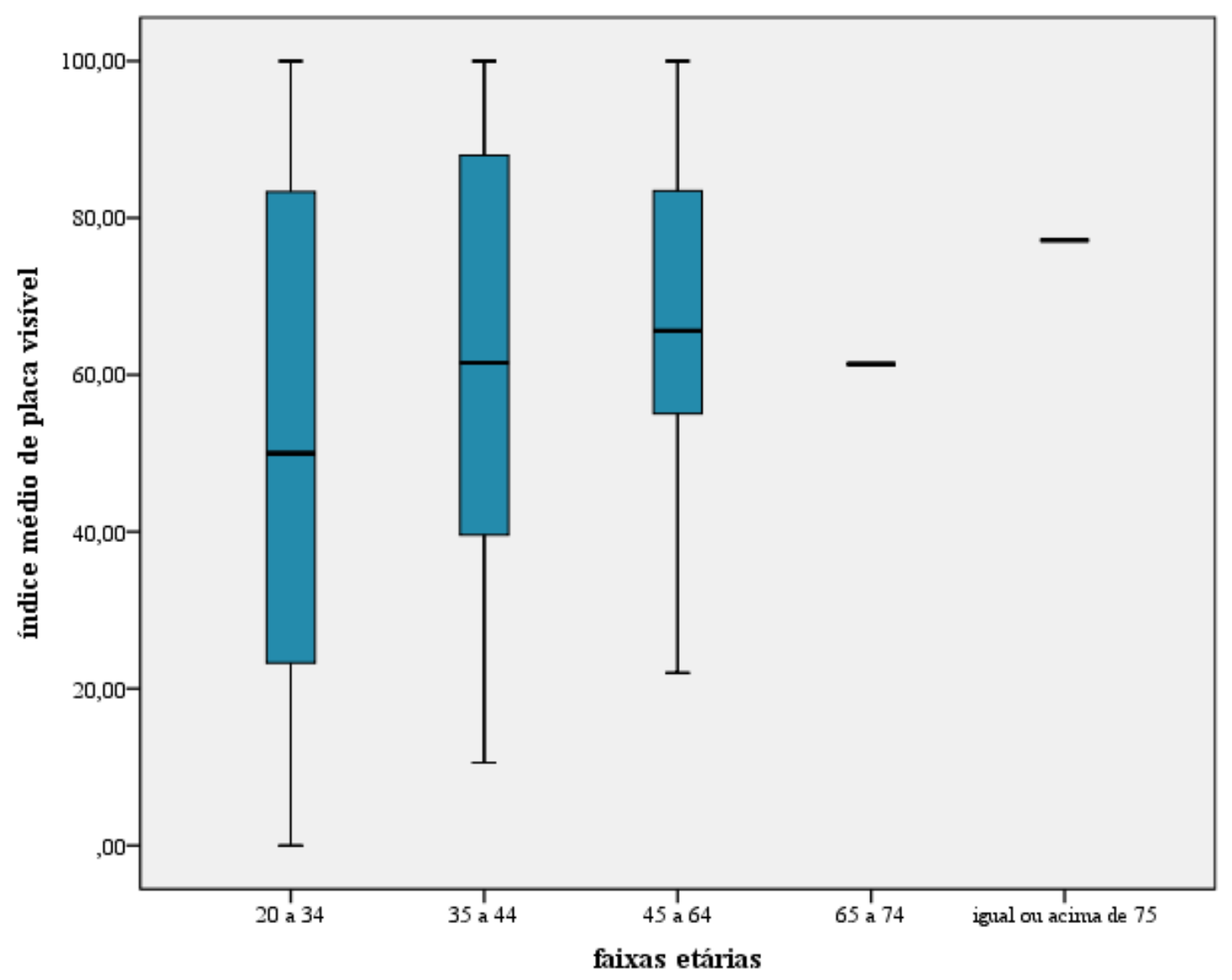

FIGURA 14. Índice médio de placa visível por faixa etária.

A recessão gengival apresentou mediana de $0,3(0,1$ e 0,9$)$ (Figura 17), enquanto que a perda do nível de inserção clínica foi de 1,3 (0,6 e 3,2) (Figura 18). Quanto aos índices relativos às faixas etárias, pacientes entre 45 e 64 anos apresentaram os maiores índices de placa visível 64,3 (47,8 e 89,6), sangramento 25 (8,8 e 58,3), profundidade de sondagem de 2,3 (1,2 e 4,0), recessão gengival 1,0 $(0,5$ e 1,8$)$ e perda nível de inserção clínica $3,2(1,7$ e 5,5). 


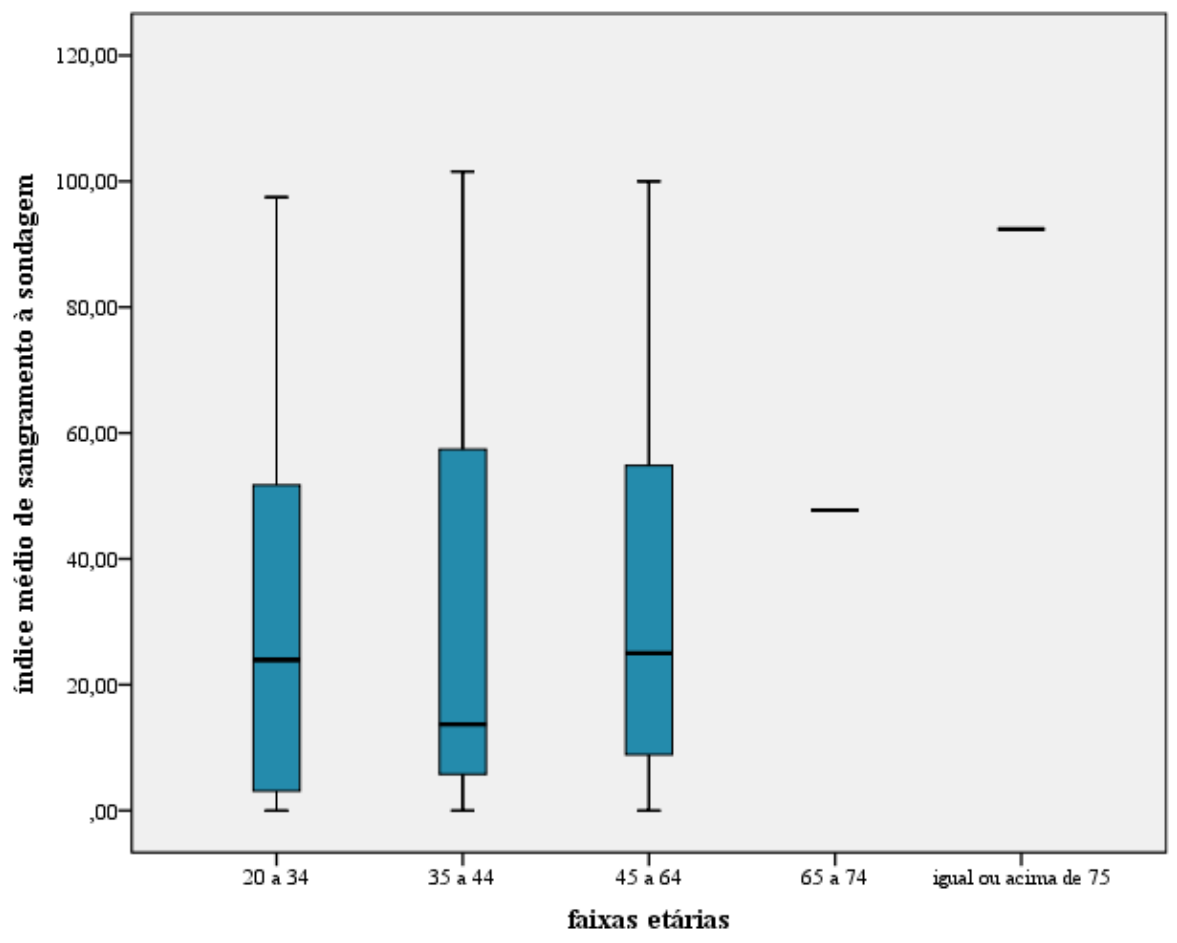

FIGURA 15: Índice médio de sangramento a sondagem por faixa etária.

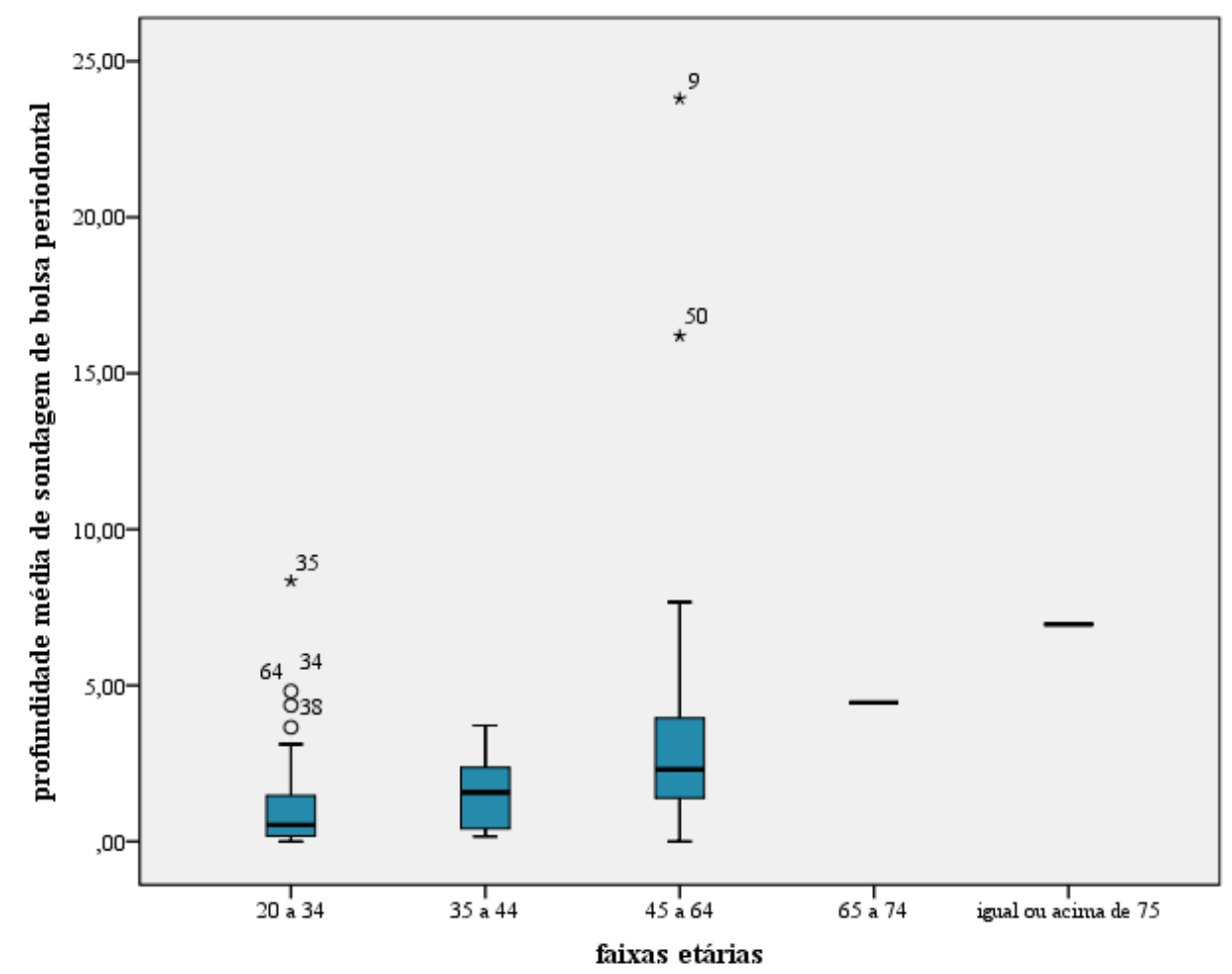

FIGURA 16. Profundidade média de sondagem de bolsa periodontal. 


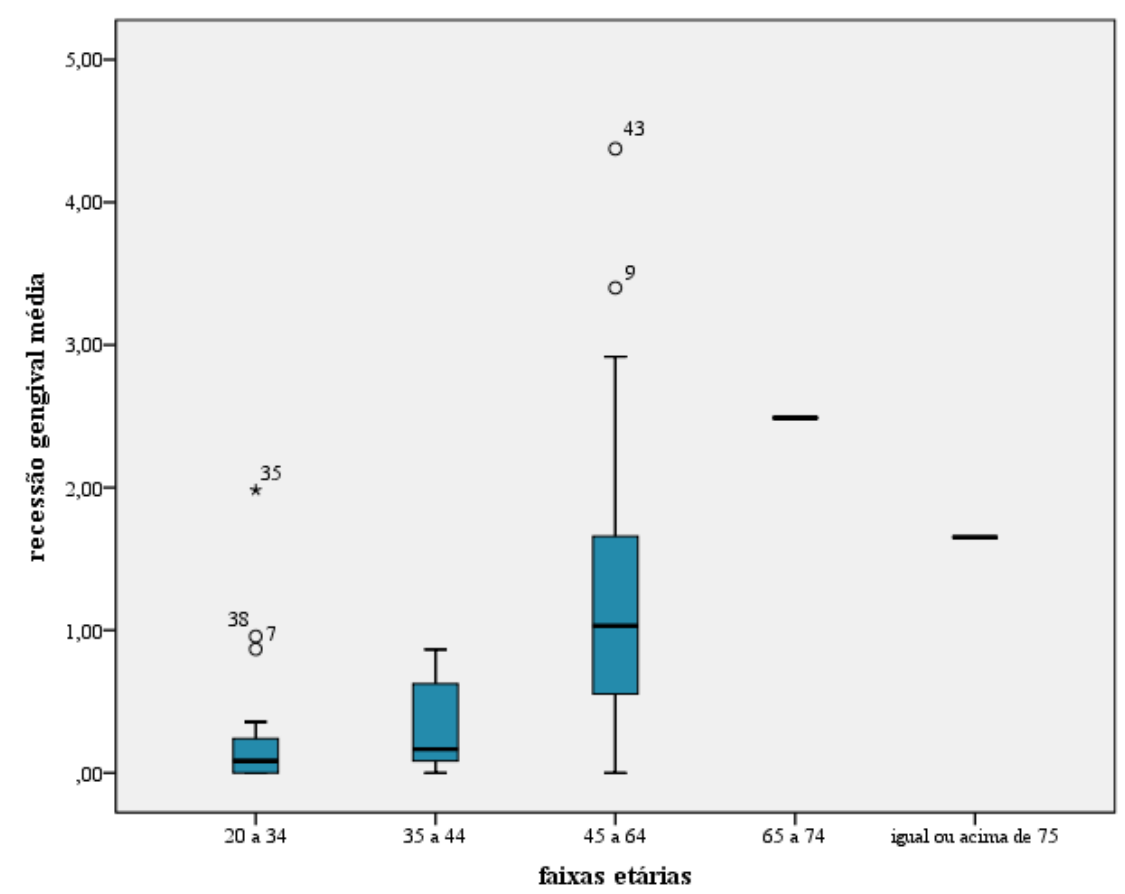

FIGURA 17. Recessão gengival média por faixa etária.

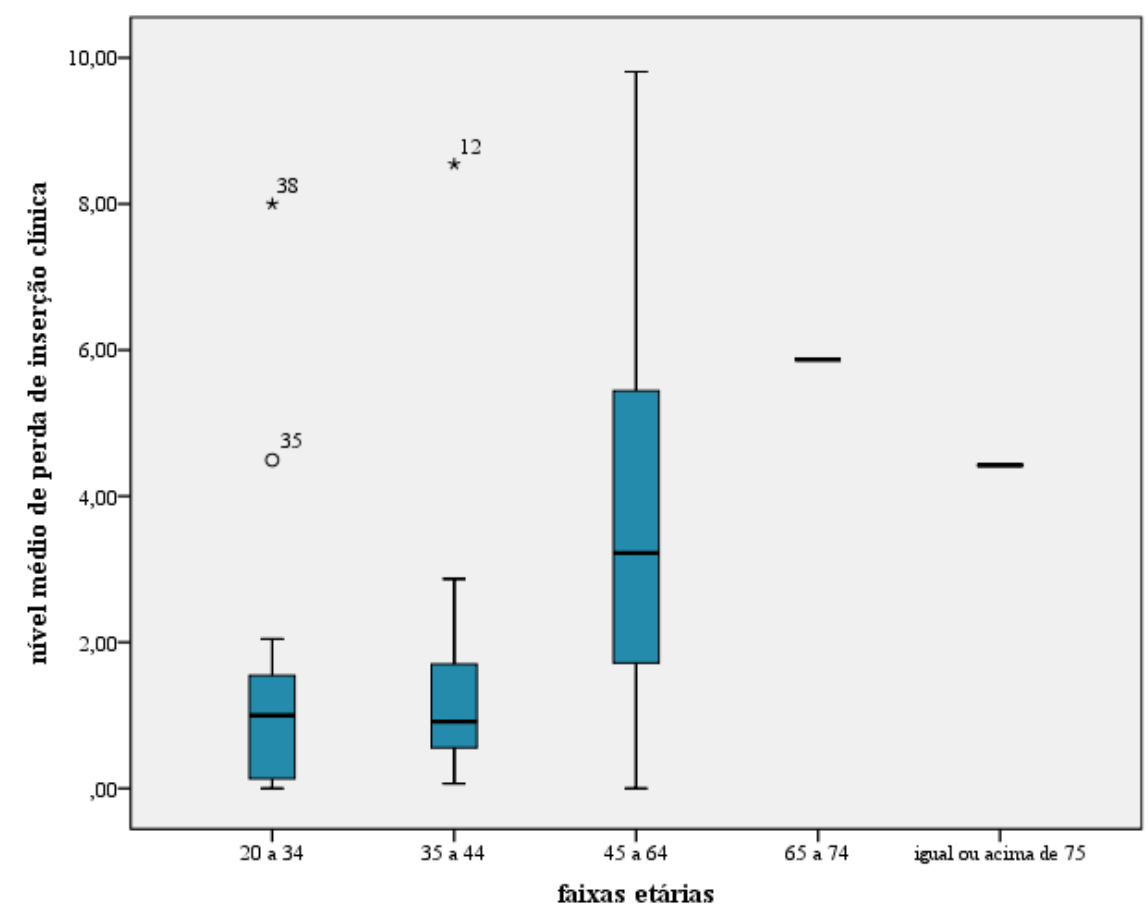

FIGURA 18. Nível médio de perda de inserção clínica por faixa etária.

\section{4 ÍNDICE CPOD}

No que diz respeito às condições dentárias, o índice CPOD dos pacientes (desvio padrão) foi de 16,5 ( \pm 8,3). A mediana (percentis 25 e 75) de dentes cariados, perdidos e restaurados foi de 1 (0 e 3), 5 (2 e 15) e 5 (0 e 8), 
respectivamente. Observou-se que a faixa etária de 45 a 64 anos, correspondente a $33 \%$ dos pacientes adultos, apresentou o pior índice CPOD que foi de 22,9 ( \pm 5 ) (Figura 19). Observou-se que 7 pacientes (11\%) usavam prótese total dupla, enquanto que $4(6 \%)$ usavam prótese total na arcada superior, sendo que 2 edêntulos total de ambas arcadas estavam na faixa etária de 35 a 44 anos (Figura 20).

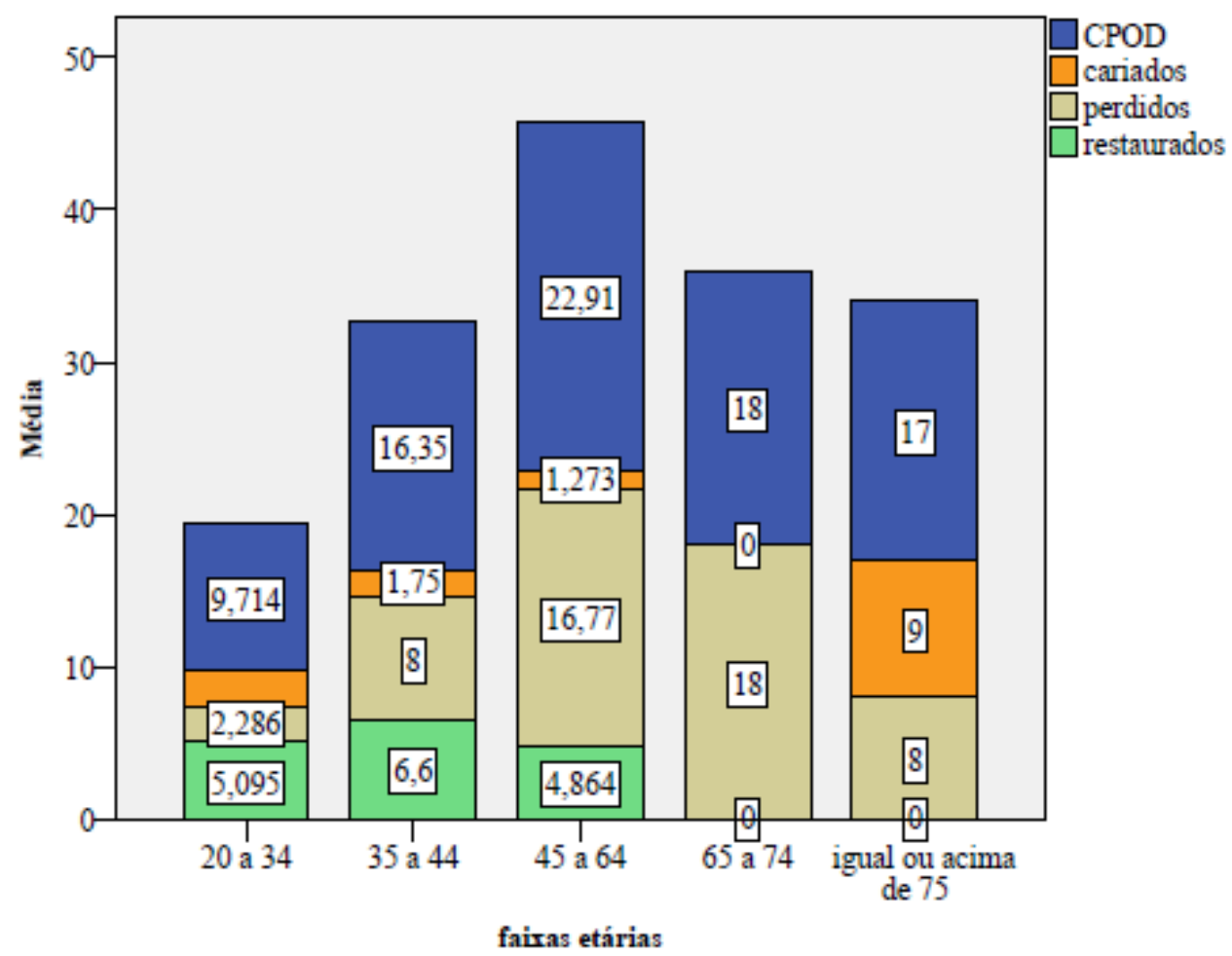

Obs: O $n$ para cada faixa etária é 20,19, 20, 2 e 1 respectivamente.

FIGURA 19. Índice CPOD por faixa etária. 


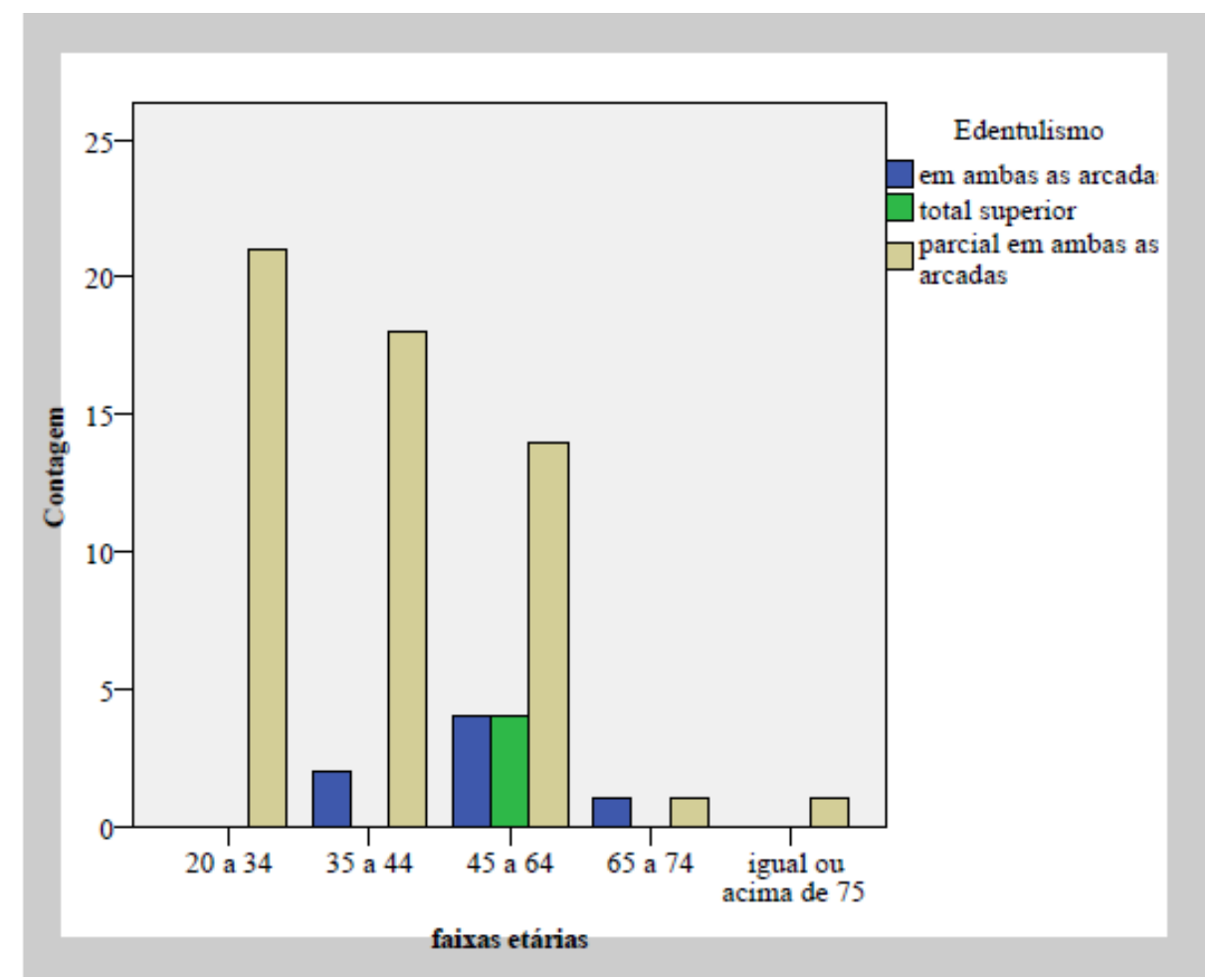

FIGURA 20. Pacientes edêntulos em diversas faixas etárias.

\subsection{CONDIÇÕES SÓCIO DEMOGRÁFICAS}

Quanto às características sócio demográficas, 28 (41\%) moravam com companheiro (a) e filhos (Figura 21), 1 (1\%) era tabagista (Tabela 3) e $66(96 \%)$ não consumiam bebidas alcoólicas (Tabela 4) e 34 (49\%) se autodeclaram pardos (Tabela 5). A média (desvio padrão) de anos de estudo da população adulta foi de $10( \pm 5)$ anos.

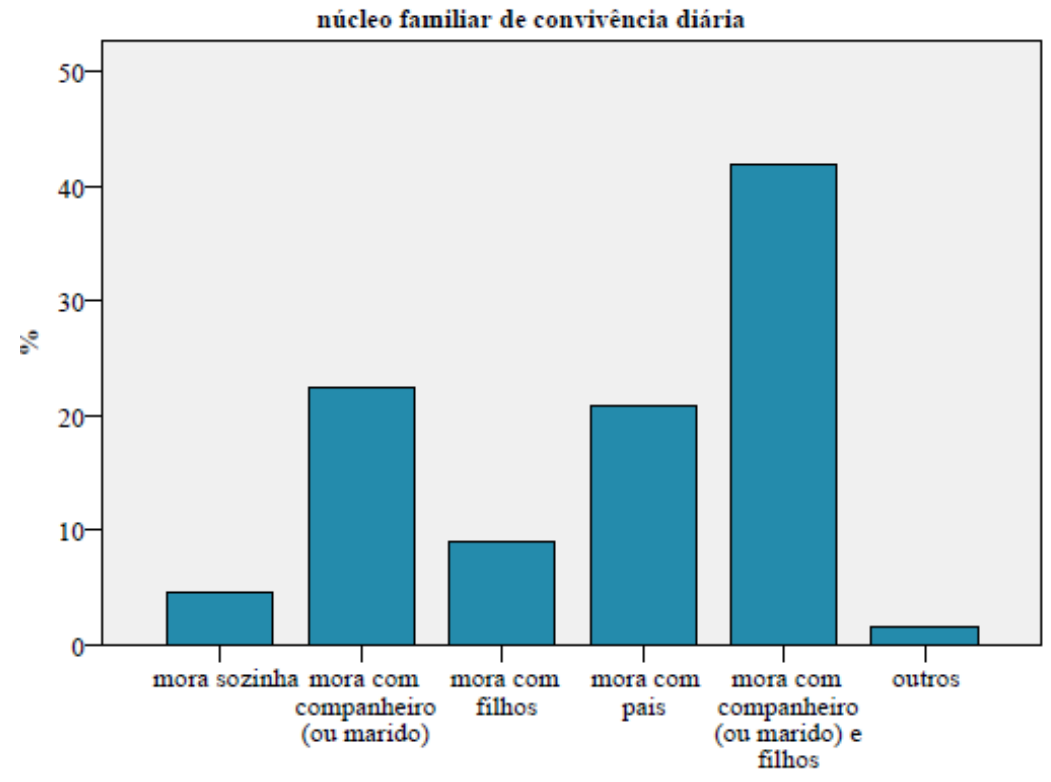

FIGURA 21. Núcleo familiar de convivência diária. 
TABELA 3 - Tabagismo

tabagismo

\begin{tabular}{lrrrrr}
\hline & Frequência & Porcentagem & $\begin{array}{c}\text { Porcentagem } \\
\text { válida }\end{array}$ & $\begin{array}{c}\text { Porcentagem } \\
\text { cumulativa }\end{array}$ \\
\hline Válido & não & 68 & 98,6 & 98,6 & 98,6 \\
& sim & 1 & 1,4 & 1,4 & 100,0 \\
& Total & 69 & 100,0 & 100,0 & \\
\hline \hline
\end{tabular}

TABELA 04. Etilismo.

\begin{tabular}{llrrrr}
\multicolumn{5}{c}{ etilismo } \\
\hline \hline Válido & não & Frequência & Porcentagem & $\begin{array}{c}\text { Porcentagem } \\
\text { válida }\end{array}$ & $\begin{array}{c}\text { Porcentagem } \\
\text { cumulativa }\end{array}$ \\
\hline & 66 & 95,7 & 95,7 & 95,7 \\
& $\begin{array}{l}\text { menos de uma vez por } \\
\text { semana }\end{array}$ & 2 & 2,9 & 2,9 & 98,6 \\
& uma a duas vezes por & 1 & 1,4 & 1,4 & 100,0 \\
& semana & 69 & 100,0 & 100,0 & \\
Total & 69 &
\end{tabular}

TABELA 05. Cor declarada.

\begin{tabular}{llrrrr}
\multicolumn{5}{c}{ cor declarada } \\
\hline \hline Válido & Frequência & Porcentagem & $\begin{array}{c}\text { Porcentagem } \\
\text { válida }\end{array}$ & $\begin{array}{c}\text { Porcentagem } \\
\text { cumulativa }\end{array}$ \\
& branca & 12 & 17,4 & 17,4 & 17,4 \\
& preta & 12 & 17,4 & 17,4 & 34,8 \\
& parda & 10 & 14,5 & 14,5 & 49,3 \\
& amarela & 34 & 49,3 & 49,3 & 98,6 \\
& Total & 1 & 1,4 & 1,4 & 100,0 \\
\hline \hline
\end{tabular}

\subsection{DIAGNÓSTICO}

A mediana (percentil 25 e 75) de meses decorridos para formulação do diagnóstico foi de 96 meses (24,8 e 238,8) nos 30 adultos (43,5\%) que tiveram esta variável avaliada (Figura 22). Verificou-se que a maior mediana de tempo decorrido foi de 120 meses (20 e 264) ocorreu nos pacientes entre 45 e 64 anos de idade. 


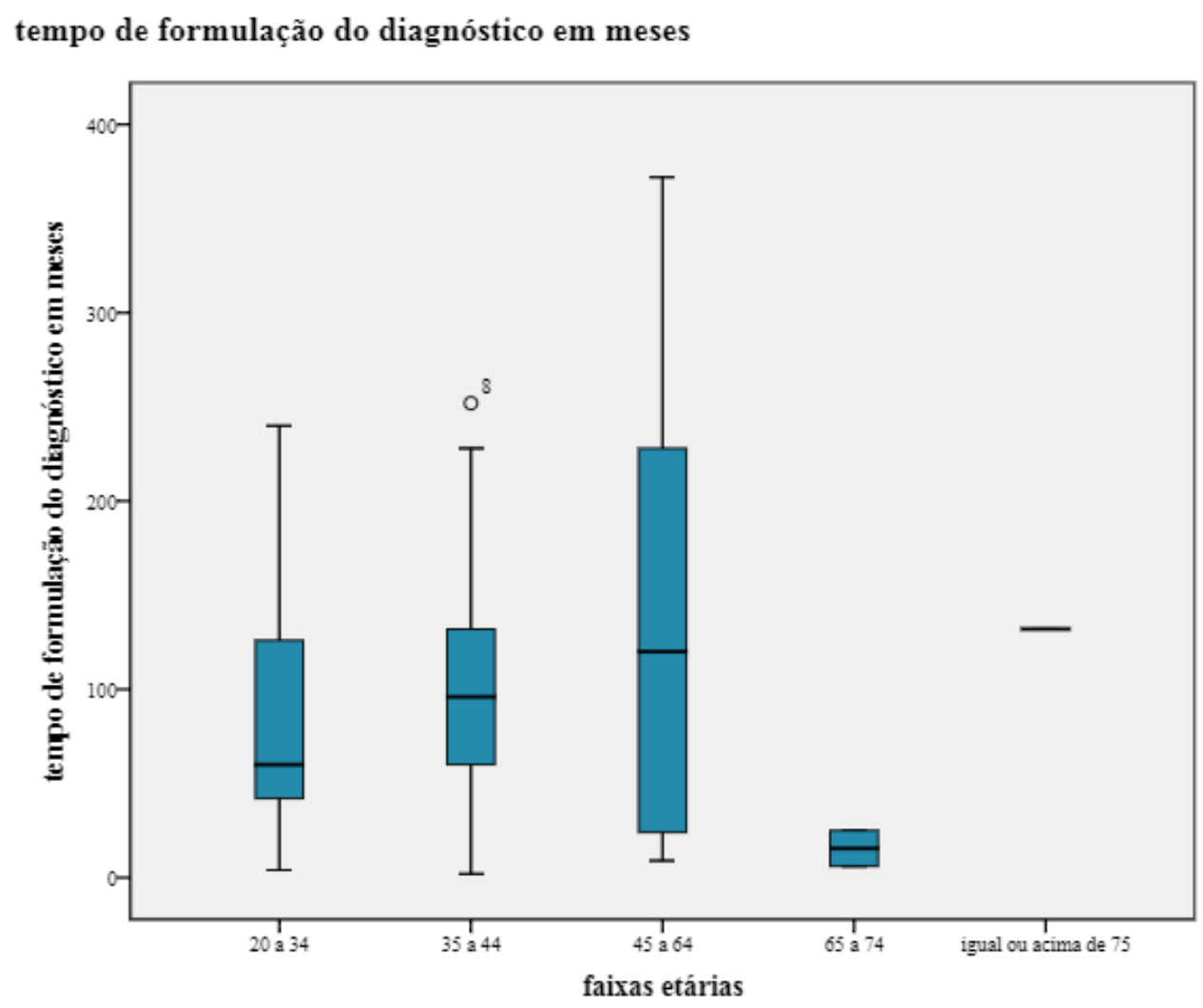

FIGURA 22. Tempo de formulação do diagnóstico do LES em meses por faixa etária.

O SLICC (Figura 23) e o SLEDAI (Figura 24) foram avaliados em 30 adultos $(45,5 \%)$ sendo que $17(56,6 \%)$ pacientes tiveram score zero para SLICC e $15(50 \%)$ tiveram score zero para SLEDAI.

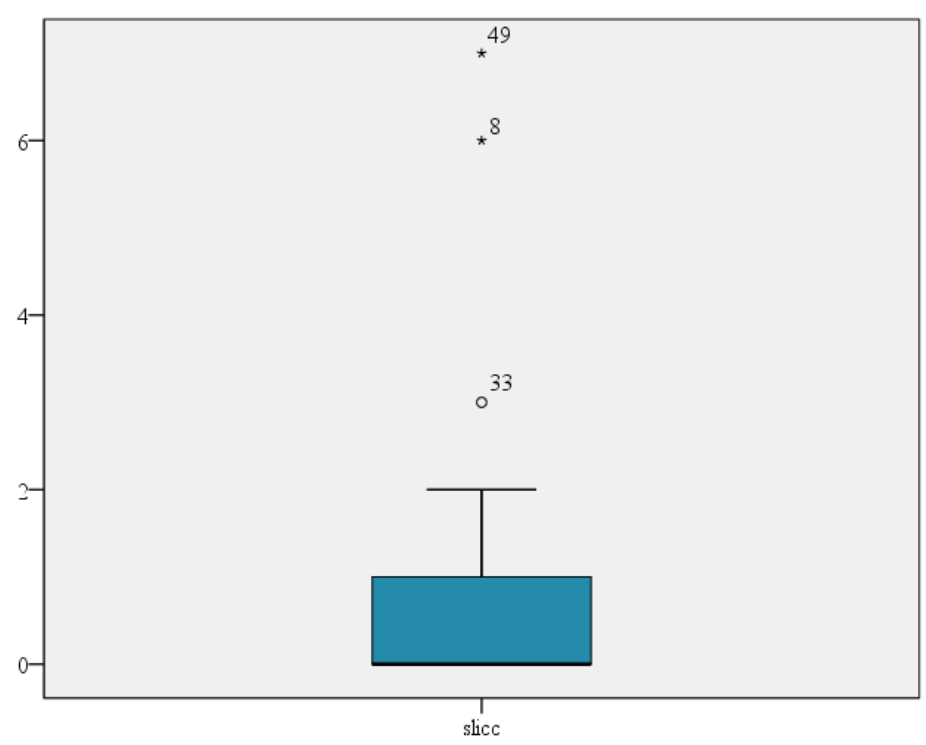

FIGURA 23. SLICC 


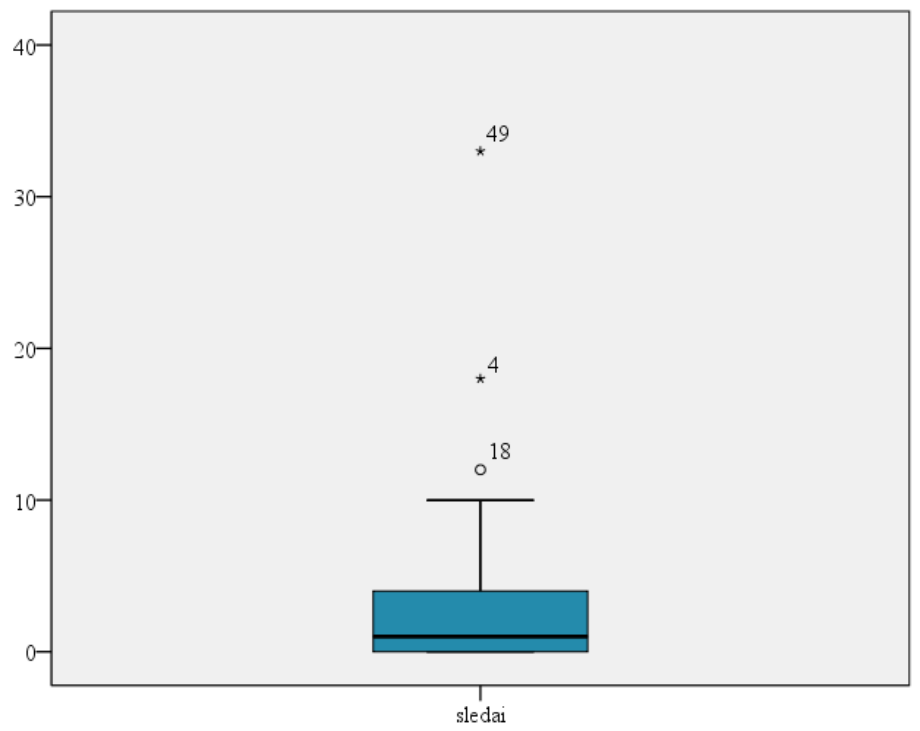

FIGURA 24. SLEDAI

Quanto à atividade do LES (Figura 25), 36 pacientes adultos (54,5\%) foram classificados e verificou-se que $18(50 \%)$ encontravam-se na fase inativa do LES e da NL e $3(8,3 \%)$ estavam com LES e NL na fase ativa.

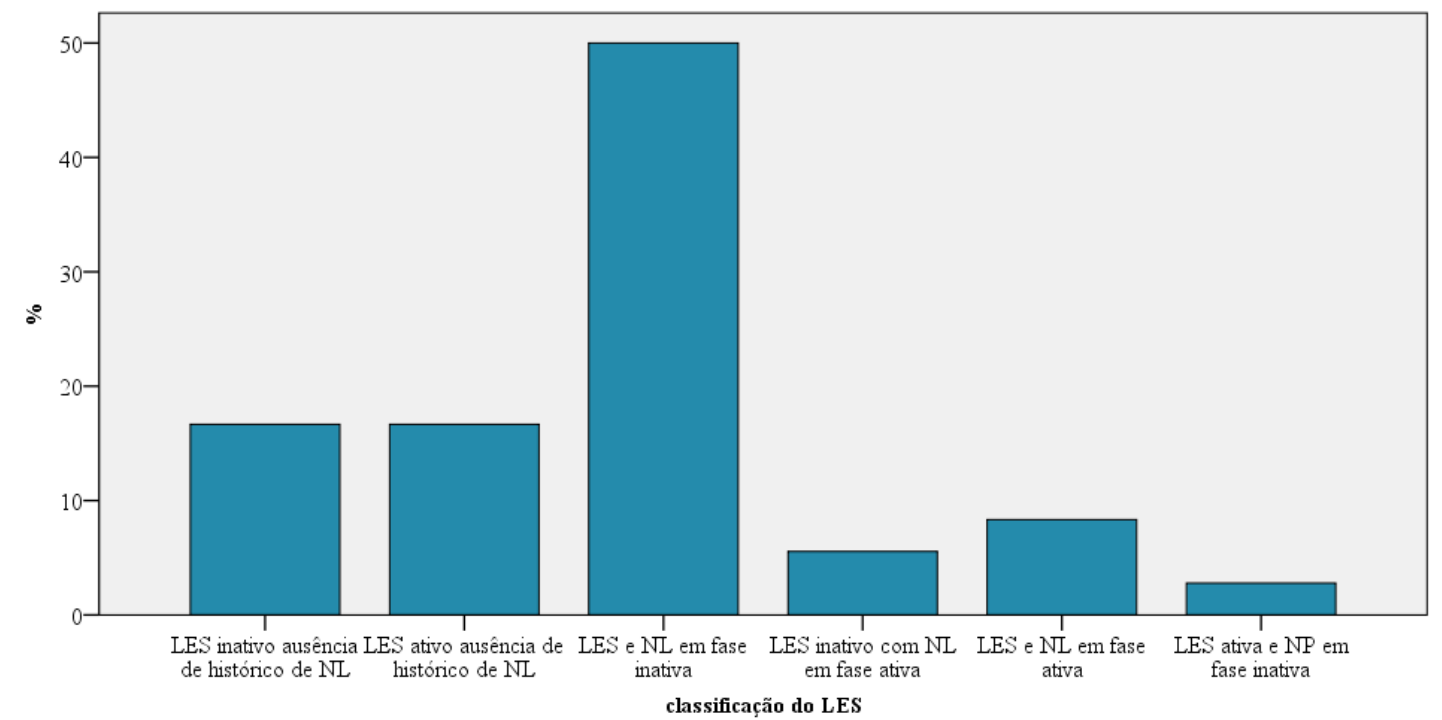

FIGURA 25. Classificação do LES e NF quanto à atividade.

\subsection{MEDICAMENTOS ADMINISTRADOS}

Observou-se que de todos os pacientes adultos, 64 (97\%) foram avaliados quanto ao uso de medicamentos (Figura 26). Hidroxicloroquina e prednisona foram os medicamentos usados por $36(54,5 \%)$ e 41 (62,1\%) dos pacientes, respectivamente. 


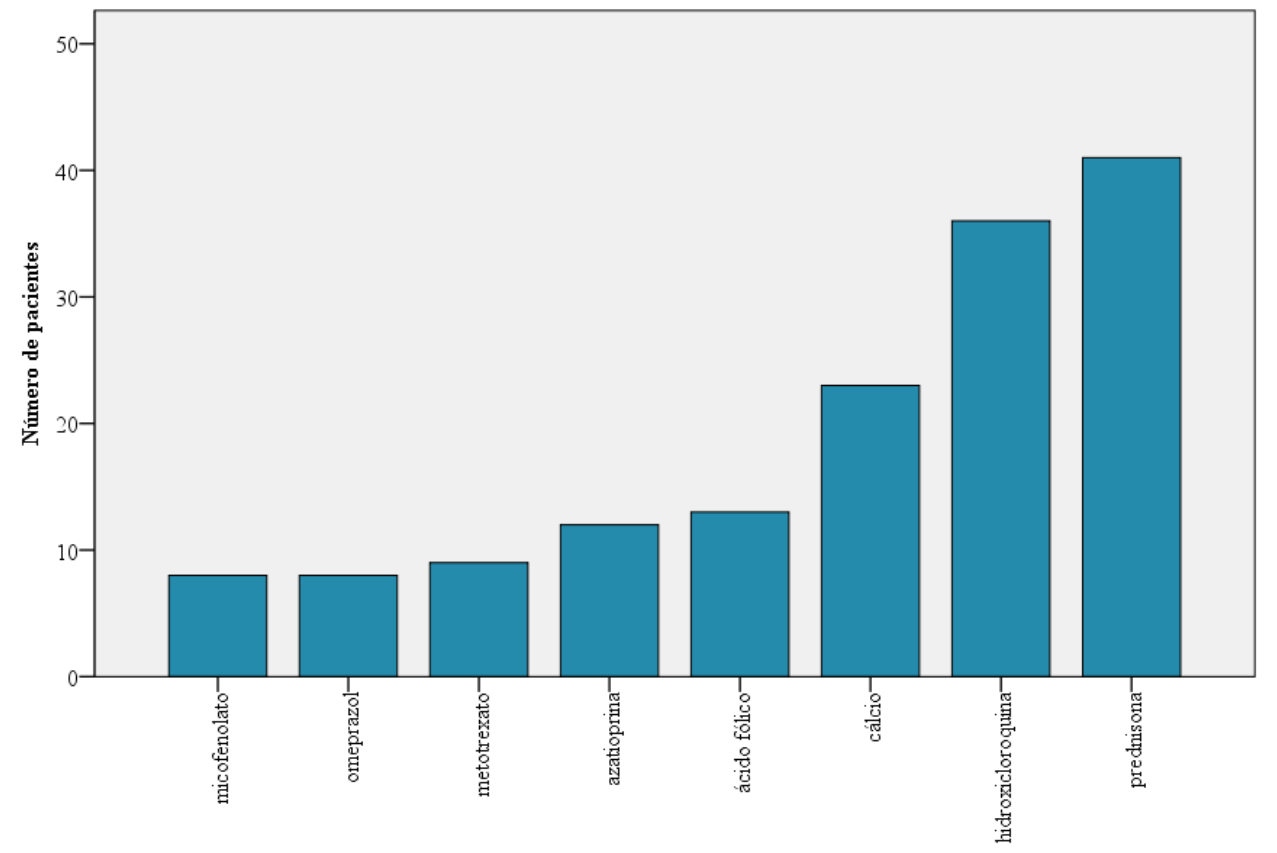

FIGURA 26: Medicamentos administrados em pacientes com LES. 


\section{DISCUSSÃO}

Este levantamento epidemiológico constituiu-se na primeira etapa de um estudo que já se encontra em desenvolvimento no Serviço de Reumatologia do Hospital Universitário de Brasília (HUB).

Apesar de, na busca realizada no banco de dados PubMed ter sido identificado somente um artigo brasileiro, ao utilizar outros termos foram encontrados mais dois artigos, totalizando três levantamentos epidemiológicos em pacientes brasileiros com LES(32, 74, 79) realizados no Rio de Janeiro, Mato Grosso e São Paulo. A identificação de necessidades bucais específicas de pacientes com LES em regiões distintas do Brasil é importante para o planejamento adequado de alocação de recursos humanos e financeiros nos ambulatórios de reumatologia.

Inicialmente, pretendia-se convidar a participar do estudo todos os pacientes com LES atendidos no Ambulatório de Reumatologia do HUB. Assim, buscou-se realizar um levantamento inicial nos prontuários. Entretanto, constatou-se que o Hospital Universitário de Brasília possui um banco de dados informatizado em que consta $\mathrm{o}$ atendimento de pacientes com doenças reumáticas, porém sem catologar a doença existente conforme a classificação internacional das doenças.

A média mensal de atendimentos é de aproximadamente 295 pacientes com algum tipo de doença reumática. De acordo com a equipe de reumatologia, estimase que o número total de pacientes com LES seja de 200 pacientes. Desse total, 69 pacientes foram avaliados pela equipe dessa pesquisa.

Entretanto, em decorrência da dinâmica do atendimento médico e da falta de cooperação de alguns pacientes, algumas variáveis da pesquisa não puderam ser coletadas adequadamente. Dentre os motivos destacam-se:

- A falta de reagente para realizar exames de sangue no laboratório do HUB, dificultou a realização do SLICC e SLEDAI, visto que esses índices necessitam de informações provenientes de exames laboratoriais complementares.

- Os períodos de greve ocorridos tanto no HUB quanto no laboratório em períodos distintos. 
- A falta de um profissional da área médica para aplicar o SLICC e SLEDAl; Para serem fidedignos, os índices deveriam ser aplicados no mesmo dia da avaliação bucal dos pacientes. Dos 69 pacientes atendidos pela equipe odontológica, apenas 30 tiveram tais índices avaliados.

- Alguns pacientes se recusaram a participar da pesquisa por motivos diversos.

- A falta de um equipo odontológico, para facilitar os exames clínicos. Foi doada uma cadeira odontológica para o Ambulatório de Reumatologia no ano de 2014. Mas, por motivos burocráticos, ela nunca foi instalada.

Neste estudo avaliou-se o fluxo salivar sem estímulo em 62 pacientes adultos, verificando-se que a mediana do fluxo foi de $0,41 \mathrm{~mL} / \mathrm{min}$, o que mostra um fluxo salivar normal. A faixa etária de 45 a 64 anos apresentou fluxo de $0,18 \mathrm{~mL} / \mathrm{min}$, que representa um fluxo salivar baixo. Esta faixa etária com o fluxo salivar diminuído foi a que mais se queixou de xerostomia contínua. A queixa de boca seca foi avaliada em 66 pacientes adultos e 21 (32\%) reportaram ocorrência de xerostomia contínua. Em um estudo realizado em 1990, todos os pacientes do estudo apresentaram xerostomia(65).

Um estudo realizado no México comparou o fluxo salivar de pacientes com LES ativo e pacientes com LES inativo. O grupo com LES ativo mostrou um fluxo salivar de 0,65 em comparação com $0,97 \mathrm{~mL} / \mathrm{min}$ do grupo com LES inativo(110). Apesar de os dois fluxos estarem dentro da normalidade, o grupo de pacientes com LES ativo apresentou fluxo salivar significativamente menor comparado ao grupo de paciente com LES inativo.

Outro estudo realizado na Europa mostra que a relação entre lesões da mucosa oral e fluxo salivar. O fluxo salivar reduzido foi encontrado em $24,8 \%$ dos pacientes, em comparação com $11,5 \%$ do grupo controle. Entre os 73 pacientes com lesões da mucosa oral, 17 (23,3\%) apresentaram fluxo salivar menor que $1 \mathrm{ml}$ por $15 \mathrm{~min}$; dos 41 controles com lesões da mucosa oral, o baixo fluxo salivar foi encontrado em $7(17,1 \%)(116)$.

Um estudo realizado no Brasil mostrou que, a atividade da doença, idade $>27$ anos, e as drogas usadas são fatores associados com a hipossalivação, resultando em uma diminuição estatisticamente significativa na produção de saliva(74). Poucos 
estudos têm sido publicados em pacientes com LES e a diferença entre estes pode ser devido às diferenças nos critérios diagnósticos da hipossalivação(74).

Uso de medicação e fatores psicológicos, tais como ansiedade e estresse desempenha um papel significativo na redução do fluxo de salivar e podem contribuir para uma sensação de boca seca. Os sintomas, tais como ardência bucal, sede, dificuldade em articular as palavras, lábios secos e mucosa ulcerada têm sido associados com a hipossalivação $(117,118)$. Neste estudo não foram avaliados parâmetros de estresse emocional, mas foram coletadas informações sobre queixa de boca seca. Os dados revelaram que 33\% sofriam de xerostomia contínua, apesar de não haver alteração significativa no fluxo salivar desses pacientes.

Os indivíduos com hipertensão e depressão, essa última muito comum em pacientes com LES que utilizam as medicações (anti-hipertensivos e antidepressivos) para o tratamento da doença, podem ter a saúde oral influenciada devido a seu efeito xerostômicos $(53,54)$.

Com relação às lesões bucais, verificou-se que $26 \%$ dos pacientes avaliados apresentaram lesões bucais, sendo 57\% macula eritematosa e 34\% das lesões totais tinham localização em palato duro. Tais achados corroboram com um estudo realizado no Rio de Janeiro no ano de 2010 evidenciou que 23,8\% dos 155 pacientes com LES apresentaram lesão oral(32). Outro estudo realizado nos EEUU também apresenta resultado semelhante aos estudos realizados no Brasil em que, dos 182 pacientes avaliados, 26\% apresentavam lesões bucais, sendo 26\% ulcerações em palato duro(80).

Durante o estudo, uma paciente que fazia uso de prótese total apresentou lesão ulcerada na região do palato mole onde não havia atrito da prótese. A mesma foi encaminhada para o serviço de estomatologia do HUB, onde foi realizada biópsia e confirmado o diagnóstico de carcinoma espinocelular. Esse achado demonstra a importância do acompanhamento desses pacientes pela equipe de odontologia.

Já está estabelecido que presença de úlceras bucais é um dos critérios de diagnóstico do LES. Um estudo realizado nos EEUU relataram prevalência de 81,3 a $87,5 \%$ para lesões bucais em pacientes com LES(119). 
Em um estudo realizado no Brasil, a prevalência de candidíase correspondeu a $20,1 \%$ e a de leucoplasia pilosa oral a 3,7\%(32). Em nossa pesquisa apenas $4(10) \%$ dos pacientes apresentaram candidíase e nenhum apresentou leucoplasia pilosa oral.

Já em estudo realizado no Irã, 54,3\% dos pacientes apresentaram lesões orais. De 102 pacientes com lesões orais, 53 (28,1\%) pacientes apresentaram úlceras, $26(13,8 \%)$ pacientes apresentavam eritema central com manchas brancas ou estrias, $18(9,5 \%)$ pacientes apresentaram eritema e $5(2,6 \%)$ pacientes tiveram placa branca(91).

A prevalência de lesões bucais em pacientes com LES relatado em estudo realizado no Irã, tendo a úlcera como a lesão mais comum(91) era comparável com os resultados encontrados no estudo realizado na Alemanha, onde a prevalência de lesões da mucosa oral foi de $48 \%$ em seu estudo com a maior frequência de úlceras(58). Neste último estudo, 51 pacientes com LES relataram manifestações orais em $51 \%$ dos pacientes. A maioria das lesões era do tipo discóide ou eritemas; apenas 3 estavam ulcerações. O palato duro, mucosa bucal e vermelhão foram os locais mais frequentes de envolvimento(78). Corrobora um estudo realizado na Albania, que relata a porcentagem de lesões orais em pacientes com LES próximos aos estudos mencionados acima $(59,1 \%)(120)$.

Em estudo realizado nos EEUU, verificou-se que a prevalência de lesões orais em pacientes com LES é de $2-80 \%$ com a média de $20-30 \%$. As diferenças podem ser por causa de uma falta de semelhança no tipo de lesões estudadas, como no estudo citado, foram avaliadas úlcera, queilite angular, mucosite e glossite(19).

Autores ressaltam que, com a maior duração da doença, existe menor número de lesões orais. Isso ocorre porque a maioria das lesões é encontrada no período ativo e à medida que o tempo passa desde o diagnóstico, o controle e o tratamento levam a uma maior estabilidade da doença, que passa para uma fase inativa e tem assim a um menor número de lesões orais(91). Em nosso estudo, dos 25 pacientes com lesões bucais, poucos foram avaliados quanto à atividade da doença através do SLICC e SLEDAI. Os resultados demonstraram que a doença 
estava inativa nesses pacientes, apesar de apresentarem lesões orais.

A atividade da doença periodontal pode ser observada pelo sangramento espontâneo do sulco gengival ou após a sondagem. Esse sangramento sinaliza a presença de inflamação nos tecidos periodontais(102). Na pesquisa, o índice de sangramento à sondagem (ISS) foi de $25(8,8$ e 58,3) das faces dos dentes presentes.

O índice de profundidade da bolsa periodontal (PB) também foi utilizado, uma vez que, quanto maior a profundidade da bolsa, mais grave é o estágio da doença periodontal (DP). O PB é um índice sensível, embora dependa da habilidade do examinador, presença ou não de cálculo e da sensibilidade do paciente para suportar a sondagem da bolsa(94). O PB médio foi de $1,6 \mathrm{~mm}$, um número considerado normal visto que a PB de até $3 \mathrm{~mm}$ está dentro dos padrões de normalidade(94).

De acordo com o levantamento das condições bucais da população brasileira realizado pelo Ministério da Saúde(129), na faixa etária de $35-44$ anos, 23\% dos indivíduos examinados apresentaram gengiva sadia, 9,8\% sangramento, 42,8\% cálculo, $10,1 \%$ bolsas periodontais com profundidade de $4-5 \mathrm{~mm}, 2,4 \%$ bolsas iguais ou maiores a $6 \mathrm{~mm}$ e $12 \%$ foram excluídos devido a ausências dentárias totais.

Quanto aos pacientes da pesquisa com a mesma faixa etária avaliada no levantamento epidemiológico citado acima, o índice de sangramento a sondagem foi de $25(8,8$ e 58,3$)$ e a profundidade de sondagem de $2,3(1,2$ e 4,0).

Um estudo de Rodhus e Johnson em 1990 relata que 83,8\% dos 16 pacientes com LES tinham periodontite(65). Novo et.al. em 1999, avaliou 30 pacientes com LES e afirmou que 60\% deles tinham periodontite(57). Kobayashi et. al. em 2003 avaliou 60 pacientes com LES e 70\% dos pacientes tinham periodontite(59). Ele comparou esse número à frequência de periodontite na população geral que era 30 - 40\%. Anos mais tarde, o mesmo autor, avaliou 71 pacientes e relatou periodontite em $64,8 \%$ dos pacientes(121). Fabbri el. al. em 2014 avaliou 55 pacientes e detectou periodontite em $89 \%$ dos pacientes com LES(60). A frequência da periodontite em pacientes com LES variou, nos diferentes estudos, entre $60 \%$ e 
$93,8 \%(57,59,60)$. Um estudo japonês relatou que os pacientes com LES apresentaram maior frequência de DP do que a população geral do seu país(59). Nesta pesquisa $36 \%$ dos pacientes apresentaram periodontite, o que está abaixo dos números citados pelos autores e dentro da frequência de periodontite na população geral segundo Kobayashi et. al.(59)

A doença periodontal e o LES apresentam características semelhantes. A existência de vias imunológicas e predisposição genética comuns à DP e às doenças do tecido conjuntivo, entre essas o lúpus eritematoso sistêmico (LES), é reconhecida e vem sendo descrita(107).

Ambas são inflamatórias e crônicas com determinados fatores/modificadores de risco semelhantes como predisposição genética, raça, tabagismo, estresse e gravidez. Considerando que o LES é uma doença autoimune, com atividade inflamatória, sob influência de fatores ambientais e infecciosos, é plausível supor que a DP pode influenciar o curso do LES(52).

Relatos de caso que sugerem associações clínicas e terapêuticas entre o LES e a DP vêm sendo publicados desde a década de $1980(105,106,108)$ e descreveram uma maior gravidade da DP em pacientes com LES, provavelmente associada à imunossupressão causada pela doença ou por seu tratamento.

Vários autores avaliaram a gravidade da DP em pacientes com LES em relação a voluntários saudáveis ou pacientes com DP sem LES e seus resultados foram conflitantes. Houve parâmetros periodontais que foram semelhantes $(51,58$, $59,121)$, menos graves ou mais graves $(32,122)$. Há também estudos que sugerem maior gravidade da DP nos pacientes com LES, sobretudo quando a doença está em atividade $(32,122)$.

Outros dois estudos avaliaram a influência do tratamento da DP sobre a atividade do $\operatorname{LES}(52,123)$. No segundo referenciado, os autores selecionaram seis pacientes com LES (média do SLEDAI de 3,5) e DP. Os pacientes foram submetidos ao tratamento periodontal não cirúrgico. Houve melhora significativa nos índices periodontais. O SLEDAl e a dosagem de PCR não apresentaram variações significativas após o tratamento periodontal(123). O outro estudo demonstrou redução na atividade do LES, observada pelo SLEDAI, em paralelo com a queda 
dos índices periodontais se mostra evidente no grupo que recebeu tratamento odontológico(52). Foram selecionados 49 pacientes com LES ativo e DP, que foram alocados em dois grupos: um com tratamento da DP realizado durante o estudo $(n=$ 32) e no outro grupo, o tratamento da DP foi protelado para um momento após o término do estudo. Não havia diferença significativa nos valores basais de SLEDAI nos dois grupos. Os pacientes foram reavaliados três meses após o tratamento da DP. Houve redução significativa do SLEDAI no grupo tratado $(5,9 \pm 4,2$ vs. $3,4 \pm 3,3$, $p=0,04)$, o que não ocorreu no grupo não tratado(52).

Autores afirmam que 0 tratamento periodontal não cirúrgico reflete diretamente na atividade da doença $(60,124)$. $O$ fato de o tratamento periodontal não cirúrgico ter reduzido os índices SLEDAI dos pacientes sugere um possível papel do tratamento da periodontite no controle do LES ativo(52). Teoricamente o controle da infecção crônica relacionada à DP poderia reduzir o grau de ativação do sistema imune e favorecer a resposta do LES ao tratamento imunossupressor(124).

Os estudos que avaliaram a influência do tratamento da DP sobre o SLEDAI em pacientes com LES apresentaram resultados conflitantes, porém o estudo que não evidenciou alteração no SLEDAI incluiu um pequeno número de pacientes sem alta atividade da doença(123).

Os pacientes deste estudo não receberam tratamento periodontal devido a falta de estrutura e pessoal para realizar SLEDAl e tratamento odontológico.

Em relação à associação entre o LES e doenças periodontais, a divergência encontrada entre estudos pode ser explicada, em parte, pela influência das medicações. O uso contínuo da medicação talvez possa mascarar ou atenuar a severidade da doença periodontal(125). O uso de diferentes medicações e em diferentes doses dificulta a análise desses pacientes, já que apresentam diferentes manifestações clínicas e, por isso, tratamentos distintos(125).

Sabe-se que o corticoide atua sobre os tecidos periodontais e pode reduzir o processo inflamatório da DP(51). Um trabalho verificou que pacientes com LES sob corticoterapia apresentavam DP mais benigna e respondiam melhor ao tratamento odontológico(52). 
A controvérsia é se a melhoria observada nos pacientes se dá pelo tratamento periodontal em si ou pelo uso da medicação imunossupressora. Sabe-se que $\mathrm{o}$ uso de corticoides pode apresentar funções antagônicas, uma vez que predispõe à infecção e, ao mesmo tempo, pode mascarar características clínicas da infecção, como um resultado dos seus efeitos imunossupressores e antiinflamatórios(125). Afirma-se que é possível que as drogas sistêmicas, como corticosteróides sejam responsáveis por essas redução da profundidades de sondagem(51).

Por outro lado, há afirmação de que a terapia sistêmica com esteroides usada no tratamento do LES contribua para o agravamento da gengivite necrosante(106). A combinação com imunodesregulação complexa associada à terapia imunossupressora empregada no tratamento do LES podem ser responsáveis pela alta taxa de lesões periodontais. Por tal fato é que nesses pacientes são encontrados maiores perdas dentárias e inflamação gengival frequente(126).

A variabilidade da frequência da periodontite encontrada nos diferentes estudos provavelmente deve-se ao uso de diferentes critérios para o seu diagnóstico ou às diferenças nos grupos de pacientes com LES quanto à gravidade ou atividade da doença. Assim, a questão da frequência da periodontite nos pacientes com LES permanece em aberto. São necessários estudos controlados para a definição se a periodontite é realmente mais comum no LES(124).

Em nosso estudo, no que diz respeito à avaliação periodontal, esperava-se pacientes com DP grave, entretanto os pacientes com LES apresentavam uma saúde periodontal melhor do que esperada o que pode ser explicado pelo uso de corticóide, pois $62,1 \%$ dos nossos pacientes usavam tal medicamento $(51,60)$.

Não foram realizadas radiografias intra-orais com técnica interproximal, tidas como protocolo para o diagnóstico da quantidade de perda óssea alveolar(127) por ser um exame complementar de alto custo e não haver estrutura no HUB para realização destes exames.

Em relação ao índice $\mathrm{CPOD}$, os números encontrados nesta pesquisa foram comparados com os dados obtidos no programa Brasil sorridente, na mesma faixa etária (35 a 44 anos). Essa faixa etária foi escolhida por ser a mais prevalente para diagnóstico do LES (terceira e quarta década de vida)(128). O número de dentes 
cariados, perdidos e obturados nesta pesquisa são 1,75; 8 e 6,6 contra 1,9; 7,3 e 7,1 , respectivamente, nos dados obtidos programa Brasil sorridente do ano de 2010. O índice CPOD encontrado na pesquisa foi 16,35. Resultados similares foram encontrados no último levantamento do programa Brasil sorridente, em que o CPOD foi 16,3(130). Deve ser considerado que o $n$ avaliado nessa faixa etária da pesquisa foi 19. $O n$ total dos adultos avaliados na faixa etária de 5 a 74 anos no programa Brasil sorridente é 38.000 mil, porém não há registro isolado do $n$ na faixa etária citada. Um $n$ maior na pesquisa seria necessário para maiores comparações. Em outro estudo realizado na cidade de São Paulo, o índice CPO-D médio correspondeu a 18,5(32), similar ao encontrado na nossa pesquisa. 


\section{CONCLUSÃO}

Quanto à saliva, verificou-se que:

- a taxa média de fluxo salivar sem estímulo apresentou-se dentro dos padrões de normalidade;

- a xerostomia estava presente em $32 \%$, semelhante à população geral - 30\% (Silvestre, 2011; Anurang, 2006).

Quanto as lesões bucais:

- $36 \%$ dos pacientes apresentaram lesões bucais. A prevalência das lesões é semelhante a outros estudos, porém o tipo de lesão mais prevalente é diferente.

Em relação a doença periodontal:

- A prevalência de DP foi de 36\%, menor que os reportados na literatura.

- O alto índice de placa comparado ao ISS, PS, REC e NIC pode estar associado ao uso de corticoide feito por esses pacientes.

Comparando-se nossos resultados relativos à condição periodontal e índice CPOD com os resultados da Pesquisa Nacional de Saúde Bucal (2011) do Ministério da Saúde, constatou-se que:

- a população estudada apresentou maior índice médio de sangramento gengival, porém a média de profundidade de sondagem foi menor;

- o índice CPOD nas faixas etárias comparadas foi menor.

- Os achados bucais encontrados apontam a não necessidade de abordagem específica para o paciente com LES. Isto porque as alterações encontradas estão dentro dos padrões encontrados na população geral. 


\section{REFERÊNCIAS BIBLIOGRÁFICAS}

1. Oliveira MNd. Lúpus erimatoso sistêmico: uma revisão de literatura das características, diagnósticos e tratamentos. 2011.

2. Vianna R, Simões J, Inforzato HCB. Lúpus eritematoso sistêmico. Rev Ceciliana. 2010;2(1):01-3.

3. Al-Rayes H, Al-Swailem R, Arfin M, Sobki S, Rizvi S, Tariq M. Lupus Around the World Systemic lupus erythematosus and infections: a retrospective study in Saudis. Lupus. 2007;16(9):755-63.

4. Brunner HI, Bennett MR, Mina R, Suzuki M, Petri M, Kiani AN, et al. Association of noninvasively measured renal protein biomarkers with histologic features of lupus nephritis. Arthritis \& Rheumatism. 2012;64(8):2687-97.

5. JÚNIOR HMM, TERAPÊUTICAS PCED. PORTARIA No-1.229, DE 5 DE NOVEMBRO DE 2013.

6. Gonzalez L, Toloza S, McGwin G, Alarcón G. Ethnicity in systemic lupus erythematosus (SLE): its influence on susceptibility and outcomes. Lupus. 2013;22(12):121424.

7. Alarcon G, Friedman A, Straaton K, Moulds J, Lisse J, Bastian H, et al. Systemic lupus erythematosus in three ethnic groups: III A comparison of characteristics early in the natural history of the LUMINA cohort. Lupus. 1999;8(3):197-209.

8. Organization WH, Chemicals I-OPftSMo. Principles and methods for assessing autoimmunity associated with exposure to chemicals: World Health Organization; 2006.

9. Vilar MP, Sato E. Estimating the incidence of systemic lupus erythematosus in a tropical region (Natal, Brazil). Lupus. 2002;11(8):528-32.

10. Silva CAAd, Bonfá E, Borba EF, Braga AP, Soares PMF, Moraes AJPd, et al. Reproductive health in male systemic lupus erythematosus. Revista Brasileira de Reumatologia. 2009;49(3):207-22.

11. Cassidy JT, Petty RE, Laxer RM, Lindsley CB. Textbook of pediatric rheumatology: expert consult: Elsevier Health Sciences; 2010.

12. Haje L. Projeto facilita aposentadoria em caso de lúpus e epilepsia 2010 [cited 20142 de junho]. Available from: http://www2.camara.leg.br/camaranoticias/noticias/151580PROJETO-FACILITA-APOSENTADORIA-EM-CASO-DE-LUPUS-E-EPILEPSIA.html.

13. Doria A, Zen M, Canova M, Bettio S, Bassi N, Nalotto L, et al. SLE diagnosis and treatment: when early is early. Autoimmunity reviews. 2010;10(1):55-60.

14. Ozbek S, Sert M, Paydas S, Soy M. Delay in the diagnosis of SLE: the importance of arthritis/arthralgia as the initial symptom. Acta Medica Okayama. 2003;57(4):187-90.

15. Pelletier EM, Ogale S, Yu E, Brunetta P, Garg J. Economic outcomes in patients diagnosed with systemic lupus erythematosus with versus without nephritis: results from an analysis of data from a US claims database. Clinical therapeutics. 2009;31(11):2653-64.

16. Furst D, Clarke A, Fernandes A, Bancroft T, Gajria K, Greth W, et al. Resource utilization and direct medical costs in adult systemic lupus erythematosus patients from a commercially insured population. Lupus. 2013:0961203312474087.

17. Oglesby A, Korves C, Laliberté F, Dennis G, Rao S, Suthoff ED, et al. Impact of Early Versus Late Systemic Lupus Erythematosus Diagnosis on Clinical and Economic Outcomes. Applied health economics and health policy. 2014;12(2):179-90.

18. Albilia JB, Lam DK, Clokie CM, Sándor GK. Systemic lupus erythematosus: a review for dentists. Journal of the Canadian Dental Association. 2007;73(9):823-30.

19. Brennan MT, Valerin MA, Napeñas JJ, Lockhart PB. Oral manifestations of patients with lupus erythematosus. Dental Clinics of North America. 2005;49(1):127-41. 
20. López-Labady J, Villarroel-Dorrego M, González N, Perez R, Mata de Henning M. Oral manifestations of systemic and cutaneous lupus erythematosus in a Venezuelan population. Journal of Oral Pathology \& Medicine. 2007;36(9):524-7.

21. Neville B. Patologia oral e maxilofacial: Elsevier Brasil; 2011.

22. De Rossi SS, Glick M. Lupus erythematosus: considerations for dentistry. Journal of the American Dental Association (1939). 1998;129(3):330-9.

23. Yu S-L, Kuan W-P, Wong C-K, Li EK, Tam L-S. Immunopathological roles of cytokines, chemokines, signaling molecules, and pattern-recognition receptors in systemic lupus erythematosus. Clinical and Developmental Immunology. 2012;2012.

24. Cassidy J. Systemic lupus erythematosus, juvenile dermatomyositis, scleroderma and vasculitis. Textbook of Rheumatology. 1993;5.

25. Sullivan KE. Genetics of systemic lupus erythematosus: clinical implications. Rheumatic Disease Clinics of North America. 2000;26(2):229-56.

26. Passos LFdS. Great expectations: SLE and the Human Genome Project. Rev bras reumatol. 2000;40(6):291-304.

27. Guo S-W, Lange K. Genetic mapping of complex traits: promises, problems, and prospects. Theoretical Population Biology. 2000;57(1):1-11.

28. Deafen D, Escalante A, Weinrib L, Horwitz D, Bachman B, Roy-Burman P, et al. A revised estimate of twin concordance in systemic lupus erythematosus. Arthritis \& Rheumatism. 1992;35(3):311-8.

29. Karim M. Immunodeficiency in the lupus clinic. Lupus. 2006;15(3):127-31.

30. Bosch X, Guilabert A, Pallares L, Cervera R, Ramos-Casals M, Bové A, et al. Infections in systemic lupus erythematosus: a prospective and controlled study of 110 patients. Lupus. 2006;15(9):584-9.

31. Simard J, Costenbader K. What can epidemiology tell us about systemic lupus erythematosus? International journal of clinical practice. 2007;61(7):1170-80.

32. Júnior AAU, Cantisano MH, Klumb EM, Dias EP, Silva A. Achados bucais e laboratoriais em pacientes com lúpus eritematoso sistêmico. J Bras Patol Med Lab. 2010;46(6):479-86.

33. Lockshin MD. Sex differences in autoimmune disease. Lupus. 2006;15(11):753-6.

34. Hochberg MC. Updating the American College of Rheumatology revised criteria for the classification of systemic lupus erythematosus. Arthritis \& Rheumatism. 1997;40(9):1725-.

35. dos Santos Ferreira MHC. A IMPORTÂNCIA DOS EXERCÍCIOS TERAPÊUTICOS NA MELHORA DA QUALIDADE DE VIDA DE PACIENTES PORTADORES DE LÚPUS ERITEMATOSO SISTÊMICO. Revista Científica dos Alunos da Faculdade São Miguel.19.

36. Vargas KS, Romano MA. Lúpus Eritematoso Sistêmico: aspectos epidemiológicos e diagnóstico. Revista Salus. 2011;3(1):79-94.

37. Bezerra ELM, Vilar MJP, Barbosa OdFC, Santos SQ, Castro MdA, Trindade MCd, et al. Lúpus eritematoso sistêmico (LES): perfil clínico-laboratorial dos pacientes do Hospital Universitário Onofre Lopes (UFRN-Natal/Brasil) e índice de dano nos pacientes com diagnóstico recente. Rev Bras Reumatol. 2005;45(6):339-42.

38. Magalhães MB, Donadi EA, Junior PL. Manifestações clínicas do lúpus eritematoso sistêmico: Abordagem diagnóstica e terapêutica na sala de urgência. Medicina (Ribeirao Preto Online). 2003;36(2/4):409-17.

39. Koopman WJ, Moreland LW, Somers D, Lazar N, Gast P. Arthritis and allied conditions: a textbook of rheumatology: Lippincott Williams \& Wilkins; 2001.

40. Dubois E, Wallace DJ. Lupus erythematosus: Dubois' lupus erythematosus: Lea \& Febiger; 1987. 
41. Cruz DELAd. Lúpus Eritematoso Sistémico na Gravidez: Impacto na mãe e no filho. 2011.

42. Salehi-Abari I. ACR/SLICC Revised Criteria for Diagnosis of Systemic Lupus Erythematosus. Autoimmune Dis Ther Approaches Open Access. 2015;2:114.

43. Gladman DD, Ibañez D, Urowitz MB. Systemic lupus erythematosus disease activity index 2000. The Journal of rheumatology. 2002;29(2):288-91.

44. Barr SG, Zonana-Nacach A, Magder LS, Petri M. Patterns of disease activity in systemic lupus erythematosus. Arthritis \& Rheumatism. 1999;42(12):2682-8.

45. Bombardier C, Gladman D, Urowitz M, et al., Caron D, Chang CH. the Committee on Prognosis Studies in SLE. Derivation of the SLEDAI: a disease activity index for lupus patients. Arthritis Rheum. 1992;35(6):630-40.

46. Liang MH, Socher SA, Roberts WN, Esdaile JM. Measurement of systemic lupus erythematosus activity in clinical research. Arthritis \& Rheumatism. 1988;31(7):817-25.

47. Decker JL. The management of systemic lupus erythematosus. Arthritis \& Rheumatism. 1982;25(7):891-4.

48. Uribe AG, Vilá LM, McGwin G, Sanchez ML, Reveille JD, Alarcón GS. The Systemic Lupus Activity Measure-revised, the Mexican Systemic Lupus Erythematosus Disease Activity Index (SLEDAI), and a modified SLEDAI-2K are adequate instruments to measure disease activity in systemic lupus erythematosus. The Journal of rheumatology. 2004;31(10):1934-40.

49. Tsao BP. Update on human systemic lupus erythematosus genetics. Current opinion in rheumatology. 2004;16(5):513-21.

50. Sato EI, Bonfá ED, Costallat LTL, Silva NAd, Brenol JCT, Santiago MB, et al. Consenso brasileiro para o tratamento do lúpus eritematoso sistêmico (LES). Rev Bras Reumatol. 2002;42(6):362-70.

51. Mutlu S, Richards A, Maddison P, Scully C. Gingival and periodontal health in systemic lupus erythematosus. Community dentistry and oral epidemiology. 1993;21(3):15861.

52. Fabbri C. Influência do tratamento da doença periodontal na atividade do lúpus eritematoso sistêmico: Universidade de São Paulo.

53. Lundgren M, Emilson C-G, Österberg T, Steen G, Birkhed D, Steen B. Dental caries and related factors in 88-and 92-year-olds: cross-sectional and longitudinal comparisons. Acta Odontologica Scandinavica. 1997;55(5):282-91.

54. Leal SC, Bittar J, Portugal A, Falcao DP, Faber J, Zanotta P. Medication in elderly people: its influence on salivary pattern, signs and symptoms of dry mouth. Gerodontology. 2010;27(2):129-33.

55. Foster H, Fitzgerald J. Dental disease in children with chronic illness. Archives of disease in childhood. 2005;90(7):703-8.

56. Pessoa L, Galvão V, Santos-Neto L. Periodontal disease as a risk factor for cardiovascular disease: Suggestion of a further link in systemic lupus erythematosus. Medical hypotheses. 2011;77(2):286-9.

57. Novo E, Garcia-MacGregor E, Viera N, Chaparro N, Crozzoli Y. Periodontitis and anti-neutrophil cytoplasmic antibodies in systemic lupus erythematosus and rheumatoid arthritis: a comparative study. Journal of periodontology. 1999;70(2):185-8.

58. Meyer U, Kleinheinz J, Handschel J, Kruse-Lösler B, Weingart D, Joos U. Oral findings in three different groups of immunocompromised patients. Journal of oral pathology \& medicine. 2000;29(4):153-8.

59. Kobayashi T, Ito S, Yamamoto K, Hasegawa H, Sugita N, Kuroda T, et al. Risk of periodontitis in systemic lupus erythematosus is associated with $\mathrm{Fc} \gamma$ receptor polymorphisms. Journal of periodontology. 2003;74(3):378-84. 
60. Fabbri C, Fuller R, Bonfá E, Guedes LK, D’Alleva PSR, Borba EF. Periodontitis treatment improves systemic lupus erythematosus response to immunosuppressive therapy. Clinical rheumatology. 2014;33(4):505-9.

61. Falcão DP, Mota LMHd, Pires AL, Bezerra ACB. Sialometry: aspects of clinical interest. Revista brasileira de reumatologia. 2013;53(6):525-31.

62. Rogers III RS, Bekic M, editors. Diseases of the lips. Seminars in cutaneous medicine and surgery; 1997: WB Saunders.

63. Jorizzo JL, Salisbury PL, Rogers III RS, Goldsmith SM, Shar GG, Callen JP, et al. Oral lesions in systemic lupus erythematosus: do ulcerative lesions represent a necrotizing vasculitis? Journal of the American Academy of Dermatology. 1992;27(3):389-94.

64. Ángel $\mathrm{N}$, Echeverry $\mathrm{N}$, Restrepo $\mathrm{P}$, González L, Rodríguez L, Vásquez G. Manifestaciones bucales en pacientes con Lupus Eritematoso Sistémico. Revista Colombiana de Reumatología. 2010;17(1):13-21.

65. Rhodus NL, Johnson DK. The prevalence of oral manifestations of systemic lupus erythematosus. Quintessence international (Berlin, Germany: 1985). 1990;21(6):461.

66. Ting W, Stone M, Racila D, Scofield R, Sontheimer R. Toxic epidermal necrolysislike acute cutaneous lupus erythematosus and the spectrum of the acute syndrome of apoptotic pan-epidermolysis (ASAP): a case report, concept review and proposal for new classification of lupus erythematosus vesiculobullous skin lesions. Lupus. 2004;13(12):941-50.

67. Cisneros CG, Romiti R, Santi CG, Aoki V, Valente N, Nico M. Toxic epidermal necrolysis-like cutaneous lupus erythematosus: A series of three patients. Acta dermatovenereologica. 2010;90(2):175-8.

68. Kim DY, Rha EY, Yoo G, Lim JS. Squamous cell carcinoma on the upper lip of a patient with discoid lupus erythematosus. Archives of plastic surgery. 2013;40(2):155-7.

69. Liu W, Shen ZY, Wang LJ, Hu YH, Shen XM, Zhou ZT, et al. Malignant potential of oral and labial chronic discoid lupus erythematosus: a clinicopathological study of 87 cases. Histopathology. 2011;59(2):292-8.

70. Anurag Gupta B, Epstein JB, Sroussi H. Hyposalivation in elderly patients. J Can Dent Assoc. 2006;72(9):841-6.

71. Field E, Longman L, Bucknall R, Kaye S, Higham S, Edgar W. The establishment of a xerostomia clinic: a prospective study. British Journal of Oral and Maxillofacial Surgery. 1997;35(2):96-103.

72. Grennan D, Ferguson M, Williamson J, Mavrikakis M, Dick W, Buchanan W. Sjogren's syndrome in SLE: Part I. The frequency of the clinical and subclinical features of Sjogren's syndrome in patients with SLE. The New Zealand medical journal. 1977;86(598):374-6.

73. Ben-Aryeh H, Gordon N, Szargel R, Toubi E, Laufer D. Whole saliva in systemic lupus erythematosus patients. Oral surgery, oral medicine, oral pathology. 1993;75(6):696-9.

74. Leite CA, Galera MF, Espinosa MM, de Lima PRT, Fernandes V, Borges ÁH, et al. Prevalence of Hyposalivation in Patients with Systemic Lupus Erythematosus in a Brazilian Subpopulation. International journal of rheumatology. 2015;2015.

75. Ravald N, List T. Caries and periodontal conditions in patients with primary Sjogren's syndrome. Swedish dental journal. 1997;22(3):97-103.

76. AlmståhI A, Wikström M, Stenberg I, Jakobsson A, Fagerberg-Mohlin B. Oral microbiota associated with hyposalivation of different origins. Oral microbiology and immunology. 2003;18(1):1-8.

77. McCauliffe DP, editor Cutaneous lupus erythematosus. Seminars in cutaneous medicine and surgery; 2001: WB Saunders. 
78. Jonsson R, Heyden G, Westberg N, Nyberg G. Oral mucosal lesions in systemic lupus erythematosus--a clinical, histopathological and immunopathological study. The Journal of rheumatology. 1984;11(1):38-42.

79. Lourenço SV, De Carvalho FR, Boggio P, Sotto MN, Vilela MA, Rivitti EA, et al. Lupus erythematosus: clinical and histopathological study of oral manifestations and immunohistochemical profile of the inflammatory infiltrate. Journal of cutaneous pathology. 2007;34(7):558-64.

80. Urman JD, Lowenstein MB, Abeles M, Weinstein A. Oral mucosal ulceration in systemic lupus erythematosus. Arthritis \& Rheumatism. 1978;21(1):58-61.

81. Schiødt M. Oral manifestations of lupus erythematosus. International journal of oral surgery. 1984;13(2):101-47.

82. Schiødt M, Halberg P, Hentzer B. A clinical study of 32 patients with oral discoid lupus erythematosus. International journal of oral surgery. 1978;7(2):85-94.

83. Schiødt M, Andersen L, Shear M, Smith CJ. Leukoplakia-like lesions developing in patients with oral discoid lupus erythematosus. Acta Odontologica. 1981;39(4):209-16.

84. Burge S, Frith P, Juniper R, Wojnarowska F. Mucosal involvement in systemic and chronic cutaneous lupus erythematosus. British Journal of Dermatology. 1989;121(6):727-41.

85. Greenspan J, Chisholm D. Connective tissue disorders and granulomatous disease of doubtful origin. Oral Manifestations of Systemic Diseases, WB Saunders, Philadelphia. 1981.

86. Heyden G, Arwill T, LILJA J, Magnusson BC. Chlorhexidine solutions in histological and histochemical techniques1. Journal of Oral Pathology \& Medicine. 1972;1(1):12-21.

87. Jonsson R, Kristensson-Aas A, Kutti J. Assessment of a tissue transport-medium in preservation of tissue-fixed immunoglobulins and complement demonstrated by direct immunofluorescence. A pilot study with skin from SLE patients. Journal of clinical pathology. 1978;31(9):823-6.

88. Andreasen J. Oral manifestations in discoid and systemic lupus erythematosus. I. Clinical investigation. Acta Odontologica Scandinavica. 1964;22(3):295-309.

89. Sverzut AT, Allais M, de Maurette M, Mazzonetto R, de Moraes M, Passeri L, et al. Oral manifestation of systemic lupus erythematosus: lupus nephritis--report of a case. General dentistry. 2007;56(1):35-41.

90. Nico M, Bologna S, Lourenço S. The lip in lupus erythematosus. Clinical and experimental dermatology. 2014;39(5):563-9.

91. Khatibi M, Shakoorpour A, Jahromi ZM, Ahmadzadeh A. The prevalence of oral mucosal lesions and related factors in 188 patients with systemic lupus erythematosus. Lupus. 2012;21(12):1312-5.

92. Albandar JM. Epidemiology and risk factors of periodontal diseases. Dental Clinics of North America. 2005;49(3):517-32.

93. Löe H, Ånerud Å, Boysen H. The Natural History of Periodontal Disease in Man: Prevalence, Severity, and Extent of Gingival Recession*. Journal of periodontology. 1992;63(6):489-95.

94. Lindhe J, Karring T, Lang N. Tratado de periodontia clínica e implantodologia oral: Guanabara Koogan; 1999.

95. Axelsson $\mathrm{P}$, Lindhe $\mathrm{J}$, Wäseby $\mathrm{J}$. The effect of various plaque control measures on gingivitis and caries in schoolchildren. Community dentistry and oral epidemiology. 1976;4(6):232-9.

96. Carranza Jr FA. Periodontia clínica de Glickman: prevenção, diagnóstico e tratamento da doença periodontal na prática da odontologia geral: Guanabara; 1986.

97. Sanz M, van Winkelhoff AJ. Periodontal infections: understanding the complexityconsensus of the Seventh European Workshop on Periodontology. Journal of Clinical Periodontology. 2011;38(s11):3-6. 
98. Hassell T, Gilbert G. Phenytoin sensitivity of fibroblasts as the basis for susceptibility to gingival enlargement. The American journal of pathology. 1983;112(2):218.

99. James JA, Irwin CR, Linden GJ. The Effects of Culture Environment on the Response of Human Gingival Fibroblasts to Cyclosporin $A^{*}$. Journal of periodontology. 1995;66(5):339-44.

100. Lucas RM, Howell LP, Wall BA. Nifedipine-Induced Gingival Hyperplasia: A Histochemical and Ultrastructural Study*. Journal of periodontology. 1985;56(4):211-5.

101. Smith ML, Mott A, Marques C, Maor Y, de Andrade M, Rodrigues V, et al. Position paper: epidemiology of periodontal diseases. Journal of periodontology. 2005;76(8):1406-19.

102. Mühlemann H, Son S. Gingival sulcus bleeding--a leading symptom in initial gingivitis. Helvetica odontologica acta. 1971;15(2):107.

103. Silness J, Löe H. Periodontal disease in pregnancy II. Correlation between oral hygiene and periodontal condition. Acta odontologica scandinavica. 1964;22(1):121-35.

104. Greenstein G, Hart TC. A critical assessment of interleukin-1 (IL-1) genotyping when used in a genetic susceptibility test for severe chronic periodontitis. Journal of periodontology. 2002;73(2):231-47.

105. Nagler RM, Lorber M, Ben-Arieh Y, Laufer D, Pollack S. Generalized periodontal involvement in a young patient with systemic lupus erythematosus. Lupus. 1999;8(9):770-2.

106. Jaworski CP, Koudelka BM, Roth NA, Marshall KJ. Acute necrotizing ulcerative gingivitis in a case of systemic lupus erythematosus. Journal of Oral and Maxillofacial Surgery. 1985;43(1):43-6.

107. Gonzales TS, Coleman GC. Periodontal manifestations of collagen vascular disorders. Periodontology 2000. 1999;21(1):94-105.

108. Vogel RI. Periodontal disease associated with amegakaryocytic thrombocytopenia in systemic lupus erythematosus. Journal of periodontology. 1981;52(1):20-3.

109. Miceli V, Braga F, Áreas A, Figueredo CMS, Fischer RG. Associação entre a doença periodontal e o lúpus eritematoso sistêmico. Revista de Ciências Médicas e Biológicas. 2010;4(2).

110. Rodriguez JL, Torres LG, Martinez RM, Mendoza CA, Solis CM, Coronel SR, et al. Frequency of dental caries in active and inactive systemic lupus erythematous patients: salivary and bacterial factors. Lupus. 2016:0961203316640909.

111. Van Story-Lewis PE, Roberts MW, Klippel JH. Oral effects of steroid therapy in a patient with systemic lupus erythematosus: report of case. The Journal of the American Dental Association. 1987;115(1):49-51.

112. Nederfors T. Xerostomia and hyposalivation. Advances in dental research. 2000;14(1):48-56.

113. O'Leary TJ, Drake RB, Naylor JE. The plaque control record. Journal of periodontology. 1972;43(1):38-.

114. Ainamo J, Bay I. Problems and proposals for recording gingivitis and plaque. International dental journal. 1975;25(4):229-35.

115. Narvai PC, Frazão P, Roncalli AG, Antunes JLF, Camargos P, Ribeiro Y. Cárie dentária no Brasil: declínio, polarização, iniqüidade e exclusão social. Rev Panam Salud Publica. 2006;19(6):385-93.

116. Aliko A, Alushi A, Tafaj A, Lela F. Oral mucosa involvement in rheumatoid arthritis, systemic lupus erythematosus and systemic sclerosis. International dental journal. 2010;60(5):353-8.

117. Scully C, Bagan J-V. Adverse drug reactions in the orofacial region. Critical Reviews in Oral Biology \& Medicine. 2004;15(4):221-39. 
118. Bardow A, Nyvad B, Nauntofte B. Relationships between medication intake, complaints of dry mouth, salivary flow rate and composition, and the rate of tooth demineralization in situ. Archives of oral biology. 2001;46(5):413-23.

119. DE ROSSI SS, Glick M. Lupus erythematosus: considerations for dentistry. The Journal of the American Dental Association. 1998;129(3):330-9.

120. Aliko A, Ciancaglini R, Alushi A, Tafaj A, Ruci D. Temporomandibular joint involvement in rheumatoid arthritis, systemic lupus erythematosus and systemic sclerosis. International journal of oral and maxillofacial surgery. 2011;40(7):704-9.

121. Kobayashi T, Ito S, Yasuda K, Kuroda T, Yamamoto K, Sugita N, et al. The combined genotypes of stimulatory and inhibitory $\mathrm{Fc} \gamma$ receptors associated with systemic lupus erythematosus and periodontitis in Japanese adults. Journal of periodontology. 2007;78(3):467-74.

122. Fernandes E, Savioli C, Siqueira J, Silva C. Oral health and the masticatory system in juvenile systemic lupus erythematosus. Lupus. 2007;16(9):713-9.

123. Sales LdAR, de Miranda MdGA, Vassalo S. Efeito do tratamento periodontal na condição do periodonto e na atividade inflamatória sistêmica em portadores de lúpus eritematoso sistêmico. Revista Interdisciplinar de Estudos Experimentais-Animais e Humanos Interdisciplinary Journal of Experimental Studies. 2011;2(3).

124. Calderaro DC, Ferreira GA, de Mendonça SMS, Corrêa JD, Santos FX, Sanção JGC, et al. Há associação entre o lúpus eritematoso sistêmico e a doença periodontal? Revista Brasileira de Reumatologia. 2015.

125. Lehman T. A practical guide to systemic lupus erythematosus. Pediatric clinics of North America. 1995;42(5):1223-38.

126. Cervera R, Khamashta MA, Font J, Sebastiani GD, Gil A, Lavilla P, et al. Morbidity and mortality in systemic lupus erythematosus during a 10-year period: a comparison of early and late manifestations in a cohort of 1,000 patients. Medicine. 2003;82(5):299-308.

127. Halse A, Molven O. A strategy for the diagnosis of periapical pathosis. Journal of endodontics. 1986;12(11):534-8.

128. Nakashima CAK, Galhardo AP, Silva JFMd, Fiorenzano GR, Santos ABdSd, Leite MFS, et al. Incidência e aspectos clínico-laboratoriais do lúpus eritematoso sistêmico em cidade do sul do Brasil. Rev bras reumatol. 2011;51(3):235-9.

129. http://idg.receita.fazenda.gov.br/- Receita Federal do Brasil.

130. BRASIL - MINISTÉRIO DA SAÚDE. Condições de saúde bucal da população brasileira 2002-2003: resultados principais. Série C. Projetos, Programas e Relatórios. Brasília-DF: MS, 2004. 
9. APÊNDICES 


\section{APÊNDICE 1. TERMO DE CONSENTIMENTO LIVRE E ESCLERECIDO}

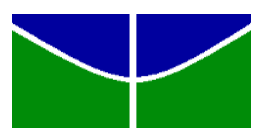

\section{Termo de Consentimento Livre e Esclarecido - TCLE}

A senhora está sendo convidada a participar do projeto: "Análise do Proteoma Salivar de Pacientes com Lúpus Eritematoso Sistêmico, com e sem Nefrite Lúpica.”

O objetivo desta pesquisa é avaliar e comparar algumas características da saliva, sangue, urina, condição periodontal (gengiva, ossos dos dentes e dentes) e dos tecidos moles da boca (região externa ou interna do lábio, na parte externa das bochechas, língua, assoalho de boca, céu da boca e gengiva) e do hálito de mulheres com lúpus eritematoso sistêmico com nefrite lúpica (problemas nos rins) com as mulheres com lúpus, mas que não possuem nefrite lúpica.

A senhora receberá todos os esclarecimentos necessários antes e no decorrer da pesquisa e Ihe asseguramos que seu nome não aparecerá, sendo mantido o mais rigoroso sigilo através da omissão total de quaisquer informações que permitam identificá-la.

A sua participação será através da respostas aos questionários de avaliação da sua saúde, exame odontológico e coleta de sangue e urina em um jejum de 08 (oito) horas, e de saliva sob jejum de 01 (uma) hora. Após as coletas, a participante receberá gratuitamente um lanche. A coleta de saliva se dará por meio de papel absorvente dentro do lábio superior que irá absorver a saliva durante 1 minuto e depois será removida e pesada. Em seguida, este procedimento será repetido para o lábio inferior. Depois será coletada a saliva sem estímulo quando a senhora deverá permanecer sentada, sem conversar, com o celular desligado, com os olhos abertos e com o pescoço inclinado para frente e para baixo para que a saliva escorra em um copo descartável sem a senhora precisar cuspir, durante os 5 minutos. Para a coleta da saliva estimulada, a senhora terá que mastigar um objeto pequeno ( 1 centímetro) de silicone e cuspir a saliva produzida em um frasco durante 5 minutos.

Somente nos casos em que a paciente possuir nefrite lúpica (comprometimento dos rins) e a equipe médica considerar necessária a realização de biópsia do rim (procedimento onde um pequeno fragmento do rim, de aproximadamente $1 \mathrm{a} 2 \mathrm{~cm}$ de comprimento com largura de um grão de arroz é obtido) a paciente será submetida à realização deste procedimento em sala cirúrgica do Hospital Universitário da Brasília - HUB. Neste caso, a paciente deverá ficar internada por aproximadamente 24 horas. Com a análise desse fragmento do rim, pode-se verificar o comprometimento renal e estabelecer diagnósticos, prognósticos e indicações para iniciar ou não tratamentos específicos dos rins.

Riscos esperados: A biópsia dos rins, quando indicada, será feita em ambiente hospitalar e sobe efeito de anestesia. Este procedimento é invasivo e pode resultar em complicações, como formação de hematoma, fístula arteriovenosa e infecção. Após a biópsia dos rins, a paciente deverá ficar internada para permanecer pelo menos 12 horas em repouso absoluto, devido ao risco de sangramento e dor. 
(continuação)

Benefícios esperados: Como benefício direto da pesquisa, quando for diagnosticada doença periodontal (inflamação/infecção da gengiva e/ou osso e ligamentos de sustentação dos dentes) secura bucal e halitose (mau hálito), você receberá tratamento gratuito pelas dentistas desta equipe de pesquisa. Caso seja encontrada alguma lesão na região externa ou interna do lábio, na parte interna das bochechas, língua, assoalho de boca, céu da boca e gengiva, as mesmas serão diagnosticadas e tratadas. Além disso, todas as voluntárias receberão orientações sobre prevenção de doenças bucais. Como benefício indireto da pesquisa, os resultados obtidos poderão permitir que os profissionais de saúde passem a adotar um novo método indolor de diagnóstico e monitoramento do Lúpus Eritematoso Sistêmico.

O local de atendimento clínico será aqui, ou seja, a senhora será atendida no Serviço de Reumatologia / Ambulatório de Colagenose do Hospital Universitário de Brasília (HUB) na data combinada. Caso a senhora não possua problemas de saúde em seus rins e sua avaliação bucal (gengiva, e tecidos moles, como língua e mucosa) não acuse necessidade de tratamento gengival, de mau hálito e nem de boca seca, a senhora precisará vir apenas mais uma vez e permanecer em atendimento durante uma manhã. Caso contrário, a senhora precisará voltar para receber tratamentos específicos e cada sessão de atendimento terá aproximadamente 1 hora de duração. Solicitamos que a senhora compareça no dia, local e horário marcado sob as condições solicitadas pelo responsável do estudo. No caso de falta no horário marcado, o mesmo será remarcado. Contudo, solicitamos se empenhar para não faltar.

Informamos que a senhora pode se recusar a responder (ou participar de qualquer procedimento) qualquer questão que lhe traga constrangimento, podendo desistir de participar da pesquisa em qualquer momento sem nenhum prejuízo no seu atendimento médico junto aos profissionais do Hospital Universitário de Brasília - HUB. Sua participação é voluntária, isto é, não há pagamento por sua colaboração.

Os resultados da pesquisa serão divulgados na Universidade de Brasília, no Hospital Universitário, em reuniões científicas no Brasil e em outros países podendo ser publicados, veiculados no jornal, televisão e rádio posteriormente. Contudo, em nenhum momento seu nome será divulgado, pois garantimos que sua identificação não será divulgada para outras pessoas que não estiverem envolvidas na pesquisa.

Os dados e materiais utilizados na pesquisa, bem como as imagens e sons de voz registrados são de responsabilidade da pesquisadora Dra. Denise Pinheiro Falcão da Rocha. Os mesmos ficarão sob a guarda da pesquisadora por um período de no mínimo cinco anos, após isso serão destruídos ou mantidos na instituição. Se a senhora tiver qualquer dúvida em relação à pesquisa, por favor telefone para: Dra. Denise Pinheiro Falcão da Rocha, no telefone: 9971-2900 em horário comercial.

Informamos que este projeto foi Aprovado pelo Comitê de Ética em Pesquisa da Faculdade de Medicina da Universidade de Brasília. As dúvidas com relação à assinatura do TCLE ou os direitos do sujeito da pesquisa podem ser obtidos através do telefone: (61) 3107-1918 ou do e-mail cepfm@unb.br. 
(continuação)

Ao assinar este documento em duas vias e rubricar cada página, a senhora estará também autorizando a utilização da sua imagem e som de voz, na qualidade de participante/entrevistada neste projeto de pesquisa, desde que sejam utilizadas apenas para análise por parte da equipe de pesquisa, apresentações em conferências profissionais e/ou atividades educacionais. Ou seja, a senhora não estará autorizando a divulgação da sua imagem nem o som da sua voz por qualquer meio de comunicação, sejam elas televisão, rádio ou internet, exceto nas atividades vinculadas ao ensino e a pesquisa explicitadas acima.

Assim, a senhora declara que compreendeu todos os itens deste convite e que os mesmos foram falados de forma muito clara e de fácil entendimento.

Portanto, eu (participante) e responsável pela menor (quando a filha for convidada a participar e a mãe aceitar) deixo claro que após a leitura deste documento estou de acordo e aceito o convite de participar deste estudo conforme os dados acima descritos e autorizo a avaliação da minha filha, caso ela concorde em participar do estudo após receber explicações contidas no Termos de Assentimento. Este documento foi elaborado em duas vias, uma ficará com a pesquisadora responsável pela pesquisa e a outra comigo.

Brasília, de de

Assinatura da Participante

Denise Pinheiro Falcão da Rocha

Pesquisadora Responsável e Professora Colaboradora

do Programa de Pós-Graduação em Ciências Médicas da UnB

Matrícula FUB: 01052080 


\section{APÊNDICE 2. FICHA DE ANAMNESE}

\section{N EIPS REUMATOLOGISTA:}

PRÓXIMA CONSULTA MÉDICA:

$$
\text { Data:____________ Prontuário: }
$$

№. Criotubo:

Tem filha(s) de 6 a 10 anos? ( ) não ( ) sim: (especificar quantidade)

Paciente:

Telefones:(

Data de Nascimento: Idade: Sexo:

Cor declarada: 0- Não informou; 1-Branca; 2- Preta; 3- Parda; 4- Amarela; 5-Vermelha Quantidade de anos que frequentou a escola (excluir repetências): Fumante: 0-Não 1-Sim

Mora sozinha () Mora com: ( ) companheiro (ou marido) () filhos () pais () amigos

Freq. de bebida alcoólica: $\mathbf{0}$ - Não 1- Menos de $1 x /$ semana $\quad$ 2- 1 a $2 x /$ semana $\quad 3-3$ a 4x/ semana 4- + de $5 x /$ sem.

Histórico pessoal de câncer: 0-Não 1-Sim: Região anatômica: Tipo de câncer:

Data do diagnóstico: Quimioterapia: 0-Não 1-Sim Radio: 0-Não 1-Sim
Grupo: 1- CONTROLE
2- LES
3- ARTRITE
4- SS PRIMÁRIA
5- SS

SECUNDÁRIA

Ano do início dos sintomas:

Tempo de diagnóstico (meses):

\section{Condição do LES (confirmar com um médico da equipe):}

1- LES em fase inativa e ausência de histórico de NL

2- LES em fase ativa e ausência de histórico de NL

3- LES e NL em fase inativa

4- LES em fase inativa e com NL em fase ativa

5- LES e NL em fase ativa

6- LES em fase ativa NL em fase inativa

Avaliação Renal: ( ) Dói/arde ao urinar ( ) Urina clara ( ) Urina escura ( ) Com sangue ( ) Apresenta odor forte ( ) Urina espumante Observacões: 
(continuação)

Medicamentos: 0 - Não 1-Sim

\begin{tabular}{|c|c|c|c|}
\hline NOME & $\mathrm{mg}$ & ADMINISTRAÇÃO & FINALIDADE (DOENÇAS) \\
\hline ( ) Arava & & & Artrite \\
\hline ( ) Atorvastatina & & & Redução do colesterol. \\
\hline ( ) Azatioprina & & & Imunossupressor. \\
\hline ( ) Ácido Fólico & & & Vitamina B9. \\
\hline ( ) Cálcio & & & $\begin{array}{l}\text { Construção e manutenção } \\
\text { dos ossos. }\end{array}$ \\
\hline ( ) Ciclobenzaprina & & & $\begin{array}{l}\text { Espasmos musculares } \\
\text { associados à dor aguda e } \\
\text { fibromialgia. }\end{array}$ \\
\hline ( ) Ciclofosfamida & & & $\begin{array}{l}\text { Doenças autoimunes e } \\
\text { câncer. }\end{array}$ \\
\hline ( ) Clonazepam & & & Ansiedade - Rivotril. \\
\hline ( ) Cloroquina & & & Malária. \\
\hline ( ) Dapsona & & & $\begin{array}{l}\text { Hanseníase e dermatite } \\
\text { herpetiforme. }\end{array}$ \\
\hline ( ) Diamicron & & & Diabetes \\
\hline ( ) Efalizumab & & & Psoríase. \\
\hline ( ) Enalapril & & & $\begin{array}{l}\text { Hipertensão arterial e } \\
\text { insuficiência cardíaca } \\
\text { congestiva. }\end{array}$ \\
\hline ( ) Furozemida & & & $\begin{array}{l}\text { Gastrite e pacientes } \\
\text { refratários a outros } \\
\text { tratamentos. }\end{array}$ \\
\hline ( ) Glifage & & & \\
\hline ( ) Losartana & & & Hipertensão arterial \\
\hline ( ) Hidroxicloroquina & & & Malária e artrite reumatoide. \\
\hline ( ) Metotrexato & & & Artrite reumatoide grave. \\
\hline ( ) Micofenolato & & & Imunossupressor. \\
\hline ( ) Natrilix & & & Hipertensão arterial \\
\hline ( ) Omeprazol (Losec) & & & Fibromialgia. \\
\hline ( ) Prednisona & & & Corticoide. \\
\hline ( ) Rituximab & & & Artrite reumatoide. \\
\hline ( ) Sulfato Ferroso & & & Anemia ferropriva. \\
\hline
\end{tabular}




\begin{tabular}{|l|l|l|l|}
\hline ( ) Tocilizumab & & & Artrite reumatoide. \\
\hline ( ) Tramal & & & Dor moderada a grave. \\
\hline ( ) Vitamina B12 & & & \\
\hline ( ) Vitamina D & & & \\
\hline ( ) Outros & & & \\
\hline
\end{tabular}

Outras Doenças sistêmicas (assinalar os domínios abaixo e especificar a doença):

( ) Circulação sanguínea; ( ) Coração; ( ) Diabetes; ( ) Estômago; ( ) Fígado; ( ) Intestino; ( ) Pulmão; ( ) Tireoide; ( )

Frequência cardíaca: bpm; Pressão arterial: $\mathrm{mmHg}$; Peso: Altura:

EXAME ODONTOTOLÓGICO (AO IDENTIFICAR UMA ALTERAÇÃO TECIDUAL, FAVOR FOTOGRAFAR)

ARDÊNCIA BUCAL: ( ) NÃO ( )SIM: ( ) Tipo I - acordo sem ardência, depois ela aparece e piora à noite;

( ) Tipo II - ao acordar e fica o dia inteiro;

( ) Tipo III - sintomas intermitentes

Local da ardência: ( ) ponta da língua; ( ) lábios; ( ) bordos da língua; ( ) dorso da língua; ( ) palato; ( ) mucosa bucal; ( ) faringe; ( ) área chapeável de prótese: sup - inf; ( ) orofaringe

( )localizados em regiões menos frequentes, como palato e faringe.

SECURA BUCAL: ( ) NÃO ( )SIM: contínua - intermitente - esporádica;

( )acorda à noite para tomar água e urinar vezes/noite.

PESO DO FLUXO DA SALIVA SEM ESTÍMULO EM 5 MINUTOS:

ASSIMETRIA FACIAL EVIDENTE: ( ) NÃO

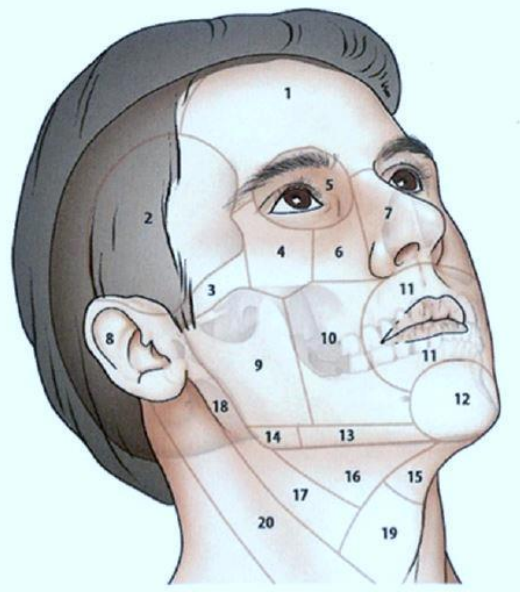

( ) SIM: ( )direito

( ) esquerdo

( ) indolor ( ) dolorida
ENFARTAMENTO GANGLIONAR: ( ) NÃO ( ) SIM: ( )direito
() indolor
() dolorida
() fixo
( ) móvel 
(continuação)

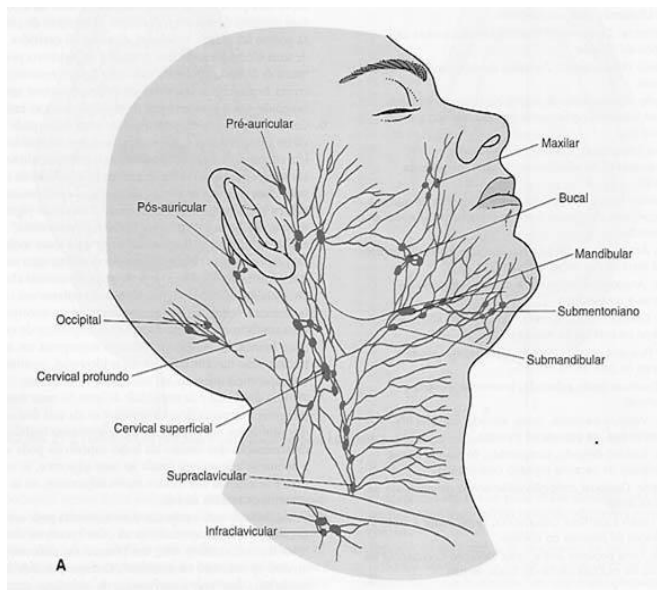

\section{Observações:}

PRESENÇA DE LESÃO EM TECIDO MOLE: ( ) NÃO

( ) SIM

LOCALIZAÇÃO ANATÔMICA DE LESÕES:
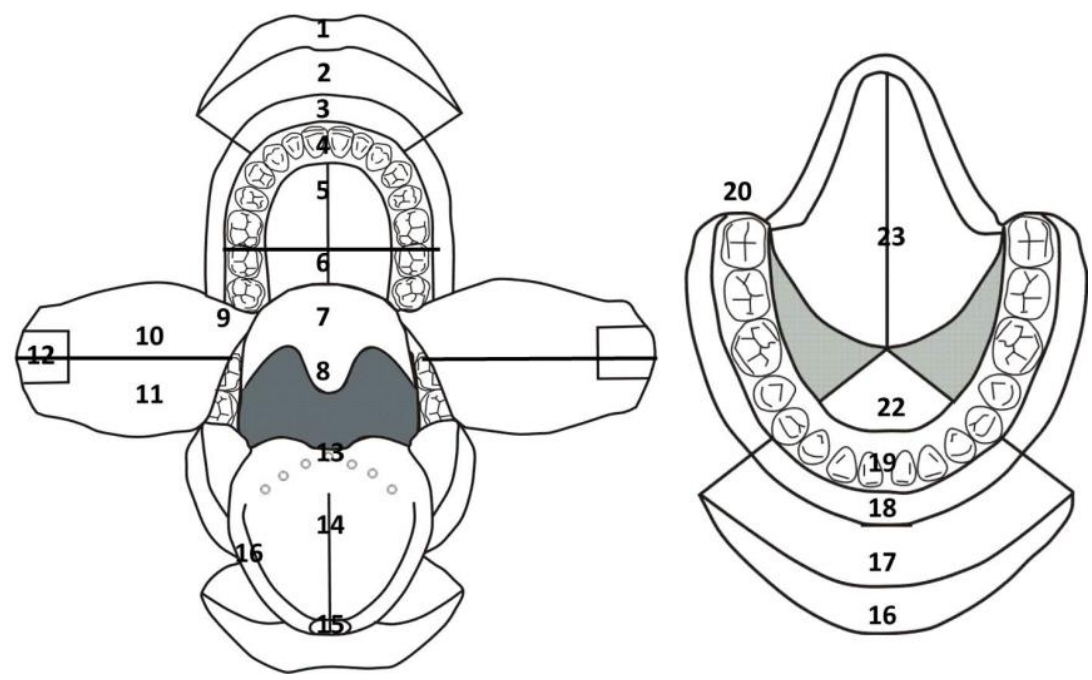

Observações:

\section{Descrição das Lesões}

EROSÃO/ATROFIA (Perda parcial do epitélio, sem exposição do tecido conjuntivo subjacente) Localização (usar a numeração do mapa) D E A Número(s): Cor: Dimensão:

Contorno/Formato: ()regular: circular-ovalado-poligonal ()irregular: festonado-difuso

MANCHA/MÁCULA (Manchas ou máculas são modificações da coloração normal da mucosa bucal, sem que ocorra elevação ou depressão tecidual)

Localização (usar a numeração do mapa):

D E A Número(s):

Cor:

Dimensão:

Superfície: ( )lisa ( )fissurada Consistência:

Contorno/Formato: () regular: circular-ovalado-poligonal ()irregular: festonado-difuso

Consistência: ( ) compatível com o tecido da região adjacente ( ) não compatível Sintomas: 
(continuação)

PLACAS (Ligeira elevação de1 a 2mm, emergindo da superfície. Seu diâmetro é maior que sua altura. não se desprende à raspagem)

Localização (usar a numeração do mapa):

D E A Número(s):

Cor:

Dimensão:

Superfície: lisa - fissurada - crostosa - verrucosa () eritematosa ( ) leucoplásica ( )leucoeritematosa () hiperqueratótica

Contorno/Formato: ()regular: circular-ovalado-poligonal ()irregular: festonado-difuso

Consistência: ( ) compatível com o tecido da região adjacente ( ) não compatível Sintomas:

ÚLCERAS/ULCERAÇÕES (Lesões em que ocorre solução de continuidade do epitélio com exposição do tecido conjuntivo subjacente)

Localização (usar a numeração do mapa):

D E A Número(s):

Cor:

Dimensão:

Evolução: ( )rápida ( )lenta ( )não sabe Profundidade: ()superficial ( )profunda

Leito: liso -irregular - vegetante - granular ( )c/ pontos hemorrágicos ( )s/ pontos hemorrágicos ( ) presença de exsudato ( ) com halo inflamatório ( )sem halo inflamatório () pseudomembrana

Limite: nítido - difuso Borda: invertida - evertida Forma: arredondada - irregular Base: infiltrativa - destrutiva

Consistência: ( ) compatível com o tecido da região adjacente ( ) não compatível Sintomas:

VESÍCULA (Elevação do epitélio contendo líquido no seu interior.)

Localização (usar a numeração do mapa):

D E A Número(s):

Cor:

Dimensão:

Evolução: ( )rápida ( )lenta ( )não sabe

PÁPULAS (Pequenas lesões sólidas, circunscritas, elevadas, cujo diâmetro não ultrapassa $5 \mathrm{~mm}$.)

Localização (usar a numeração do mapa):

D E A Número(s):

Cor:

Dimensão:

Evolução: ( )rápida ( )lenta ( )não sabe

\section{NÓDULOS:}

Localização (usar a numeração do mapa): D E A Número(s):

Cor:

Dimensão:

Número(s): ( )único ()múltiplos

Dimensão:

Altura: Profundidade:

Cor do tecido que recobre:

Conteúdo: ( )sólido ( )líquido

Superfície: ( )lisa ( )fissurada ( )ulcerada ( )não ulcerada

Contorno da base: ( )séssil ( )pediculado

Formato: ()regular: circular - ovalado - poligonal ( )irregular: festonado - difuso

Base: infiltrada - não infiltrada Consistência: elástica - flutuante -óssea Deslizamento: ( )endurecida ( )c/ aderência

Sintomas: 
(continuação)

INDICAÇÃO PARA:

( ) $\mathrm{RX:}$

( )Tomografia:

( )Ressonância magnética

()Biópsia ( )incisional ()excisional ( )punção ()Citologia esfoliativa ()Cultura

HIPÓSTESE DE DIAGNÓSTICO:

Resultado

Observações: 
(continuação)

EXAME PERIODONTAL
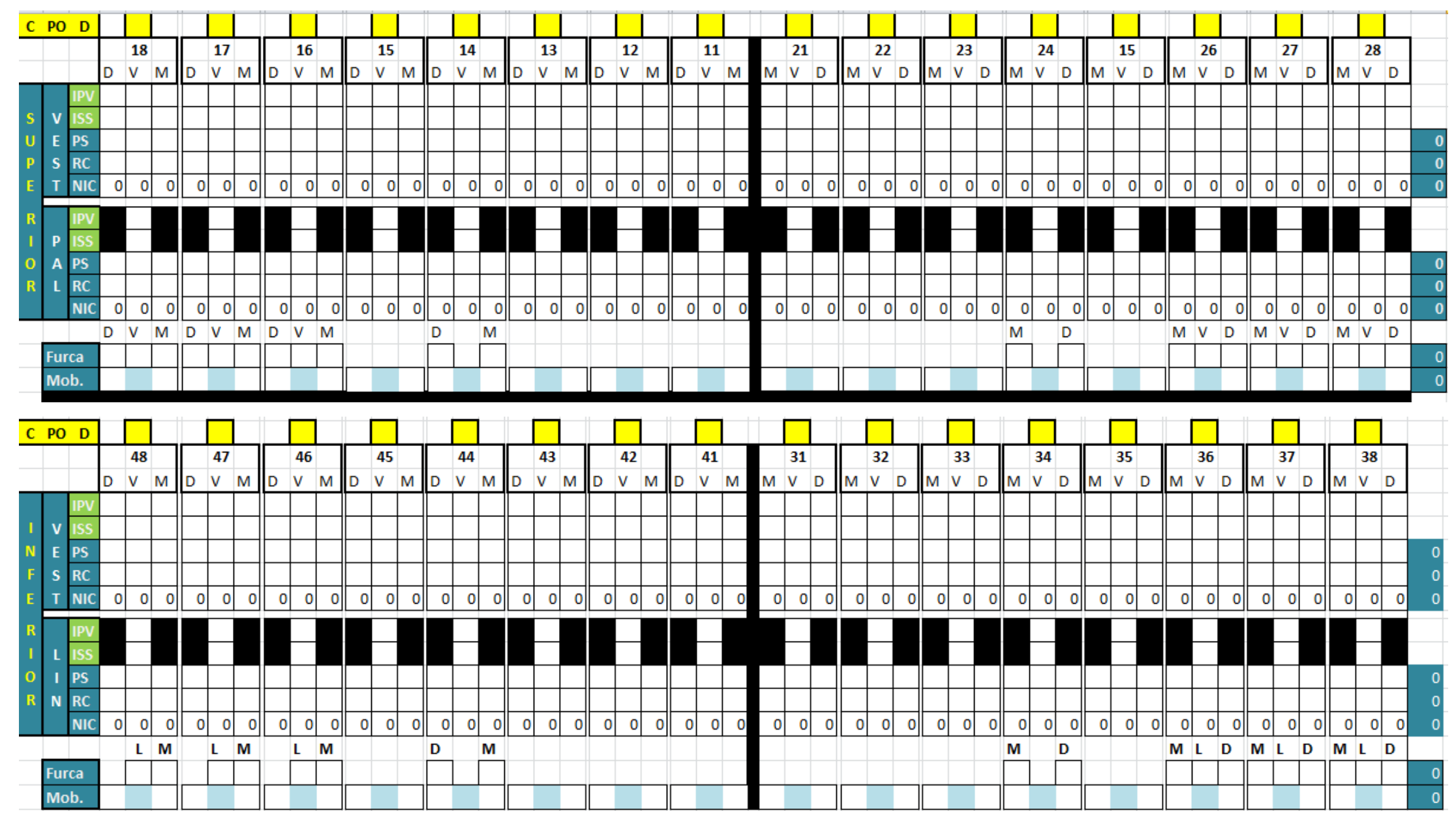

$0(A) \rightarrow$ hígido; $1(B) \rightarrow$ cariado; $2(C) \rightarrow$ restaurado, mas com cárie; $3(D) \rightarrow$ rest. e sem cárie; $4(E) \rightarrow$ perdido devido à cárie; $5(F) \rightarrow$ perdido por outras razões; $6(\mathrm{G}) \rightarrow$ apresenta selante; $7(\mathrm{H}) \rightarrow$ apoio de ponte ou coroa; $8(\mathrm{~K}) \rightarrow$ não erupcionado e raiz não exposta; $9(\mathrm{~L}) \rightarrow$ dente excluído; $\mathrm{T}(\mathrm{T}) \rightarrow$ trauma 
11. ANEXOS 
ANEXO 1. SLICC

\section{SLICC:}

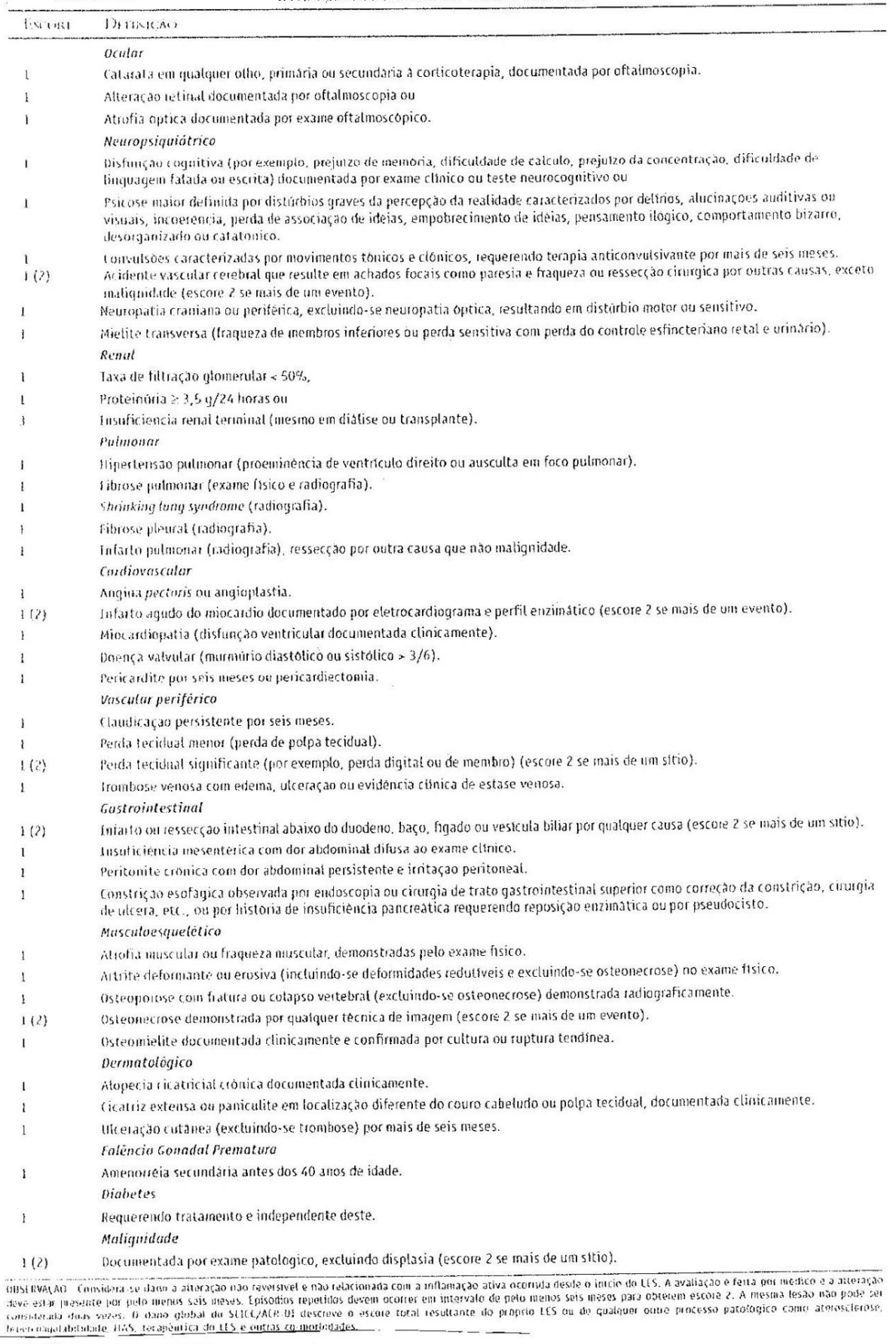

\section{- Avaliação (Realizar o SLICC anualmente)}


ANEXO 2. SLEDAI

\section{SLEDAI:}

Índice de Atividade de Doença do LES (SLEDAI-2K)

\begin{tabular}{|c|c|c|}
\hline $\begin{array}{l}\text { Manifestaçōes } \\
\text { clinicas }\end{array}$ & Descriçōes de sinais e sintomas & Pts \\
\hline Convuisão & $\begin{array}{l}\text { Inicio recente, excluidas causas metabólicas infecciosas e secundarias ao uso } \\
\text { de drogas }\end{array}$ & 8 \\
\hline Psicose & $\begin{array}{l}\text { Distúrbio severo da percepção da realidade, excluidas causas metabólicas e } \\
\text { drogas. Inclui alucinaçōes, incoerência, perda marcada das associaçóes de } \\
\text { ideias, pensamento pobre, ilógico; comportamento bizarro, desorganizado ou } \\
\text { catatônico. }\end{array}$ & 8 \\
\hline & $\begin{array}{l}\text { Alteração abrupta e flutuante das funçöes mentais, atingindo a orienlação, a } \\
\text { atenção, a memória e outras funçöes inlelectuais. Inclui a reduçäo da vigitia, }\end{array}$ & \\
\hline $\begin{array}{l}\text { Delirium (sindrome } \\
\text { cerebral orgänica) }\end{array}$ & $\begin{array}{l}\text { com diminuição da atenção, acompanhada de pelo menos dois sintomas } \\
\text { descritos a seguir - perturbação da percepção, discurso incoerente, insönia ou } \\
\text { hipersonia diurna, aumento ou redução da atividade psicomotora. Exclui } \\
\text { causas melabólicas, infecciosas ou secundárias ao uso de drogas. }\end{array}$ & 8 \\
\hline Distúrbios visuais & $\begin{array}{l}\text { Alteração da retina caracterizada por corpos cistoides, hemorragias retinianas, } \\
\text { exsudatos serosos ou hemorragias do plexo coroide ou neurite óptica. Excluir } \\
\text { HTA, infecções e drogas. }\end{array}$ & 8 \\
\hline $\begin{array}{l}\text { Comprometimento } \\
\text { de pares cranianos }\end{array}$ & Neuropatia sensorial ou motora, de inicio ou reinicio recente. & 8 \\
\hline Cefaleia lúpica & $\begin{array}{l}\text { Severa e persistente, do tipo enxaqueca que näo responde a analgésicos } \\
\text { convencionais. }\end{array}$ & 8 \\
\hline $\begin{array}{l}\text { Acidente vascular } \\
\text { encelálico }\end{array}$ & Presença de AVE. Excluir causa aterosclerótica. & 8 \\
\hline Vasculite & $\begin{array}{l}\text { Uiceraçöes, gangrenas, infartos periungueais, nódulos digitais dolorosos, } \\
\text { àreas hemorrägicas subungueais, biópsia ou angiografia de qualquer área do } \\
\text { corpo apresentando vasculite }\end{array}$ & 8 \\
\hline Artrites & $\begin{array}{l}\text { Envolvimento de duas ou mais articulaçöes com sinais e sintornas de } \\
\text { inflamaçäo (palpação dolorosa, tumefação ou derrame articular) }\end{array}$ & 4 \\
\hline Miositos & $\begin{array}{l}\text { Dor ou fraqueza muscular proximal acompanhada de aumento de } \\
\text { CPK/aldolase, eletromiografia alterada, biópsia compativel com miosite }\end{array}$ & 4 \\
\hline Cilindros urinärios & Hemáticos, granulosos ou eritrocitários & 4 \\
\hline Hematüria & $\begin{array}{l}\text { Mais de } 5 \text { eritrocilos/campo. Excluir outras causas tais como litiase renal, } \\
\text { infecções. }\end{array}$ & 4 \\
\hline Proteinuria & Concentração > a 0,5 g/24 horas & 4 \\
\hline Piúria & Mais de 5 leucócitos/campo na ausência de infecçāo & 4 \\
\hline Rash cutâneo & Inicio recente ou recorrente, caráter inflamatório & 2 \\
\hline Alopecia & inicio recente ou recorrente, excessiva, difusa ou localizada & 2 \\
\hline Úicera de mucosa & Inicio recente ou recorrente, nasais ou orais & 2 \\
\hline Pleurisia & Dor pleuritica com atrito, derrame ou espessamento pleural & 2 \\
\hline Pericardite & $\begin{array}{l}\text { Dor no peito, com atrito ou derrame pericárdico, confirmado por ECG ou } \\
\text { Ecocardiograma }\end{array}$ & 2 \\
\hline $\begin{array}{l}\text { Complemento } \\
\text { baixo }\end{array}$ & $\mathrm{CH} 50 ; \mathrm{C} 3$ ou C4 abaixo dos valores de referência & 2 \\
\hline Anti-DNAds & Acima dos valores de referência do laboratório & 2 \\
\hline Febre & Temperatura axilar $>38^{\circ}$, na ausência de processo infeccioso & 1 \\
\hline Trombocitopenia & $\begin{array}{l}\text { Concentraçäo de plaquetas inferior a } 100000 / \mathrm{mm}^{3} \text { (excluidas causas } \\
\text { farmacológicas) }\end{array}$ & 1 \\
\hline Leucopenia & $\begin{array}{l}\text { Concentraçāo de leucócitos inferior a } 3000 / \mathrm{mm}^{3} \text {, exciuidas causas } \\
\text { farmacologicas }\end{array}$ & 1 \\
\hline \multicolumn{3}{|l|}{ - Avaliação } \\
\hline SLEDAI: & & \\
\hline
\end{tabular}




\section{ANEXO 3. TERMO DE ACEITE PELO COMITÊ DE ÉTICA EM PESQUISA DA UNIVERSIDADE DE BRASÍLIA (UNB).}

\section{FACULDADE DE MEDICINA DA UNIVERSIDADE DE BRASILIA - UNB}

\section{PARECER CONSUBSTANCIADO DO CEP}

DADOS DO PRONETO DE PESQUISA

Titulo da Pocqulea: Andiles do Froteoma aslvar de Pacientes com Lúpus Eritematoso alatemico, com e sem Nefrite Lùplca

Pocquicador: Denise Pinheiro Faicto da Rocha

Area Tematioa:

Vercso: 2

CAAE: 25085114.5 .0000 .5558

Inctitulọso Proponente: Faculdade de Medleina da Univeraldade de Erasilla - UNB

Patroolnador Prinolpal: Financlamento Proprio

DADOS DO PARECER

Numero do Pareoer: 753.161

Data da Relatorla: $3007 / 2014$

Aprecentagso do Projoto:

O projeto retoma para avalaç\$o das modincaģbes sollcitadas no primeiro parecer consubstanciado emitido pelo CEP-FM

Objetivo da Pocquica:

Permanecem inatterados eslo adequados.

Avallagso doc Ricoot o Benefloloc:

Vide primeiro parecer.

Comentarioc o Conclderapoec cobre a Pocquica:

As modificą̧les requeridos no parecer iniclal foram atendidos pelos pesqulasdores e projeto atual e adequado para execuçbo conforme os principlos eticos estabeiecidos na regulamentaç5o vigente.

Conelderagoec cobre oc Termoc de aprecentagso obrigatorla:

O TA E TCLE foram modilcados conforme requerido.

Recomendapoec:

Nenhums.

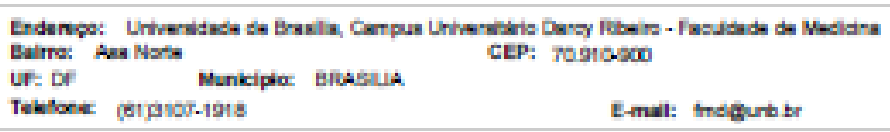


12. ARTIGO PUBLICADO 